Aus der Klinik für Innere Medizin V I

Pneumologie, Allergologie, Beatmungs- und Umweltmedizin des Universitätsklinikums des Saarlandes Direktor: Univ.-Professor Dr. Gerhard W. Sybrecht

\title{
Veränderungen der Körperzusammensetzung von COPD-Patienten
}

Dissertation zur Erlangung des Grades eines Doktors der Medizin

der Medizinischen Fakultät

der UNIVERSITÄT DES SAARLANDES

2009

vorgelegt von

Constantin Marcu

geb. am 26.10.1977

in Kronstadt / Rumänien 
Diese Arbeit wurde erstellt am Universitätsklinikum des Saarlandes unter Leitung von Herrn Professor Dr. Gerhard W. Sybrecht, Direktor der Klinik für Innere Medizin V / Pneumologie, Allergologie, Beatmungs- und Umweltmedizin.

Dekan: Univ.-Professor Dr. Michael D. Menger 


\section{Inhaltsverzeichnis}

1. Zusammenfassung

2. Einleitung

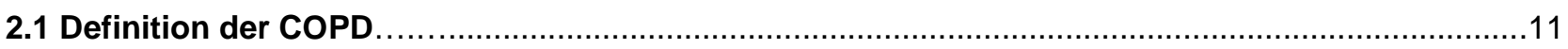

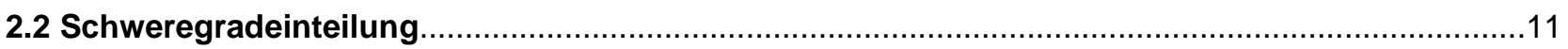

2.3 Risikofaktoren

2.4 Prävalenz der COPD

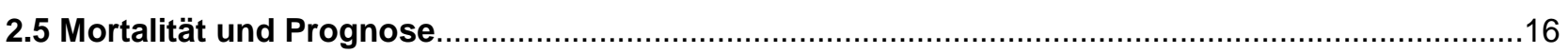

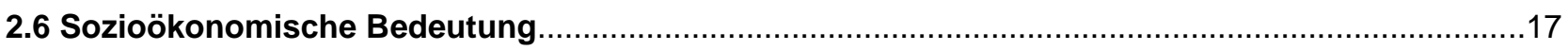

2.7 Pathogenese der COPD

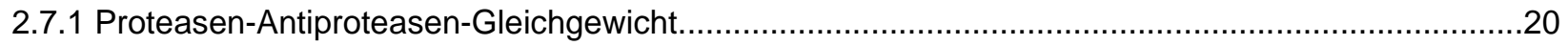

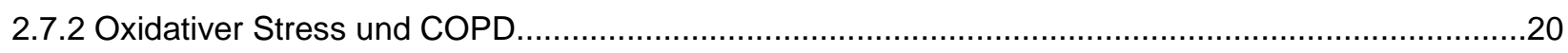

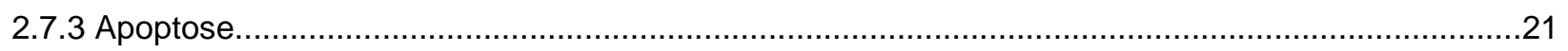

2.8 COPD, eine Systemerkrankung ………………………

2.8.1 Systemische Inflammation bei COPD

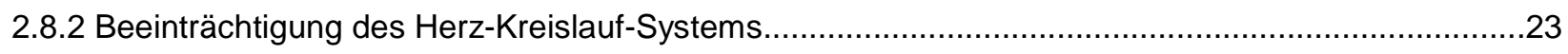

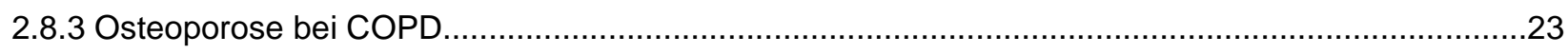

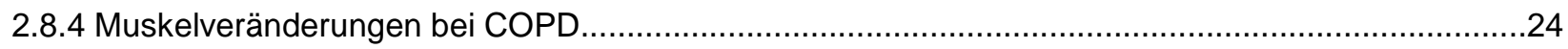

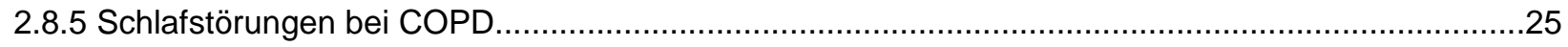

$2.9 \mathrm{BMI}$, Body mass index

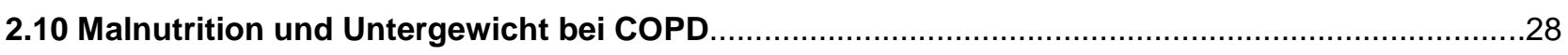

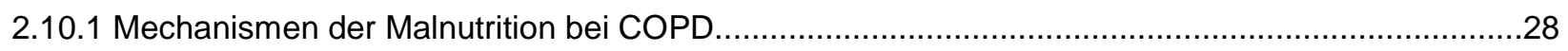

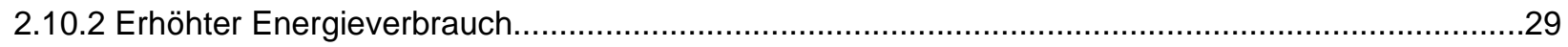

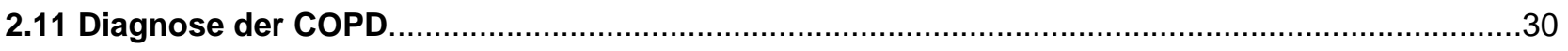

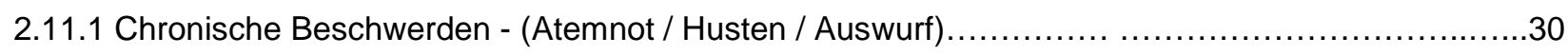

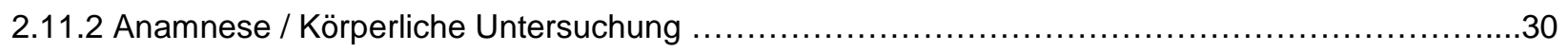

2.11 .3 Spirometrie

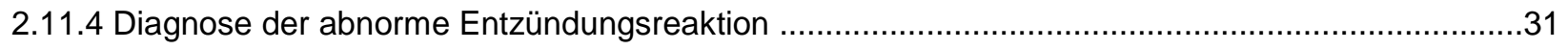

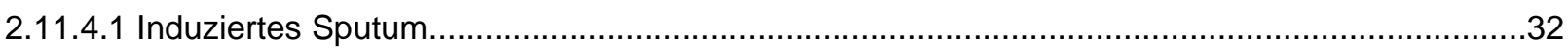

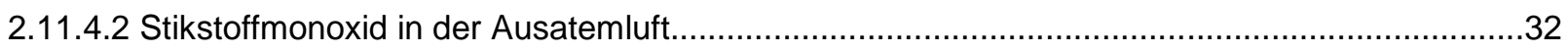

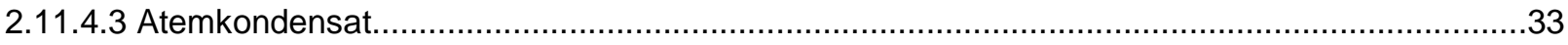

2.12 Therapie der COPD

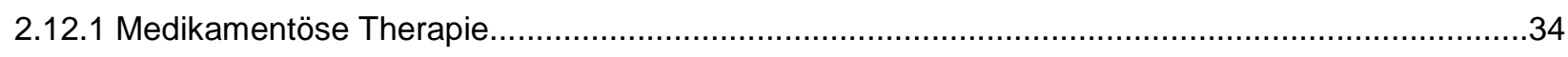

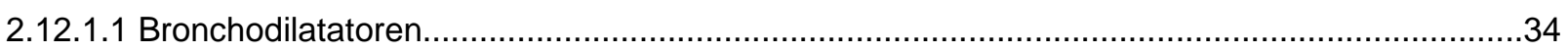

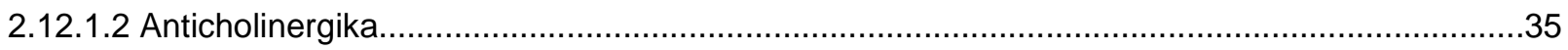




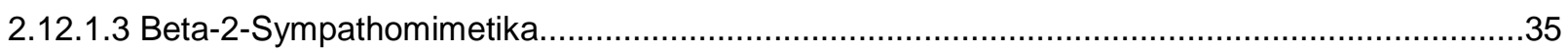

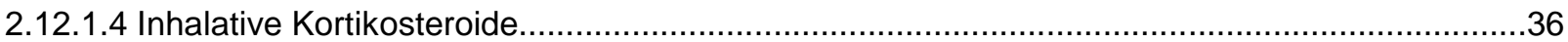

2.12.1.5 Neue pharmakologische Ansätze - Neue Ansätze mit alten Medikamenten..........................37

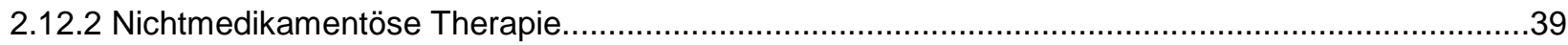

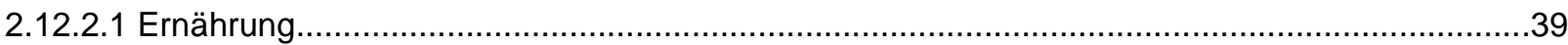

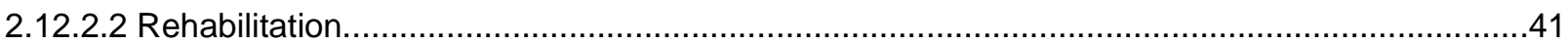

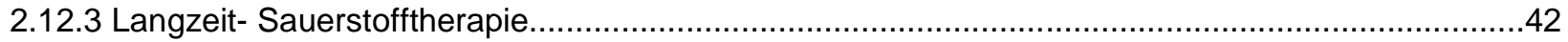

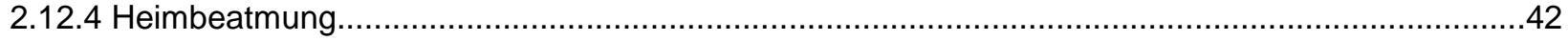

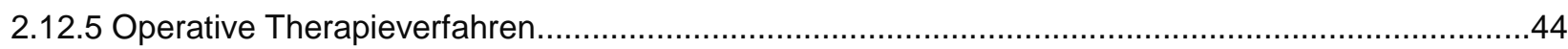

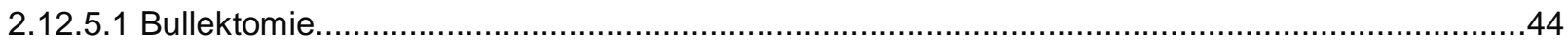

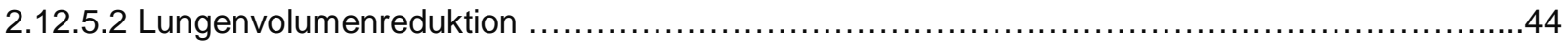

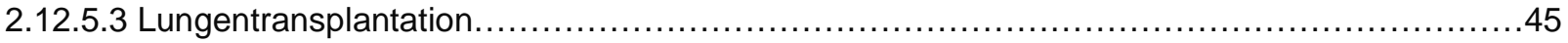

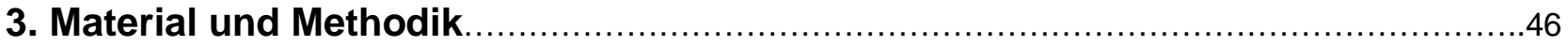

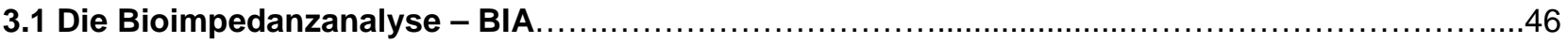

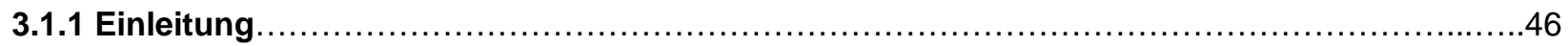

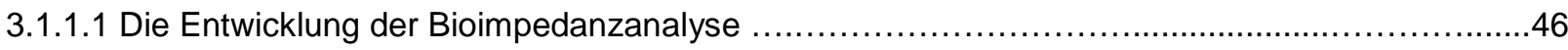

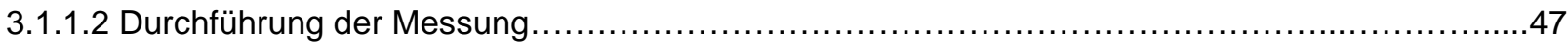

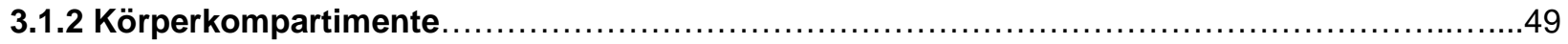

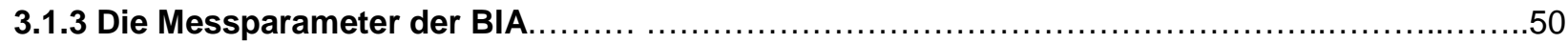

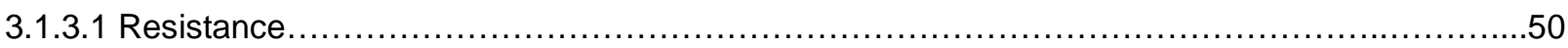

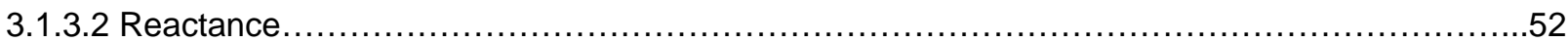

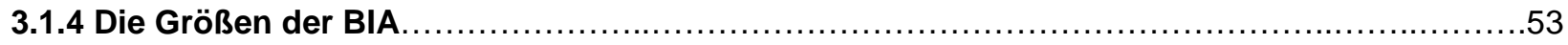

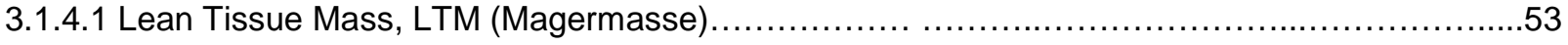

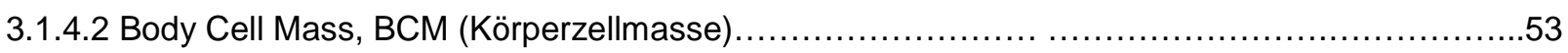

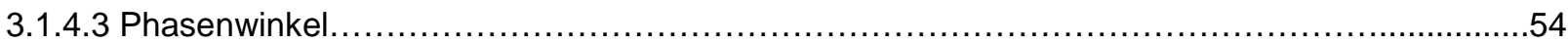

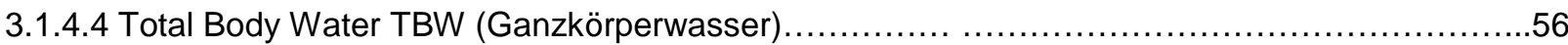

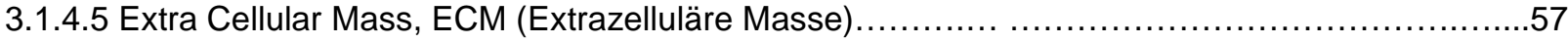

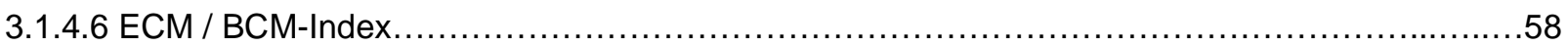

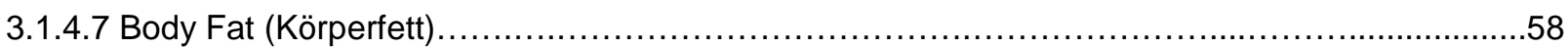

3.1.5 Andere Untersuchungsmethoden zur Bestimmung der Körperzusammensetzung .............59

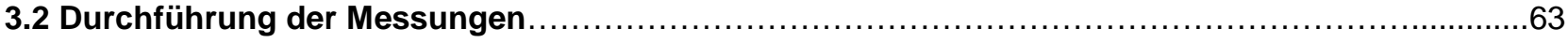

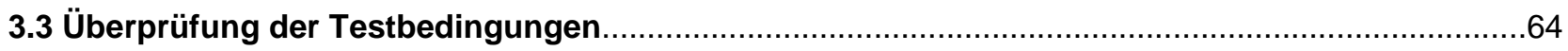

3.3.1 Test der Prüfgrössen auf Normalverteilung nach Shapiro \& Wilk ............................64

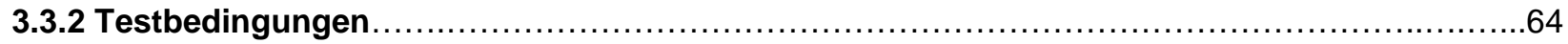

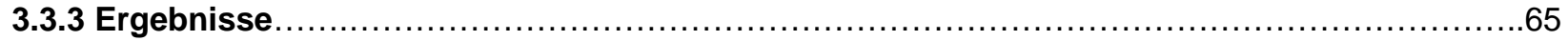

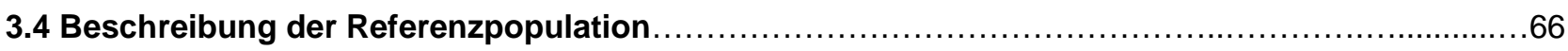

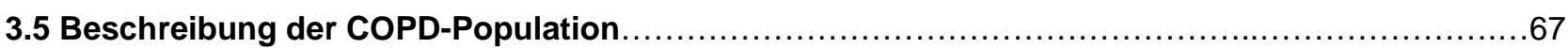

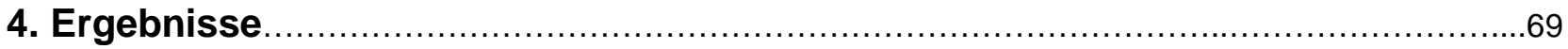




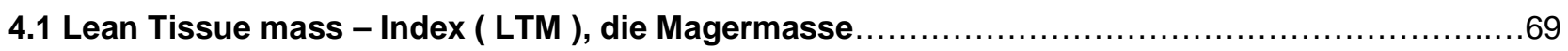

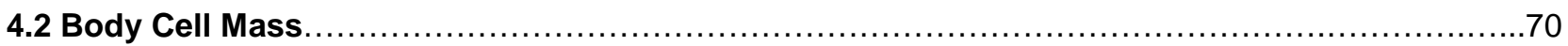

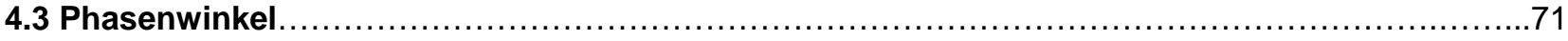

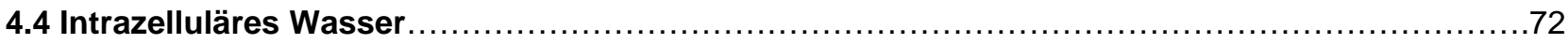

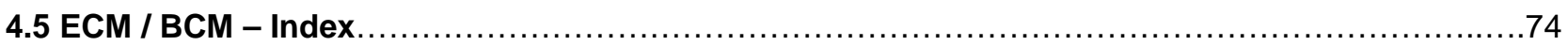

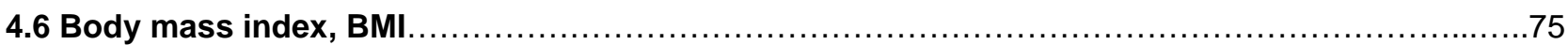

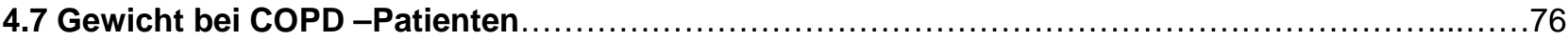

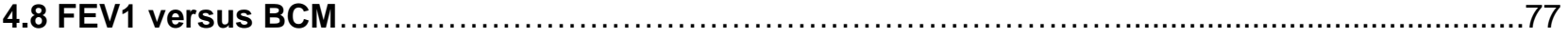

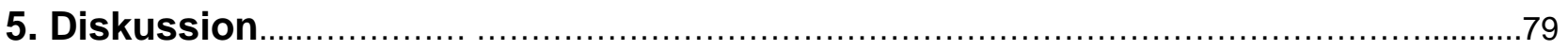

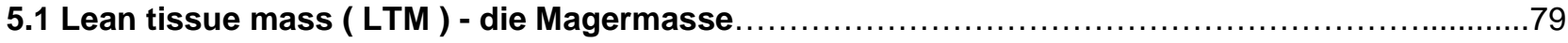

5.2 BCM - Zu wenig Körperzellmasse bei den Patienten mit chronischer Bronchitis ...................79

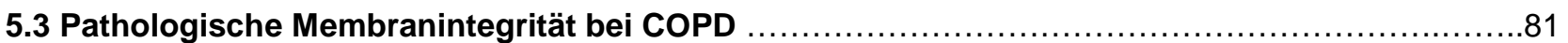

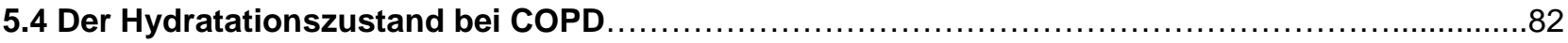

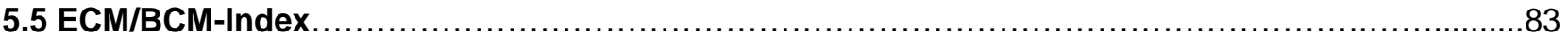

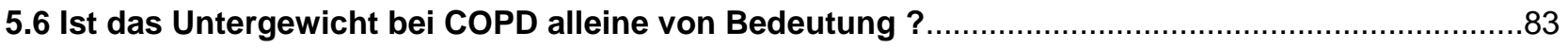

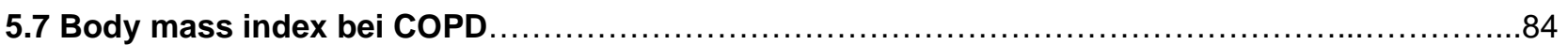

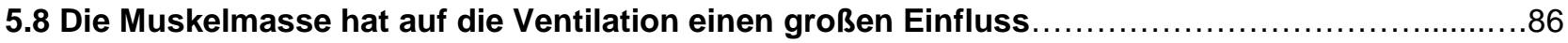

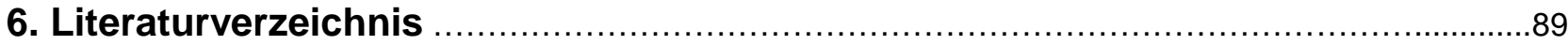

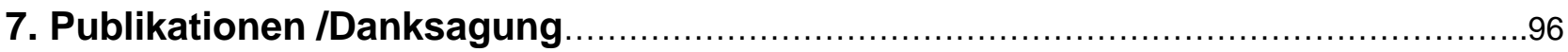

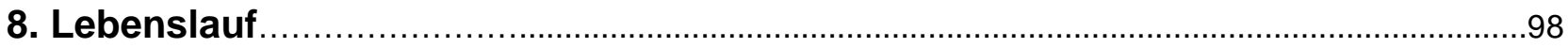




\section{Verzeichnis der Abbildungen und Tabellen}

\section{Abbildungen:}

Abbildung 1: Korrelation BODE-Index / Mortalität.

Abbildung 2: COPD-Prävalenz weltweit, nach BOLD-Studie .....

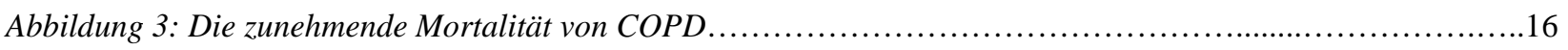

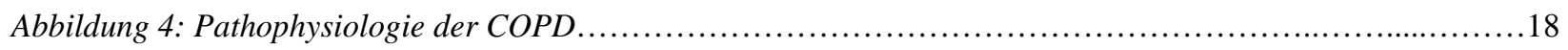

Abbildung 5. Entzündungszellen im Bereich der kleinen Atemwege in unterschiedlichen COPD-Stadien..............19

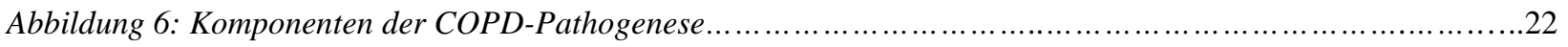

Abbildung 7: Zwei Körper mit ähnlicher Größe und ähnlichem Gewicht. Der BMI bietet hier keinen Aufschluss über

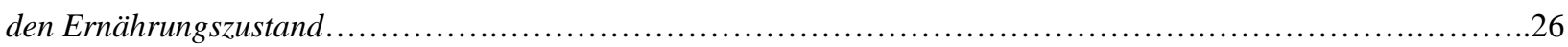

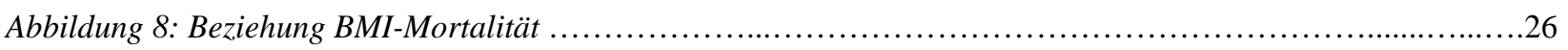

Abbildung 9: Positionierung der Elektroden bei Bioimpedanzmessung .....................................48

Abbildung 10: Durchführung der Bioimpedanzanalyse ................................................48

Abbildung 11: Einteilung in verschiedener Kompartimente der Körperzusammensetzung..............................50

Abbildung 12: Einfluss der Körperformen auf die Resistance..............................................51

Abbildung 13: Messgrößen der Bioelektrischen Impedanz Analyse: $R$ und Xc....................................51

Abbildung 14: Die Bestimmung von R und Xc aus Impedanz und Phasenwinkel....................................52

Abbildung 15: Intakte Zelle mit hoher Membranintegrität oder "’hohe Zelldichte', - hoher Phasenwinkel................55

Abbildung 16: Geschädigte Zelle oder niedrige Zelldichte - niedriger Phasenwinkel.....................................55

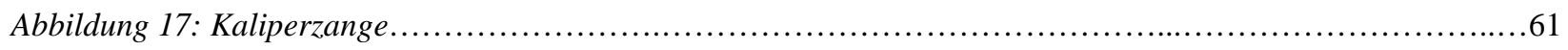

Abbildung 18: Messung der Körperzusammensetzung mit ',Dual-energy x-ray absorptiometry', .....................62 


\section{Tabellen}

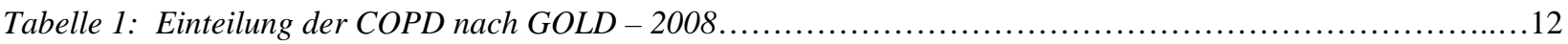

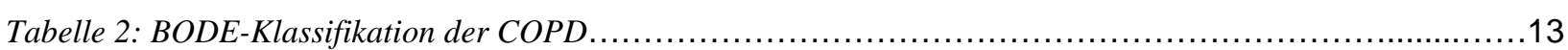

Tabelle 3: Prävalenz der COPD zwischen 1988 und 1994 in den USA in Abhängigkeit vom Alter..........................14

Tabelle 4: Direkte und indirekte Kosten der chronischen Bronchitis.........................................18

Tabelle 5: Charakterisierung des Ernährungszustandes von Erwachsenen mit Hilfe des Body Mass Index (BMI);

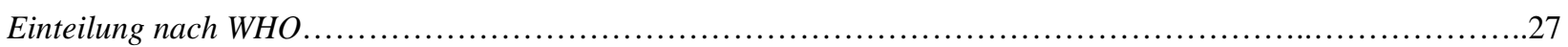

Tabelle 6: Alters- und Geschlechtsabhängigkeit des BMI’s mit der höchsten Lebenserwartung ........................27

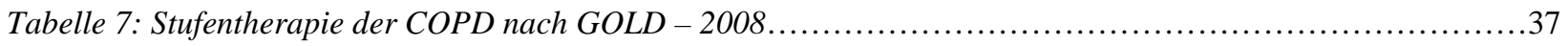

Tabelle 8: Terminologie der Körperzusammensetzung..............................................................................................49

Tabelle 9: Methoden und ihre primären Zielgrößen der Körperzusammensetzung ....................................59

Tabelle 10: Nachteile verschiedener Untersuchungsmethoden zur Bestimmung der Körperzusammensetzung........60 


\section{Abkürzungen:}

BIA

$\mathrm{BCM}$

$\mathrm{BCM}-1$

$\mathrm{BMI}$

COPD

ECM

ECW

FEV 1

FFM

ICM

ICW

ICW - I

LTM

LTM - I

$\mathrm{R}$

TBW

TNFa

$\mathrm{Xc}$

\section{Erläuterung:}

Bioimpedanzanalyse

Körperzellmasse, Body Cell Mass

Körperzellmasse - Index

Body-Mass-Index

Chronicobstructive pulmonary disease

Extrazelluläre Masse

Extrazelluläres Wasser, extracellular water

forciertes exspiratorisches Volumen in der ersten Sekunde

Fettfreie Masse

Intrazelluläre Masse

Intrazelluläres Wasser, intracellular

water

Intrazelluläres Wasser - Index

Lean Tissue mass, Magermasse

Lean Tissue mass - Index

Resistance

Ganzkörperwasser, total body

Water

Tumornekrosefaktor $\alpha$

Reactance 


\section{Zusammenfassung}

Die chronisch obstruktive Lungenkrankheit (COPD, Chronic Obstructive Pulmonary Disease) ist eine Systemerkrankung, die mit generalisierter Inflammation, körperlicher Inaktivität, Hypoxämie und hormonellen Problemen einhergeht. In den letzten Jahren ist zunehmend deutlich geworden, dass es sich bei der COPD nicht um eine reine Lungenerkrankung handelt, sondern dass multiple systemische Veränderungen vorliegen unter anderen die muskuloskelettale Dysfunktion.

Im Verlauf dieser Arbeit wurde die Körperzusammensetzung von 47 COPD-Patienten (24 Männer; 23 Frauen) bestimmt. Die Messung der Körperzusammensetzung erfolgte mittels Bioimpedanzanalyse (BIA). Die BIA ist eine nicht-invasive Methode zur Messung der Körperzusammensetzung, welche die elektrischen Eigenschaften des Körpers nutzt. Für die Messung wurde ein Multifrequenzanalysator (BIA SCOUT, Fresenius Kabi) benutzt.

Das Ziel der Arbeit war die Beurteilung der Körperzusammensetzung, der Validität des BMI's (body mass index) versus BCM (Körperzellmasse, Body Cell Mass) und die Charakterisierung einer Korrelation erniedrigte $\mathrm{BCM}$ und vermindertes FEV1 bei COPD-Patienten.

Die Daten von COPD-Patienten wurden mit einer Kontrollgruppe von 529 gesunden und normalgewichtigen Probanden verglichen.

Zusammenfassend, kammen wir zu den folgenden Ergebnissen:

1. Der Verlust von Körperzellmasse, d. h. Verlust von metabolisierendem und kontraktilem Gewebe dargestellt durch BCM-Index, ist bei COPD-Patienten sehr ausgeprägt

2. Die Membranintegrität und der metabolische Zustand der Muskelzellen, dargestellt durch Phasenwinkel, sind bei COPD Patienten pathologisch verändert

3. Der Hydratationsgrad der Körperzellmasse ist aufgrund des intrazellulären Proteinverlustes reduziert

4. Der intrazelluläre Proteinverlust führt zu einer Verkleinerung der Körperzellmasse. Gleichzeitig kommt es durch Abgabe des proteingebundenen intrazellulären Wassers zu einer Vergrößerung des Extrazellulärraumes. Das extrazelluläre Wasser nimmt zu und dadurch bleiben das Gewicht und der BMI in den meisten Fällen normal oder sogar erhöht, so dass die Validität vom BMI bei COPD-Patienten in Frage gestellt werden soll

5. Die FEV1-Werte sind deutlich besser bei den COPD-Patienten, die mehr Muskelmasse aufweisen, im Vergleich zu den Patienten mit einer reduzierten Muskelmasse

Durch Messung der Bioimpedanz haben wir gezeigt, dass bei COPD-Patienten sowohl eine reduzierte Muskelmasse als auch intrinsische Veränderungen der Muskulatur vorliegen. Die BIA ist eine einfache, nicht-invasive und preisgünstige Methode zur Messung der Körperzusammensetzung, die zur Früherkennung der Mangelernährung bei COPD-Patienten angewendet werden kann, so dass diese Patienten von einem früheren gezielten Muskelaufbau profitieren können. 


\begin{abstract}
$\underline{\text { Abstract }}$
COPD is a systemic disease accompanied by general inflammation, muscle dysfunction, physical inactivity, hypoxemia and hormonal changes.The last couple of years have shown an increasing importance of the systemic component in the prognosis of COPD.

We determined the body composition of 47 COPD-Patients (24 men and 23 women) with a Bioelectrical Impedance Analysis (BIA). For the measurement was applied a BodyScout multi-frequency analyser from Fresenius Kabi, Germany. Bioelectrical Impedance Analysis is a non-invasive method for estimation of body compartments based on the property of tissues to conduct electrical current.

The objective of our study was the estimation of body composition, the validity of BMI (body mass index) versus BCM (Body Cell Mass) and the characterisation of a correlation - reduced BCM and decreased FEV1 in COPD patients.

We have compared the results with a control group of 529 healthy people with a normal weight.
\end{abstract}

The examination has shown that:

1. the loss of muscle mass, represented by BCM Index-values, was in COPD-patients very pronounced

2. The cell membran degradation was detected by a reduced density of cells (determinated by phase angle)

3. The hydratation of lean mass is reduced as a result of intracellular water loss

4. The degradation of intracellular protein causes a reduced muscle mass. The intracellular water decreases and the extracellular water increases. For this reason the weight and the body-massindex are normal or increased in the majority of cases. Our results suggest that BMI alone doesn't allow conclusions regarding the nutritional state and physical training.

5. the FEV1 values are better in COPD patients with increased muscle mass, compared to the patients with reduced muscle mass

The determination of body composition with bioimpedance has shown that COPD is characterised by weight lost, reduction of muscle mass and change of body composition. Bioelectrical Impedance Analysis represents a simple and low-cost bedside-tool for estimating body composition and it could be a useful part in the early diagnosis of malnutrition in COPD patients. Therapeutic strategies could be applied for exactly defined lot of patients. 


\section{Einleitung}

\subsection{Definition der COPD}

Die chronisch-obstruktive Lungenerkrankung (COPD; engl.: chronic obstructive pulmonary disease) wird definiert als eine Erkrankung mit langsam progredienter, nicht vollständig reversibler Atemflussbehinderung, die mit abnormen Entzündungsreaktionen auf inhalative Noxen verbunden ist [74].

Durch chronische Entzündungsprozesse kommt es zum Umbau und zur Verengung der Bronchioli in Kombination mit einer irreversiblen Erweiterung der Lufträume, Parenchymdestruktion und Verlust der Lungenelastizität distal der terminalen Atemwege. Lungenfunktionell manifestiert sie sich durch einen persistierend unter 70\% verminderten Tiffeneau-Quotienten [8].

In mehreren Definitionen für die Beschreibung der chronisch-obstruktiven Lungenerkrankungen werden die Begriffe chronische Bronchitis und Emphysem hervorgehoben. Dabei handelt es sich beim Emphysem um die Destruktion der Alveolen; nach Definition der World Health Organization (WHO) liegt eine chronische Bronchitis vor, wenn Husten und Auswurf über wenigstens 3 Monate in mindestens 2 aufeinanderfolgenden Jahren bestehen.

Differentialdiagnostisch ist die COPD von anderen Ursachen einer Atemwegsobstruktion abzugrenzen wie Asthma bronchiale, Mukoviszidose, Brochiektasie und Bronchiolitis obliterans.

\subsection{Schweregradeinteilung}

Die Einteilung der COPD erfolgt mittlerweile nach den international anerkannten GOLD-Kriterien (Global Initiative of Chronic Obstructive Lung Disease) anhand weniger Parameter wie der Einsekundenkapazität FEV1, dem Quotienten aus der Einsekundenkapazität und der forcierten Vitalkapazität FEV1/FVC sowie einzelner klinischer Symptome (Tabelle 1).

Ältere Einteilungen nach der American Thoracic Society (ATS) und der European Respiratory Society (ERS) nach Schweregrad in Bezug auf die Lungenfunktion wurden mittlerweile der heutzutage gebräuchlichen GOLD-Einteilung angepasst [8]. In allen genannten Klassifikationen werden Referenzbzw. Sollwerte für die Beurteilung der Lungenfunktionsparameter herangezogen, die sich auf die Ergebnisse großer epidemiologischer Studien stützen. In Europa sind die Referenzwerte der Europäischen Gemeinschaft für Kohle und Stahl gebräuchlich, die Regressionsgleichungen für die wichtigsten Lungenfunktionsparameter in Abhängigkeit von der Körpergröße, dem Körpergewicht, von Geschlecht und von Alter angeben [53]. Alle FEV1-Werte beziehen sich auf Werte nach Inhalation eines Bronchodilators.

In der alten Fassung der Leitlinie war auch ein Stadium 0 aufgeführt. Das Stadium 0 wurde bei Angabe von chronischem Husten und/oder Auswurf und bei Vorliegen von Risikofaktoren bei gleichzeitig unauffälliger Spirometrie festgestellt. Es wurde angenommen, dass Patienten in diesem Stadium ein gesteigertes Risiko aufweisen, eine manifeste COPD zu entwickeln. Es gibt zwar Hinweise darauf, dass 
Männer mit Atembeschwerden, d. h. Dyspnoe, persistierendem Husten und/oder Auswurf ein signifikant gesteigertes Mortalitätsrisiko aufweisen. Andererseits fanden sich in neueren Studien keine Anhaltspunkte dafür, dass Husten und Auswurf (nach Definition der WHO für chronische Bronchitis) allein relevante Risikofaktoren für die Entstehung einer Bronchialobstruktion sind [108]. Daher wurde das Stadium 0 in der neuen Fassung der Leitlinie in Übereinstimmung mit dem neuen GOLD-Update gestrichen.

\begin{tabular}{|l|c|c|c|}
\hline & Symptome & FEV1/FVC & FEV1 (\% Soll) \\
\hline \hline I - leicht & $\begin{array}{c}\text { Mit oder ohne } \\
\text { Symptome }\end{array}$ & $<70 \%$ & $>80 \%$ \\
\hline II - mittel & $"$ & $<70 \%$ & $50 \%<$ FEV1 $<80 \%$ \\
\hline III - schwer & $"$ & $<70 \%$ & $30 \%<$ FEV1 $250 \%$ \\
\hline $\begin{array}{l}\text { IV - sehr } \\
\text { schwer }\end{array}$ & $"$ & $<70 \%$ & FEV1 $<30 \%$ \\
\hline
\end{tabular}

Tabelle 1: Einteilung der COPD nach GOLD - 2008

Wenn die $\mathrm{FEV}_{1} \leq 30 \%$ des Solls beträgt, liegt ein Schweregrad IV vor. Besteht eine chronische respiratorische Insuffizienz, darf die $\mathrm{FEV}_{1}<50 \%$ des Solls betragen, um einen Schweregrad IV zu definieren.

Häufig suchen die Patienten den Arzt anlässlich einer akuten respiratorischen Insuffizienz im Rahmen einer Exazerbation auf. Bei zahlreichen Patienten im Stadium IV treten gehäuft Exazerbationen mit einem potenziell lebensbedrohlichen Verlauf auf. Arterielle Hypoxämie, häufig verbunden mit einer Hyperkapnie, oder ein Cor pulmonale mit peripheren Ödemen als Zeichen der Rechtsherzinsuffizienz kennzeichnen das Spätstadium der Erkrankung.

Eine neue multidimensionale Schweregradeinteilung, der BODE-Index (B: Body-mass-index, O: obstruction, D: dyspnoea, E: exercise capacity), berücksichtigt Ausmaß der Obstruktion, Atemnot, körperliche Belastbarkeit und body-mass-index [19]. Dieser Index charakterisiert die Beeinträchtigung des Patienten deutlich besser als die FEV 1 allein. Die Obstruktion wird anhand der FEV ${ }_{1}$, die Dyspnoe mittels des modifizierten MRC (Medical Research Council) Scores, die Belastbarkeit über die 6Minuten-Gehstrecke gemessen. Durch Addition der Punkte für jeden Parameter ergibt sich der BODE-Score. 


\begin{tabular}{|l|l|l|l|l|}
\hline \multicolumn{1}{|c|}{ Parameter } & \multicolumn{3}{c|}{ Punkte auf der BODE Skala } \\
\cline { 2 - 6 } & 0 & 1 & 2 & 3 \\
\hline FEV 1 (\% Soll) & $\geq 65$ & $50-64$ & $36-49$ & $<35$ \\
\hline 6 Min Gehtest $(\mathrm{m})$ & $>350$ & $250-349$ & $150-249$ & $\leq 149$ \\
\hline MRC Dyspnoe (Stufe) & $0-1$ & 2 & 3 & 4 \\
\hline body-mass-index $\left(\mathrm{kg} / \mathrm{m}^{2}\right)$ & $>21$ & $\leq 21$ & & \\
\hline
\end{tabular}

Tabelle 2: BODE-Klassifikation der COPD [19]

Modifizierter MRC Score:

0: Atemnot nur bei außergewöhnlicher Belastung, 1: Atemnot beimTreppensteigen, Bergaufgehen, 2: Atemnot bei Gehen in der Ebene, 3: Atemnot nach 100m, 4: Atemnot bei An- und Ausziehen

Die BODE-Scorebereiche 0-2, 3-4, 5-6 und 7-10 Punkte korrelierten mit der Gesamtmortalität und mit der COPD bedingten Mortalität in der untersuchten internationalen COPD Patientenpopulation besser als die $\mathrm{FEV}_{1}$. Für die Patienten mit den höchsten Werten betrug das Sterberisiko 80\% in 52 Monaten [19].

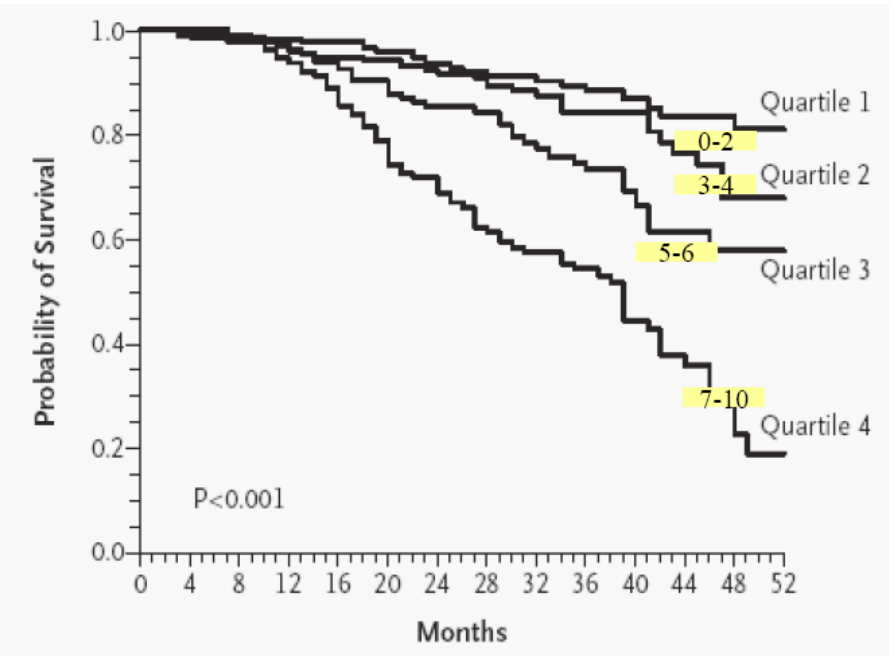

Abbildung 1: Korrelation BODE-Index / Mortalität nach Celli et al. [19]

\subsection{Risikofaktoren}

Die Risikofaktoren lassen sich in genuine und erworbene Faktoren einteilen. Zu den genuinen Faktoren gehören die genetische Prädisposition (z.B. Alpha-1- Protease-Inhibitor-Mangel), bronchiale Hyperreaktivität und Störungen des Lungenwachstums.

Der am besten untersuchte genetische Risikofaktor ist der Mangel an Alpha-1-Antitrypsin. Seine Prävalenz beträgt weltweit 1:6000, in Nordeuropa 1:2500. Er verursacht eine verminderte 
Antielastaseaktivität, in deren Verlauf es zu einem verstärkten Untergang von Elastingewebe und damit zur Ausbildung eines Emphysems kommt [51]. Chen analysierte in einem Review Familien- und Zwillingsstudien und fand eine familiäre Häufung [20].

Inhalativer Tabakkonsum, berufsbedingte Stäube sowie allgemeine Luftverschmutzung und häufige Atemwegsinfektionen in der Kindheit sind den erworbenen Faktoren zuzuordnen. Dabei kommt dem Rauchen die größte Bedeutung zu. 80-90\% der COPD-Erkrankungen sind auf inhalativen Tabakkonsum zurückzuführen. In älteren Veröffentlichungen wird die Prävalenz der COPD unter Rauchern noch mit 15$20 \%$ angegeben (ATS 1995). Neuesten Studien zufolge beträgt sie jedoch 50\% [60]. Eine große Umfrage in den USA zwischen 1988 und 1994, welche Fragen über subjektive Atemwegssymptome beinhaltete, ergab eine starke Abhängigkeit des Auftretens dieser Symptome vom Rauchverhalten der Befragten. So gaben unter den weiblichen Befragten 20,6\% der Raucher Symptome an im Gegensatz zu 5,0\% der Nichtraucher. Bei den Männern waren es 24,0\% im Vergleich zu 4,0\% [95]. Die gleiche Studie untersuchte auch die Prävalenz von Atemwegsobstruktionen, die mit FEV1/FVC $<70 \%$ definiert waren. Zwar zeigte sich eine geringere Prävalenz der Atemwegsobstruktion im Vergleich zu subjektiven Symptomen, jedoch war auch hier eine starke Abhängigkeit vom Rauchverhalten zu verzeichnen.

In mehreren Studien und Reviews wird der Einfluss von Rauchen und allgemeiner Luftverschmutzung auf die Entwicklung einer COPD beschrieben. Dabei scheint sich die Wirkung dieser beiden Risikofaktoren zu addieren [16].

Eine nicht geringe Rolle spielt auch das Passivrauchen. In einer multizentrischen Studie in der Schweiz, an der 4197 Nichtraucher teilnahmen, wurde eine hohe Korrelation zwischen Expositionszeit und Bronchitissymptomen gefunden [58]. Eine große amerikanische Studie zeigt ebenfalls ein erhöhtes Risiko für die Entwicklung einer obstruktiven Lungenerkrankung bei Nichtrauchern [25].

\subsection{Prävalenz}

Schätzungen der WHO zufolge leiden weltweit 600 Millionen Menschen an COPD [74]. Die Prävalenz der COPD wurde in der BOLD-Studie (Burden of Obstructive Lung Disease) in insgesamt zwölf Ländern untersucht. Die Ergebnisse, die 2007 im Lancet publiziert wurden, zeigten dass die Prävalenz der COPD höher ist, als vielfach angenommen wurde. In Deutschland war die COPD-Prävalenz am niedrigsten - sie betrug bei Männern 7,5 \% und bei Frauen 3,1 \%. Am höchsten war die Prävalenz in Kapstadt: 14,2\% bei Männern und $11 \%$ bei Frauen. Weltweit, beträgt die Prävalenz $11,8 \%$ bei den Männern und $8,5 \%$ bei den Frauen [15]. 

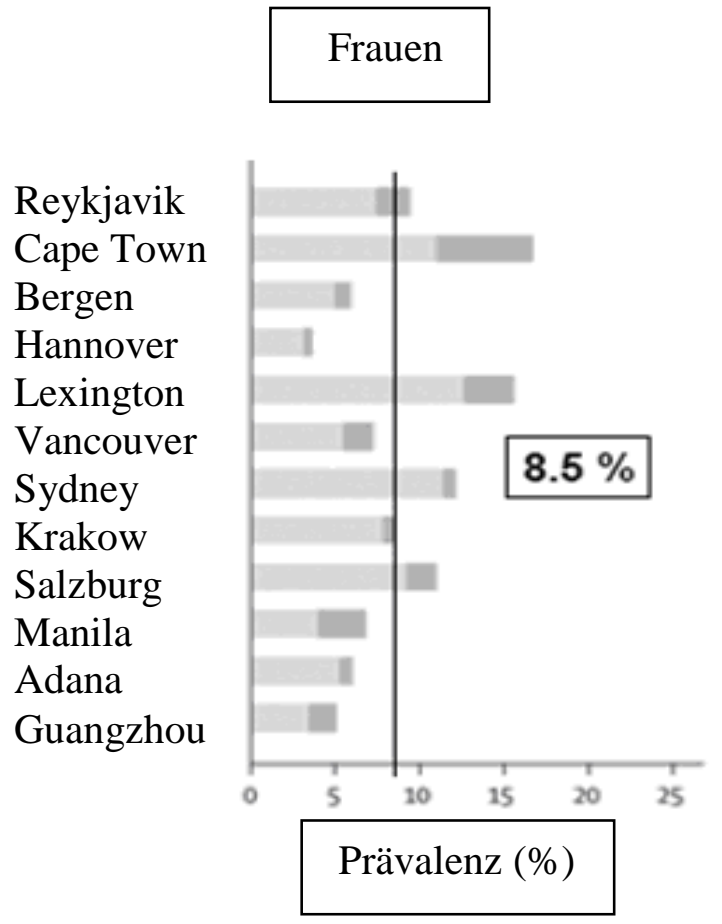

Männer

Cape Town

Manila

Adana

Guangzhou

Krakow

Hannover

Lexington

Bergen

Reykjavik

Salzburg

Vancouver

Sydney

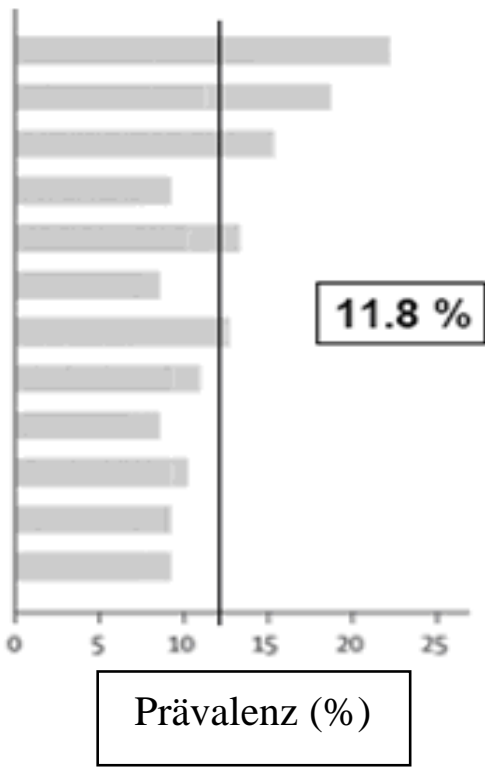

Abbildung 2: COPD-Prävalenz weltweit, nach BOLD-Studie - 12 Orte, 9425 Personen [15]

In Bezug auf das Alter zeigt sich eine unterschiedliche Entwicklung der COPD. Mannino et al. fanden in einer großen US-amerikanischen Studie eine mit dem Alter deutliche Zunahme der Prävalenz [63].

\begin{tabular}{|c|c|c|}
\hline Altersgruppe & COPD Std. I und II & COPD Std. III und IV \\
\hline 25-44 Jahre & $3,68 \%$ & $2,29 \%$ \\
\hline 45-54 Jahre & $8,71 \%$ & $7,24 \%$ \\
\hline $55-64$ Jahre & $12,62 \%$ & $14,05 \%$ \\
\hline $65-74$ Jahre & $16,54 \%$ & $20,66 \%$ \\
\hline$>75$ Jahre & $17,82 \%$ & $22,93 \%$ \\
\hline
\end{tabular}

Tabelle 3: Prävalenz der COPD in den USA in Abhängigkeit vom Alter [63]

In Widerspiegelung der historischen Geschlechtsunterschiede in Bezug auf das Rauchen ist die Prävalenz der COPD bei Männern höher als bei Frauen [67]. Der in den Nachkriegsjahren stetig steigende Anteil rauchender Frauen, aber auch eine erhöhte Exposition der häuslichen Luftverschmutzung durch Heizen und Kochen mit natürlichen Brennstoffen bedingt aktuell eine im 
Vergleich zu den Männern weltweit stärkere Zunahme der COPD-Prävalenz der Frauen [67]. Ein weiterer Grund für die zunehmende COPD-Prävalenz bei Frauen ist die Tatsache, dass die Diagnosestellung bei Frauen oftmals später als bei Männern erfolgt. In einer randomisierten, kontrollierten Studie wurden die geschlechtsspezifische Voreingenommenheit bezüglich der COPD-Diagnosestellung in USamerikanischen und kanadischen Hausarztpraxen untersucht; es wurde gefunden, dass vor allem bei Frauen die Erkrankung unterdiagnostiziert ist [95].

Auch geografisch zeigen sich erhebliche Unterschiede in der Prävalenz der COPD. In entwickelten Industrienationen, in denen die Diagnose anhand von Spirometriewerten ermittelt wurde, liegt die Prävalenz zwischen 3,7\% in Dänemark und 11\% in Italien [15].

\subsection{Mortalität und Prognose}

Laut WHO-Angaben ist die COPD die europaweit fünfthäufigste (nach ischämischer Herzkrankheit, zerebrovaskulären Erkrankungen, Krebserkrankungen des Atemtraktes sowie Infektionen der unteren Atemwege) und weltweit die sechsthäufigste Todesursache (nach ischämischer Herzkrankheit, zerebrovaskulären Erkrankungen, Infektionen der unteren Atemwege, Durchfallerkrankungen und Ereignissen während der Perinatalperiode) [59].

Schätzungen zufolge wird sich die COPD bis zum Jahr 2020 zur dritthäufigsten Todesursache (nach ischämischer Herzkrankheit und zerebrovaskulärer Erkrankung) weltweit entwickeln [59].

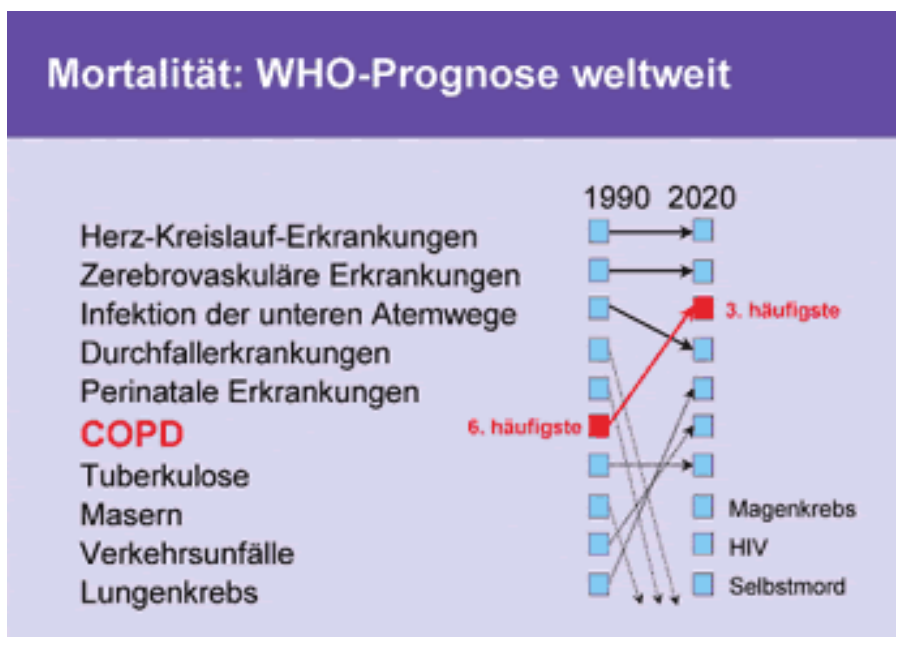

Abbildung 3: Die zunehmende Mortalität von COPD [59]

Im Gegensatz zu Erkrankungen wie der koronaren Herzkrankheit, Schlaganfall und anderen zerebrovaskulären Erkrankungen, die eine beständige und deutliche Abnahme zeigen, nimmt die 
Häufigkeit der COPD als Todesursache zu (NHLBI - National Heart 1998). Dieser Trend zeigt sich auch in einer Studie aus den USA, wo die Mortalität bei COPD-Patienten über 65 Lebensjahre seit 1980 kontinuierlich anstieg [2].

Weltweit nimmt die COPD in Bezug auf die Dauer in Jahren, die mit der Krankheit verbracht werden müssen zu, (Years lived with Disability = YLD), nach Depression, Eisenmangelanämie, unfallbedingten Stürzen und Alkoholismus am fünften Stelle. 1990 gab es 14,69 Millionen mit der COPD assoziierten Krankheitsjahre [67].

In einer Studie von Anto et al. wird einer von acht Patienten mit COPD im Krankheitsverlauf mit einer Exazerbation hospitalisiert. Von diesen:

- benötigt die Hälfte Behandlung einer Intensivpflegestation,

- stirbt jeder Zehnte im Krankenhaus,

- stirbt ein Drittel innerhalb von sechs Monaten,

- werden innerhalb eines Jahres $43 \%$ und innerhalb von drei Jahren ca. $67 \%$ gestorben sein [2].

Kompliziert wird die COPD durch Folgeerkrankungen wie die pulmonale Hypertonie, das Cor pulmonale durch eine permanente Rechtsherzbelastung, die Pneumonie, Polyzythämie und letztendlich das Lungenversagen.

\subsection{Sozioökonomische Bedeutung}

Die beträchtliche Morbidität der COPD wird sowohl vom Staat als auch von den Patienten unterschätzt. Dies zeigte sich in einer großen internationalen Umfrage unter COPD-Patienten mit einem hohen Prozentsatz an Patienten mit stark eingeschränkter Aktivität im täglichen Leben, Arbeitsunfähigkeitszeiten in regelmäßigen Abständen sowie regelmäßiger Inanspruchnahme von Gesundheitsleistungen [80].

In den fortgeschrittenen Industrienationen stellt die angemessene Versorgung chronisch Kranker die wichtigste und größte Herausforderung für das Gesundheitswesen dar. Chronisch Kranke verursachen als einen erheblichen Teil der direkten und indirekten Kosten im sozialen Versorgungssystem, vor allem im Gesundheitswesen.

Aufgrund der demografischen Alterung der Bevölkerung und der damit im Zusammenhang stehenden Krankheitslast sowie des medizinischen Fortschritts wird die Bedeutung chronischer Erkrankungen in Zukunft weiter zunehmen. Die chronische Bronchitis verursacht jährlich etwa 25 Millionen Arbeitsunfähigkeitstage (ATS 1995). Die GOLD-Studie ermittelte anhand internationaler Literatur folgende direkte und indirekte Kosten: 


\begin{tabular}{|l|l|l|l|l|}
\hline Staat & Jahr & $\begin{array}{l}\text { Direkte Kosten } \\
(\text { Millionen US-\$) }\end{array}$ & $\begin{array}{l}\text { Indirekte Kosten } \\
\text { (Millionen US-\$) }\end{array}$ & $\begin{array}{l}\text { Kosten insgesamt } \\
\text { (Millionen US-\$) }\end{array}$ \\
\hline Großbritannien & 1996 & 778 & 3.312 & 4.090 \\
\hline Niederlande & 1993 & 256 & nicht angegeben & nicht angegeben \\
\hline Schweden & 1991 & 179 & 281 & 460 \\
\hline USA & 1993 & 14.700 & 9.200 & 23.900 \\
\hline
\end{tabular}

Tabelle 4: Direkte und indirekte Kosten der chronischen Bronchitis[82]

In Deutschland wurden in einer prospektiven Krankheitskostenstudie anhand der Daten von 758 COPD-Patienten direkte und indirekte Kosten von 4,5 bzw. 3,94 Milliarden $€$ ermittelt. Die Arzneimittelkosten nehmen mit 41,4\% den größten Anteil bei den direkten Kosten ein. Es folgen mit 31,6 $\%$ die Kosten für die Hospitalisierung und mit 20,6 \% die Kosten für ärztliche Leistungen. Bei den indirekten Kosten bildet die Arbeitsunfähigkeit mit einem Anteil von 45,8 \% den größten Kostenblock, gefolgt von den Pflegekosten mit 21,7 \% [82].

\subsection{Pathogenese der COPD}

Die COPD wird definiert als eine Erkrankung mit langsam progredienter, nicht vollständig reversibler Atemflussbehinderung, die mit abnormen Entzündungsreaktionen auf inhalative Noxen verbunden ist [74]. Diese wird in erster Linie durch Zigarettenrauchen verursacht.

Diese Definition bringt zum Ausdruck, dass im Zentrum der Pathogenese eine Entzündungsreaktion in der Lunge steht. Diese induziert eine Bronchialobstruktion, strukturelle Veränderungen und eine mukoziliäre Dysfunktion.

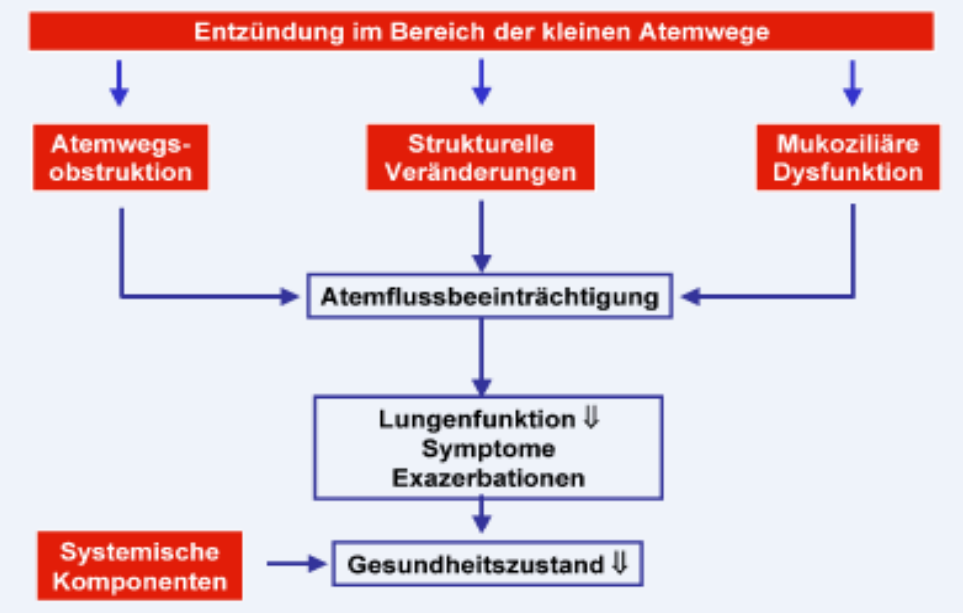

Abbildung 4: Pathophysiologie der COPD 
Untersuchungen von bronchoskopisch und operativ gewonnenem Lungengewebe sowie Sputumproben haben unzweifelhaft ergeben, dass bei der COPD eine ausgeprägte Entzündung im Bereich der großen und der kleinen Atemwege vorliegt. Hogg et al. haben mit aufwändigen quantitativen histopathologischen Methoden die kleinen Atemwege ( $<2 \mathrm{~mm}$ ) einer großen Anzahl von Patienten aller COPD-Schweregrade analysiert. Dabei zeigte sich, dass schon bei frühen Stufen der Erkrankung eine Entzündung nachweisbar ist und diese mit zunehmendem Schweregrad zunimmt. Es ist anzumerken, dass die meisten der evaluierten Patienten mit schwerer und sehr schwerer COPD schon Jahre nicht mehr geraucht hatten [45].

In der Bronchialschleimhaut von Patienten mit COPD wurden dominierend T-Lymphozyten (insbesondere CD8-positive Zellen), Makrophagen und Neutrophilen gefunden aber auch Eosinophilen und CD4-Zellen wurden identifiziert (Abb 5) [45].

Die Aktivierung der Epithelzellen führt zum Einstrom in den Lungen von Lymphozyten und neutrophilen Granulozyten. Der genaue Mechanismus, durch den CD8-positive T-Lymphozyten in den Lungen von Patienten mit COPD akkumulieren, ist bislang nicht verstanden. Es könnte sein, dass die chronische Kolonisierung der tieferen Atemwege von COPD-Patienten durch bakterielle oder virale Pathogene eine Rolle spielt [45].

COPD Stadium 1 COPD Stadium 2 COPD Stadium 3 COPD Stadium 4

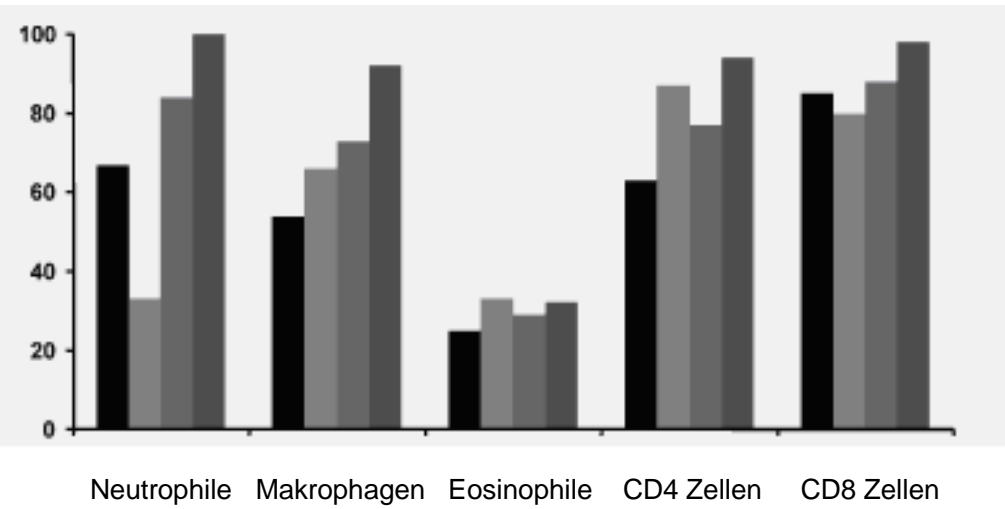

Abbildung 5. Entzündungszellen im Bereich der kleinen Atemwege in unterschiedlichen COPD-Stadien [45]

\section{Die Rolle vom Rauchen in der Pathogenese der COPD}

In diesem Zusammenhang stellt sich immer wieder die Frage, warum nur etwa 15-20\% der Raucher eine COPD entwickeln. Dafür sind vielfältige Ursachen möglich - von genetischen Faktoren bis zu stattgehabten Infektionen. Es könnte sein, dass die chronische Kolonisierung der tieferen Atemwege von COPD-Patienten durch bakterielle oder virale Pathogene für die gesteigerte inflammatorische Reaktion verantwortlich ist [45]. Es wurde vermutet, dass die Anwesenheit der CD8-positiven T-Lymphozyten bei Rauchern ohne COPD vs. mit COPD unterschiedlich ist und dass es eine Korrelation zwischen der Anzahl der T-Zellen, dem Ausmaß der alveolären Destruktion und dem Schweregrad der Atemwegsobstruktion 
gibt. Jedoch finden sich auch bei Rauchern mit normaler Lungenfunktion, erhöhte Zahlen an CD8positiven Zellen im Vergleich zu Nichtrauchern [62].

Noxen wie Zigarettenrauch führen zu einer Aktivierung von Alveolarmakrophagen, aber auch Epithelzellen. Die Alveolarmakrophagen werden als zentrale Zellen für die Induktion der Entwicklung einer COPD aufgefasst. Ihre Anzahl ist in den Atemwegen, dem Lungenparenchym und der bronchoalveolären Lavage von Patienten mit COPD 5- bis 10fach erhöht. Die Makrophagenzahlen in den Atemwegen korrelieren mit dem Schweregrad der COPD [7]. Die Makrophagenaktivierung bedingt die Freisetzung von proinflammatorischen Mediatoren wie Tumornekrosefaktor $\alpha$, Interleukin-8, Leukotrien B4 und reaktiven Sauerstoffmetaboliten.

Es ist bekannt, dass Zigarettenrauchen die Anzahl der zirkulierenden neutrophilen Granulozyten steigert und eine Sequestration von Neutrophilen in den Lungenkapillaren verursacht, indem es deren Deformierbarkeit herabsetzt. Zigarettenrauch hat ebenso einen direkten stimulierenden Effekt auf die Granulozytenproduktion im Knochenmark, möglicherweise vermittelt über den GranulozytenMakrophagen-Kolonien stimulierenden Faktor (GM-CSF) und den Granulozytenkolonien stimulierenden Faktor (G-CSF), die von Makrophagen freigesetzt werden [61].

Es besteht eine Korrelation zwischen der Anzahl von neutrophilen Granulozyten in Bronchusbiopsien/induziertem Sputum und dem Schweregrad der Erkrankung sowie dem Abfall der Lungenfunktion [32]. Neutrophile Granulozyten enthalten große Mengen an Serinproteinasen. Diese können zur alveolären Destruktion beitragen und stimulieren darüber hinaus in erheblichem Ausmaß die Mukussekretion.

\subsubsection{Proteasen-Antiproteasen-Gleichgewicht}

Gross et al. haben bereits seit vielen Jahren Ergebnisse von Tierexperimenten publiziert, bei denen sie Papain in die Lungen von Nagern instilliert hatten, mit dem Ziel, Granulome zu produzieren [42]. Im Gegensatz dazu fanden sie ein Emphysem. Im weiteren Verlauf haben eine Reihe von Arbeitsgruppen verschiedene Proteasen in Tierlungen instilliert, u. a. Pankreaselastase und die noch relevantere humane neutrophile Elastase. Diese Experimente bildeten die Basis für die Protease-Antiprotease-Hypothese. Sie geht davon aus, dass das relative Gleichgewicht zwischen Proteasen und ihren Inhibitoren die Empfänglichkeit der Lunge für die emphysemtypische Destruktion determiniert.

Hinsichtlich des a1-Antitrypsin-Mangels ist schon bekannt, dass bestimmte Mutationen zu einer Verminderung des a1-Antitrypsin-Spiegels im Serum führen. Diese Mutationen vermindern die Sekretion des Proteins aus Hepatozyten in die Blutbahn.

\subsubsection{Oxidativer Stress und COPD}

Zigarettenrauch enthält ungefähr 1017 Moleküle von reaktiven Sauerstoffmetaboliten pro Zug. Eine Reihe von Studien ergab, dass oxidativer Stress in den Lungen von Patienten mit COPD im Vergleich zu 
gesunden Individen, aber auch im Vergleich zu Rauchern ohne Atemwegsobstruktion, vermehrt ist [8]. Rauchende Patienten mit COPD weisen höhere Spiegel an $\mathrm{H}_{2} \mathrm{O}_{2}$ im exhalierten Atemwegskondensat auf als Exraucher mit COPD oder Nichtraucher. Peroxynitrit und Nitrotyrosin wurden bei COPD-Patienten ebenfalls vermehrt gefunden. Diese Anhaltspunkte führten zu der Hypothese, dass ein Ungleichgewicht zwischen Oxidantien und Antioxidantien in die Pathogenese der COPD involviert sein könnte [8].

Oxidantien sind in der Lage, die Schleimsekretion durch Atemwegsepithelzellen zu induzieren. $\mathrm{H}_{2} \mathrm{O}_{2}$ kann in relativ niedrigen Konzentrationen eine signifikante Verschlechterung des Zilienschlags und damit der mukoziliären Clearance bewirken. Diese pathogenetischen Faktoren können in der Akkumulation von Schleim resultieren. Reaktive Sauerstoffmetaboliten sind darüber hinaus in der Lage, eine gesteigerte Exsudation von Plasma in das Gewebe als Folge einer vermehrten Permeabilität des Epithels und eine Bronchokonstriktion zu bewirken [62].

\subsubsection{Apoptose}

Dieser genau regulierte Mechanismus für Zelltod erlaubt die Eliminierung von unerwünschten, beschädigten oder infizierten Zellen. Gegenwärtig sind verschiedene Mechanismen bekannt, die in die Regulation der Apoptose involviert sind. Eine wichtige Rolle spielen dabei verschiedene Caspasen (Cysteinyl-aspartate-cleaving-Proteasen) mit einer wichtigen Bedeutung für die Apoptose. Der programmierte Zelltod ist kritisch für die Erhaltung der normalen Gewebehomöostase und steht im Gleichgewicht mit Proliferation und Differenzierung [36]. Es gibt zunehmende Hinweise dafür, dass bei der COPD im Lungengewebe eine Störung der Balance zwischen Apoptose und Proliferation besteht [28].

Kasahara et al. demonstrierten eine gesteigerte Anzahl von apoptotischen Epithel- und Endothelzellen in den Alveolarsepten von Emphysemlungen im Vergleich zu Lungen von Nichtrauchern. Darüber hinaus fanden sie eine signifikant reduzierte Expression von VEGF („vascular endothelial growth factor“) und VEGF-Rezeptoren. Sie demonstrierten in einem Rattenmodell, dass die Blockade des VEGF-Rezeptors eine Alveolarzellapoptose induziert und zu einer Vergrößerung der Lufträume führt. Darüber hinaus wurden durch die Behandlung mit einem Kaspaseinhibitor die Apoptose der Zellen der Alveolarsepten verhindert und die Emphysembildung blockiert [49].

Wie oben dargestellt, tragen verschiedene Mechanismen zur Pathogenese der COPD bei. Die Inhalation von Partikeln und Gasen wie Zigarettenrauch verursacht einen Einstrom von Entzündungszellen in die Atemwege und die Lungen mit der Konsequenz einer chronischen Entzündung unter Beteiligung verschiedener Arten von Entzündungszellen (Makrophagen, Neutrophile, CD8-positive T-Lymphozyten, B-Zellen).

Im Zusammenhang damit kommt es zu einer Störung des Gleichgewichts zwischen proteolytischen und antiproteolytischen Molekülen mit der Folge einer gesteigerten proteolytischen Aktivität. Diese kann eine Destruktion von Lungenparenchym verursachen. Des Weiteren besteht ein oxidativer Stress als Folge eines Ungleichgewichts zwischen reaktiven Sauerstoffmetaboliten und antioxidativen Verteidigungsmechanismen. Er kann zur Dysfunktion von Zellen und zum Zelltod führen und eine 
Schädigung der extrazellulären Matrix der Lunge bewirken. Schließlich kommt eine gesteigerte Apoptose von Strukturzellen der Lunge als pathogenetischer Faktor in Betracht, der zur Destruktion des Lungengewebes mit der Konsequenz eines Emphysems beitragen kann. Alle diese genannten Faktoren stehen nicht für sich, sondern bedingen sich wechselseitig.

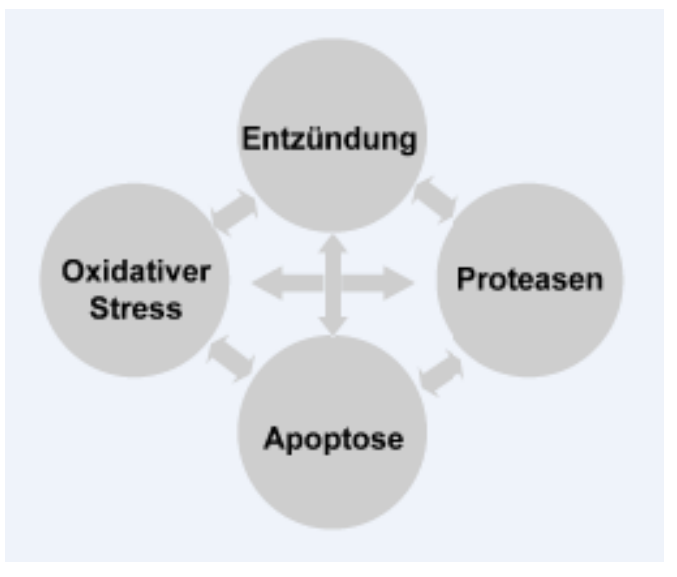

Abbildung 6: Komponenten der COPD-Pathogenese

\subsection{COPD, eine Systemerkrankung}

\subsubsection{Systemische Inflammation bei COPD}

Es ist seit langem bekannt, dass der bedeutendste Auslöser der COPD, das Rauchen, zu einer Entzündung im Bronchialbaum führt. Hierbei spielen neben der direkten Aktivierung von Neutrophilen und Makrophagen die Imbalance zwischen Oxidanzien und Antioxidanzien und das fehlende Gleichtgewicht zwischen Proteasen und Antiproteasen eine bedeutsame Rolle. Zigarettenrauch enthält zum einen eine sehr große Menge an reaktiven Sauerstoffmetaboliten, zum anderen aktiviert er deren Freisetzung in der Lunge. Die Sauerstoffmetaboliten gelangen durch die Lunge in den systemischen Kreislauf und führen zur Freisetzung von Entzündungsmetaboliten, beispielsweise Zytokinen, die ebenfalls einen systemischen Effekt haben [62].

Diese am Anfang akute und reversible Inflammation ruft eine chronisch persistierende Entzündung hervor, die schließlich zu einem Gewebeschaden in der Lunge führt. Zytokine aktivieren periphere Blutneutrophile, die in die Lunge einströmen und die lokale Entzündung unterhalten. Diese systemische Inflammation ist mitverantwortlich für die Beteiligung anderer Organsysteme, wie z.B. Muskeln, Gefäße 
und Knochen. Häufige Exazerbationen führen zu einer rasanten Verschlechterung der Lungenfunktion und verstärken die systemischen Effekte [21], [73].

Das Ausmaß, in welchem systemische Effekte zur gesamten Pathologie der COPD beitragen, variiert von Patient zu Patient. Aufgrund großer Statistiken besteht der Verdacht, dass die systemischen Komponenten für den größten Teil der Morbidität und Mortalität von COPD-Patienten verantwortlich sind.

Parallel dazu wurde gezeigt dass die Intensität des inflammatorischen Prozesses mit dem Schweregrad der Grunderkrankung korreliert ist. Im Vergleich zu gesunden Kontrollen zeigen Patienten mit COPD signifikant erhöhte systemische Spiegel von Fibrinogen, Leukozyten, TNFa sowie Interleukin-8. Auch fand sich bei innen eine gesteigerte systemische Belastung mit reaktiven Sauerstoffmetaboliten. Die neutrophilen Granulozyten von COPD-Patienten setzen mehr reaktive Sauerstoffmetaboliten frei als die von Normalprobanden [73].

Eine Reihe von Arbeitsgruppen haben schließlich Veränderungen der Apoptose oder apoptotische Signale in der systemischen Zirkulation oder im Skelettmuskel von COPD-Patienten beschrieben. So konnte gezeigt werden, dass T-Zellen im peripheren Blut von COPD-Patienten vermehrt in Apoptose übergehen [29].

\subsubsection{Beeinträchtigung des Herz-Kreislauf-Systems}

Aus einer Reihe von epidemiologischen Untersuchungen ist bekannt, dass ein Großteil der COPDPatienten an kardiovaskulären Erkrankungen verstirbt. Umgekehrt stellt die COPD eine der bedeutendsten Komorbiditäten bei Myokardinfarkt dar.

Patienten mit Myokardinfarkt, die gleichzeitig eine COPD haben, weisen eine höhere Mortalität auf als solche ohne COPD. Des Weiteren konnte gezeigt werden, dass das Risiko für einen kardiovaskulären Tod indirekt mit der Lungenfunktion korreliert ist, und zwar unabhängig vom aktuellen Raucherstatus [50].

\subsubsection{Osteoporose bei COPD}

Osteoporose als Begleiterkrankung der COPD ist erst seit kurzem bekannt. Es gibt nur wenige Angaben über deren Inzidenz, und diese Daten wurden meist bei Schwerkranken erhoben. Die genaue Pathogenese ist noch weitgehend unklar. Dabei könnten viele Faktoren eine Rolle spielen: Immobilität durch Dyspnoe, verminderte bzw. veränderte Muskelmasse oder Behandlung mit Kortikosteroiden.

Ein großes klinisches Problem stellt die Osteoporose dar, wenn es zu Frakturen, insbesondere im Bereich der Wirbelkörper, kommt. Die auftretenden Schmerzen in Kombination mit der Dyspnoe führen zu einer weiteren Bewegungseinschränkung und oft zu einer dramatischen Verschlechterung der Erkrankung [4].

Risikofaktoren für die Entwicklung einer Osteoporose sind bei COPD-Patienten vielfältig: zum einen scheint das Rauchen ein Risikofaktor zu sein, aber auch ein niedriger Bodymass-Index (BMI) bzw. eine niedrige fettfreie Masse gehen mit einem höheren Osteoporoserisiko einher. Die systemische 
Inflammation mit Freisetzung von Zytokinen führt neben dem Gewichtsverlust ebenfalls zu Veränderungen im Knochenstoffwechsel, die zu einer Osteoporose prädestinieren [48].

\subsubsection{Muskelveränderungen bei COPD}

Biochemische und morphologische Veränderungen in peripheren Muskeln wurden bei COPDPatienten, insbesondere durch Analysen von Muskelgewebe, mehrfach bestätigt. So unterscheidet sich die Zusammensetzung der Muskelfasertypen zwischen Gesunden und COPD-Patienten. Bei COPDPatienten wurden geringere Typ-I- und höhere Typ-II-Myosin-heavy-chain-(MyHC-)Isoformen im peripheren Muskel gefunden [83].

Die Aktivität der oxidativen Enzyme im Muskel von COPD-Patienten wurde als deutlich erniedrigt beschrieben. Rabinovich et al. konnten zeigen, dass die Glutathion-(GSH-)Regulation in der Muskulatur von COPD-Patienten gestört ist [76]. Vor allem ist das reduzierte Glutathion eines der wichtigsten Antioxidanzien. Bei 17 Patienten mit COPD konnte die Arbeitsgruppe durch Nadelbiopsien aus dem M. vastus lateralis vor und nach Belastungstraining zeigen, dass es im Gegensatz zu Gesunden zu keinem Anstieg des reduzierten Glutathions kam.

Die Arbeitsgruppe von Schols beschrieb, dass es bei COPD-Patienten zu einer Veränderung in der Zusammensetzung der Muskelfaseranteile kommt und diese mit einer reduzierten antioxidativen Kapazität einhergeht [87]. Ebenso fanden sie, dass die verminderte Muskelmasse bei COPD-Patienten hauptsächlich durch die Atrophie von Muskelfasern verursacht wird.

In einer anderen Studie zeigte die Arbeitsgruppe von Jobin, dass Lipofuszin ein Marker für kumulativen oxidativen Stress ist. Nach Belastung fand sich bei COPD-Patienten im M. vastus lateralis deutlich mehr Lipofuszin als bei Kontrollpersonen [1]. Ferner konnte gezeigt werden, dass die Belastungen des M. quadriceps bei COPD-Patienten zu einem lokalen oxidativen Stress führen, während dies bei Gesunden nicht der Fall ist. Zudem fehlt bei COPD-Patienten die erwartete antioxidative Antwort, gemessen an der Konzentration der Glutathion-Peroxidase. Alle diese Ergebnisse deuten darauf hin, dass oxidativer Stress eine nicht unbedeutende Rolle bei der schnelleren Ermüdung der Muskulatur bei COPD spielt [1].

Eines der Hauptsymptome von COPD-Patienten ist die fortschreitende Reduktion der körperlichen Belastbarkeit. Diese zeigt eine klare Korrelation mit dem Schwund der Muskelmasse, die insbesondere an der Oberschenkelmuskulatur (M. quadriceps) untersucht wurde [6].

Der Verlust an Muskelmasse hat auch einen direkten Einfluss auf die Atemmuskulatur. Ein niedriger BMI stellt einen unabhängigen, negativen Effekt für die Sauerstoffsättigung im Muskel dar. Daher wirken sich sowohl Gewichtsverlust als auch ein Verlust an Muskelmasse ungünstig auf die Mortalität und Morbidität von COPD-Patienten aus [9].

Die Atemmuskulatur ist, ebenso wie die übrige Skelettmuskulatur, den katabolen Veränderungen bei Mangelernährung und Kachexie in Form von reduzierter Proteinsynthese und erhöhtem Eiweißabbau unterworfen. Ob ein allgemeiner Verlust an Muskelmasse die Atemmuskulatur prozentual mehr betrifft als die übrige Muskulatur, wird kontrovers diskutiert [3]. 


\subsubsection{Schlafstörungen bei COPD}

Aus der verminderten Ventilation, besonders im REM-Schlaf, resultieren länger anhaltende Perioden mit Sauerstoffmangel. Als Konsequenz des Sauerstoffmangels steigt der Druck im Lungenkreislauf während der Nacht deutlich an. Als Folge der vermehrten Rechtsherzbelastung und des zunehmenden Sauerstoffmangels können im Schlaf gehäuft Herzrhythmusstörungen beobachtet werden. Die Anzahl an Todesfällen ist in der Nacht verglichen mit dem Tage deutlich erhöht [50].

Als Folge der Störung der Ventilation durch den Schlaf kommt es auch zu erheblichen Störungen des Schlafprofils; in der Regel schlafen Patienten mit schwergradiger COPD deutlich weniger Stunden als Gesunde. Auch die Häufigkeit der Schlafstadienwechsel ist im Vergleich zum Gesunden um das Dreifache erhöht. Wenn zusätzlich zur COPD auch noch ein Schlafapnoesyndrom besteht, ist die Sauerstoffsättigung im Rahmen der Apnoen/Hypopnoen noch niedriger. Bei Tagesschläfrigkeit von

COPD-Patienten sollte an die Möglichkeit der Kombination mit einem obstruktiven Schlafapnoe-Syndrom (OSAS) gedacht ein Schlafscreening durchgeführt werden. Im Zweifelsfall sollte eine nächtliche Messung der Sauerstoffsättigung (Pulsoxymetrie) durchgeführt werden [99].

\subsection{BMI, »Body mass index"}

Die Berechnung des Körpermassenindexes (Body mass index, BMI) wurde zur Bewertung des tatsächlichen Verhältnisses von Körpermasse und -länge eingeführt mit dem Ziel einer Klassifizierung von Unter- bzw. Übergewicht. Die Formel hierzu lautet:

$$
\mathrm{BM}=\frac{\mathrm{KG}[\mathrm{kg}]}{\text { Größe }\left[\mathrm{m}^{2}\right]}
$$

Das Konzept des BMI geht zurück auf einen Pionier der Anthropometrie und Statistik, dem belgischen Anthronomen Adolphe Quetelet, der im Jahre 1869 erkannte, dass das Gewicht eine Funktion des Quadrats der Große ist. Der amerikanische Ernahrungswissenschaftler Ancel Keys hat den BMI dann 1972 endgultig als Maß der Adipositas eingeführt.

Der BMI unterscheidet nicht zwischen Fett- und Muskelmasse. Bei gleichem BMI haben Frauen und ältere Menschen einen höheren prozentualen Fettanteil als Männern bzw. Junge Menschen. Die Beziehung zwischen BMI und Fettmasse ist in verschiedenen Populationen unterschiedlich. Polynesier und Kaukasier haben bezogen auf ihren BMI eine niedrige Fettmasse. Die Beziehung zwischen BMI und Fettmasse ist fragwürdig bei sehr kleinen (Körpergroße $<150 \mathrm{~cm}$ ) und sehr muskulösen Menschen. 

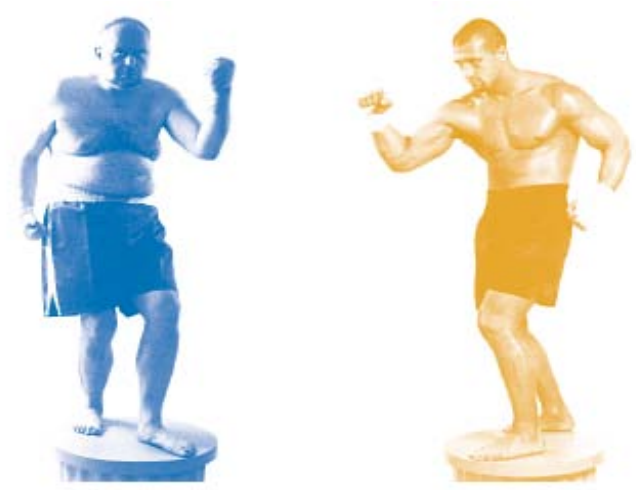

Abbildung 7: Zwei Körper mit ähnlicher Größe und ähnlichem Gewicht. Der BMI bietet hier keinen Aufschluss über den Ernährungszustand

Der BMI hat eine Beziehung zu Morbidität und Mortalität. Mit steigendem BMI steigen Morbidität und Mortalität. Es besteht eine hyperbole Beziehung: Ein BMI $>30$ bzw. $<18,5 \mathrm{~kg} / \mathrm{m}^{2}$ geht mit einer erhöhten Mortalitat einher [66].

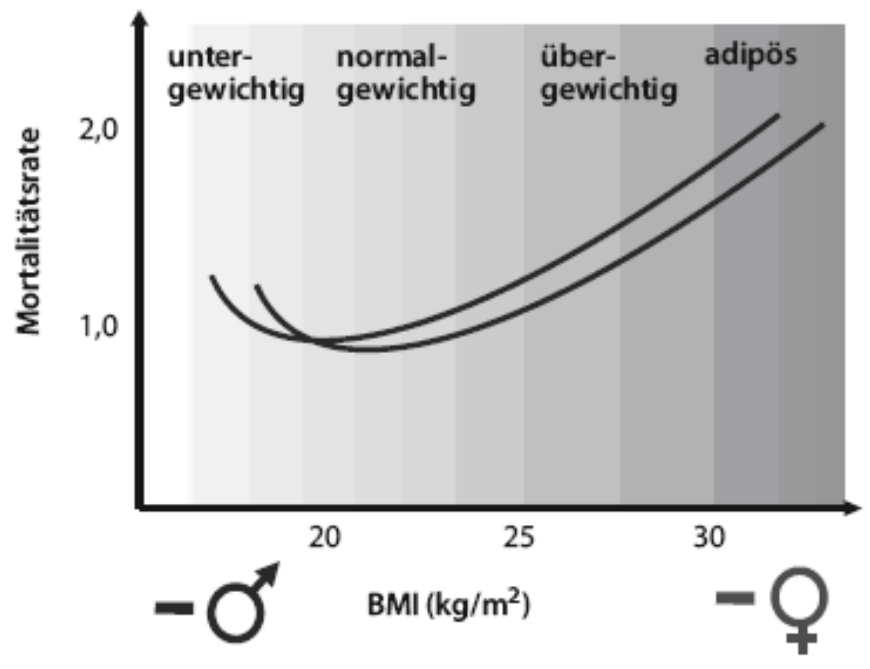

Abbildung 8: Beziehung BMI-Mortalität [66]

In einem Alter zwischen 18-60 Jahren sind BMI-Werte von 18,5-25 kg/m2 normal und sie gehen mit einem niedrigeren Krankheits- und Mortalitätsrisiko einher. Die WHO empfiehlt einen BMI von 20,5-25 $\mathrm{kg} / \mathrm{m} 2$ für Männer bzw. 18,7-23,8 kg/m² für Frauen. Für ältere Menschen (>60 Lebensjahr) beträgt der normale BMI 18,5-27,5 kg/m². Bei einem BMI $<16,0 \mathrm{~kg} / \mathrm{m}^{2}$ besteht eine ausgeprägte Malnutrition. Werte $<12 \mathrm{~kg} / \mathrm{m} 2$ sind mit dem Leben nicht vereinbar [66]. 


\begin{tabular}{l|l}
\hline Beurteilung des Körpergewichtes & BMI $\left(\mathbf{k g} / \mathbf{m}^{2}\right)$ \\
\hline Untergewicht & $<18,5$ \\
\hline Normalgewicht & $18,5-24,9$ \\
\hline Ubergewicht & $>25$ \\
\hline - Präadipös & $\mathbf{Z} 25-29,9$ \\
- Adipositas Grad I & $\mathbf{Z} 30-34,9$ \\
- Adipositas Grad II & $\mathbf{Z} 35-39,9$ \\
- Adipositas Grad III & $\mathbf{Z}>40$
\end{tabular}

Tabelle 5: Charakterisierung des Ernährungszustandes von Erwachsenen mit Hilfe des Body Mass Index (BMI). Einteilung nach $\mathrm{WHO}$

Die Frage nach dem optimalen BMI-Bereich für eine günstige Prognose bei den COPD-Patienten ist schwer zu beantworten. Während ein $\mathrm{BMI}<18,5 \mathrm{~kg} / \mathrm{m}^{2}$ als Untergewicht angesehen wird, weisen Überlebensdaten von COPD-Patienten bereits bei einem BMI $<21 \mathrm{~kg} / \mathrm{m}^{2}$ eine ungünstige Prognose auf. Augenmerk sollte aber nicht nur auf das Unter-, sondern auch auf das Übergewicht (BMI $>30 \mathrm{~kg} / \mathrm{m}^{2}$ ) gelegt werden, denn Letzteres führt zu einer gesteigerten Atemarbeit und hat somit ebenfalls einen negativen Einfluss auf die Belastbarkeit der Patienten [99].

\begin{tabular}{|l|l|l}
\hline $\begin{array}{l}\text { Altersgruppe } \\
\text { (Jahre) }\end{array}$ & Männer & Frauen \\
\hline $20-29$ & 21,4 & 19,5 \\
\hline $30-39$ & 21,6 & 23,4 \\
\hline $40-49$ & 22,9 & 23,2 \\
\hline $50-59$ & 23,2 & 25,2 \\
\hline $60-69$ & 26,6 & 27,3 \\
\hline
\end{tabular}

Tabelle 6: Alters- und Geschlechtsabhängigkeit des BMI’s mit der höchsten Lebenserwartung [66]

Fett ist nicht nur Energiereservoir, sondern spielt auch eine Rolle bei unterschiedlichen Stoffwechselprozessen. Das erst vor wenigen Jahren entdeckte Leptin ist bei COPD verändert. Leptin ist ein Proteohormon, das von Adipozyten sezerniert wird und eine wichtige Rolle bei der Regulierung des Fetthaushalts spielt [5]. Takabatake et al. fanden einen mit dem BMI korrelierenden erniedrigten Leptinspiegel bei COPD-Patienten [100]. Sie konnten zeigen, dass der Spiegel, insbesondere bei Emphysempatienten, erniedrigt war. Eine neue Studie zeigte, dass die Leptinspiegel bei kachektischen Patienten unter der Norm liegen. Zudem war im Vergleich zu Gesunden und normalgewichtigen COPDPatienten die zirkadiane Rhythmik der Leptinspiegel aufgehoben [100]. Die Autoren schlossen aus ihren Beobachtungen, dass das Fehlen des nächtlichen Peaks des Leptins eine Kompensation bei kachektischen Patienten darstellt, um Fett zu bewahren (verhindert Thermogenese). 


\subsection{Malnutrition und Untergewicht bei COPD}

Gewichtsverlust bei Patienten mit COPD und die Bedeutung der Ernährung für die Atemfunktion sind seit Jahren bekannt. Sie haben in der letzten Zeit aufgrund neuer Erkenntnisse zunehmend an Bedeutung gewonnen.

In der Literatur wird, abhängig vom Schweregrad der COPD, eine Inzidenz von 20-60\% von Untergewicht bzw. eine Mangelernährung angegeben [12]. Die Ursache des Untergewichts bzw. Gewichtsverlusts ist bislang noch unklar. Im Allgemeinen liegt der Gewichtsverlust, insbesondere der Verlust an Muskelmasse und der negativen Energiebilanz zugrunde; der Gewichtsverlust scheint häufiger bei Patienten mit Emphysem aufzutreten. Darüber hinaus ist der Energiestoffwechsel bei COPD-Patienten erhöht [12].

Einige Studien zeigten sowohl zwischen BMI und Lungenfunktionsparametern als auch zwischen BMI und Mortalität Korrelation [84]. Die älteren Studien beziehen sich auf das reine Körpergewicht bzw. den BMI. Sie sind bei Patienten mit Adipositas oder Patienten mit Ödemen als Parameter für den Nachweis einer verminderten Muskelmasse nicht geeignet.

Neben der Hautfaltenmessung, die nur eine Unterteilung in Fett- und fettfreie Körpermasse erlaubt, stellten das Computertomogramm (CT) der Oberschenkelmuskulatur und die Bioimpedanzanalyse (BIA) einen wesentlich besseren Parameter zur Beurteilung der Muskelmasse zur Verfügung [38].

Eines der Hauptsymptome von COPD-Patienten ist die fortschreitende Reduktion der körperlichen Belastbarkeit. Diese zeigt eine klare Korrelation mit dem Schwund der Muskelmasse, die insbesondere an der Oberschenkelmuskulatur (M. quadriceps) untersucht wurde [6]. Entsprechend ist die Ermüdbarkeit bei COPD-Patienten deutlich höher als bei Gesunden.

Ziel weiterer Studien muss es daher sein, die Muskelfunktion und die Veränderungen in diesem Bereich bei COPD-Patienten noch besser zu verstehen, um dann hierauf Einfluss nehmen zu können. Zukünftige Therapien sollten sich daher nicht nur auf die Behandlung der Inflammation und Dilatation der Bronchien beschränken, sondern darauf ausgerichtet sein, den veränderten Metabolismus bei COPDPatienten zu beeinflussen, um so die Belastbarkeit der Patienten und vielleicht auch die Prognose zu verbessern.

\subsubsection{Mechanismen der Malnutrition bei COPD}

Die Ursachen der Malnutrition sind vielfältig; reduzierte Aufnahme von Nahrung, verminderte Absorption, erhöhter Energieverbrauch, veränderter Metabolismus. Für die verminderte Aufnahme von Nahrung bei Patienten mit fortgeschrittener Lungenerkrankung gibt es selten nur einen einzigen Grund. Es sind mehrere Faktoren, die dazu beitragen, wie die chronische Mundatmung bei respiratorischer Insuffizienz, die Dyspnoe, die oft bereits in Ruhe vorhanden ist, verstärkt sich durch Nahrungsaufnahme. Die Medikamente wie Antibiotika und Theophyllin könnten zu gastrointestinalen Beschwerden führen. Nicht zu vernachlässigen sind die Depressionen, die bei den Patienten, die unter zunehmender 
Immobilität, Dyspnoe und Behinderung durch die Erkrankung leiden. Eine der Ursachen für einen höheren Ruhe-Energieverbrauch bei respiratorisch eingeschränkten Patienten ist die erhöhte Atemarbeit. Bei Gesunden werden in Ruhe ca. 2 - 3 \% der Gesamtenergie für die Atmung benötigt. Bei Patienten mit COPD wird alleine aufgrund der verminderten Elastizität des Thorax und der mechanisch ungünstigeren Ausgangslage bei Überblähung mehr Energie für die Atmung benötigt [33]. Die medikamentöse Therapie der COPD (Theophyllin und $\beta_{2}$-Sympathomimetika) könnte zu einer Erhöhung des Grundumsatzes führen. Kortikosteroide in höheren Dosierungen (> $60 \mathrm{mg} / \mathrm{d}$ ) verursachen eine Reduktion der Atemmuskelstärke [109]. In den letzten Jahren ist zunehmend darüber Erkenntnis gewonnen worden, dass der Metabolismus bei Patienten mit COPD gegenüber Gesunden verändert ist. Diese Veränderungen wurden insbesondere durch Analysen von Muskeln gewonnen. Das Überwiegen von anaeroben Typ-1-Muskelfasern bei COPD-Patienten könnte mitverantwortlich für die frühere Ermüdung der Patienten sein, weil diese Muskeln ATP weniger effizient produzieren und die Produktion von Laktat höher ist.

\subsubsection{Erhöhter Energieverbrauch}

Die erhöhte Atemarbeit ist eine der wesentlichen Ursachen für einen höheren Ruhe-Energieverbrauch bei respiratorisch eingeschränkten Patienten. Bei Exazerbationen ist bereits nachgewiesen, dass ein hypermetabolischer Zustand vorliegt. Es gibt Hinweise darauf, dass auch bei stabilen COPD-Patienten der Serumspiegel einiger inflammatorischer Zytokine erhöht ist und diese für einen Hypermetabolismus verantwortlich sind. Insbesondere der Tumor-Nekrose-Faktor- $\alpha$ (TNF- $\alpha$ ) wurde untersucht. Es zeigte sich, dass Patienten mit Untergewicht und Gewichtsverlust höhere Werte von TNF- $\alpha$ aufweisen als gewichtsstabile [31].

Muskelverlust und Kachexie werden bei vielen chronischen Erkrankungen beobachtet (z.B. schwere Herzinsuffizienz, AIDS, chronische Niereninsuffizienz, Karzinome). Bei den meisten dieser Erkrankungen konnten, ebenso wie bei COPD, klare Korrelationen zur Prognose festgestellt werden. Die Tatsache, dass Kachexie ein gemeinsames Phänomen der Endstrecke mehrerer chronischer Erkrankungen ist, legt einen gemeinsamen ursächlichen Mechanismus nahe. So konnte gezeigt werden, dass anabole Hormone (z.B. „insulin-like growth factor"[IGF] und Testosteron) bei diesen Patienten erniedrigt sind, während proinflammatorische Substanzen (z.B. TNF- $\alpha$, Interleukin-[ IL-]1, IL-6, IL-8, Interferon-[ IFN-]Y) erhöht sind. Ebenso konnte gezeigt werden, dass Muskelverlust und Muskelschwäche bei Patienten mit COPD ähnlich generalisiert und ausgeprägt waren wie bei Patienten mit schwerer Herzinsuffizienz [41]. Es ist gezeigt worden, dass die Veränderungen, insbesondere im Muskel, bei COPD-Patienten bereits in einer relativ frühen Phase der Erkrankung auftreten.

In mehreren Studien wurde nachgewiesen, dass das Aminosäureprofil, sowohl im Blut als auch im Muskel, von Patienten mit COPD verändert ist. Engelen et al. konnten zeigen, dass auch bei COPDPatienten ohne Hypoxämie Veränderungen des Aminosäureprofils im Plasma und Muskel (M. quadriceps) zu finden sind. Die Zusammensetzung der Aminosäuren bei Gesunden und COPD-Patienten vor und 
nach Belastung zeigte, dass bei COPD-Patienten die Konzentration fast aller Aminosäuren im Muskel nach Belastung erniedrigt war, im Plasma hingegen erhöht. Dies stellt einen weiteren Hinweis auf einen erhöhten Umsatz und Ausstrom von Aminosäuren aus dem Muskel bei COPD-Patienten dar [35].

\subsection{Diagnose der COPD}

Die Diagnose der COPD wird über die Anamnese, körperliche Untersuchung, Röntgen-Thorax und vor allem durch die Spirometrie und den Bronchospasmolysetest gestellt.

\subsubsection{Chronische Beschwerden - (Atemnot I Husten I Auswurf)}

Häufig führt ein chronischer Husten, der von Patienten häufig verharmlosend als „Raucherhusten“ wahrgenommen wird, zu einem Arztbesuch. Meist ist damit ein chronischer Auswurf verbunden, der aber auch fehlen kann. Die WHO klassifiziert eine Bronchitis als chronisch bei Vorliegen von Husten und Auswurf über mindestens drei Monate in mindestens zwei aufeinanderfolgenden Jahren. Die Erstdiagnose wird nicht selten durch eine akute Exazerbation im Rahmen eines Infektes gestellt.

Oft kommen die Patienten auch erstmalig mit dem Leitsymptom Dyspnoe zum Hausarzt, ohne dass weitere Symptome vorliegen. Die Dyspnoe tritt hierbei anfangs nur unter Belastung auf, erst in späteren Stadien auch in Ruhe.

In einer Studie von Guyatt et al. bewerteten Patienten die ausgeprägte Müdigkeit subjektiv belastender als die Atemnot [43]. Es wird auch eine Ermüdung der Armmuskulatur angegeben. Neben der daraus resultierenden Einschränkung der Mobilität und Leistungsfähigkeit, beklagen die Patienten auch Schlafstörungen und Stimmungsschwankungen.

Angst vor dem tödlichen Ausgang ihrer Erkrankung und Depression finden sich unter COPD-Patienten häufig und tragen zum schlechten Allgemeinbefinden bei.

\subsubsection{Anamnese I Differentialdiagnose I Körperliche Untersuchung}

Die Anamnese sollte auf die typischen Leitsymptome, chronischer Husten mit Auswurf und Belastungsdyspnoe, abzielen, die in ihren jeweiligen Ausprägungen variieren können. Die Exposition gegenüber Tabak, berufsbedingten Stäuben und allgemeiner Luftverschmutzung, Familienanamnese bezüglich Lungenerkrankungen sollten zudem abgefragt werden. Die schwierigste differentialdiagnostische Abgrenzung besteht zum Asthma bronchiale. Hier kann auch eine Mischform auftreten. Dieser Sachverhalt kann eventuell nur durch Bronchoprovokation, ggf. mit Durchführung einer Ganzkörperbodyplethysmographie differenziert werden. Als schwerwiegende, nicht pulmonale Ursache, muss differentialdiagnostisch eine Herzinsuffizienz, unter Umständen mit begleitendem Lungenödem, als 
Ursache der Dyspnoe in Betracht gezogen werden. Auch eine KHK, Übergewicht, Trainingsmangel oder schwere Anämie kommen in Betracht. Eine Untersuchunga auf -Antitrypsin-Mangel sollte nur bei Patienten erwogen werden, die jünger als 45 Jahre sind oder bei denen Hinweise auf eine familiäre Häufung bestehen.

Bei der körperlichen Untersuchung zeigt sich häufig ein Giemen, Pfeifen und Brummen mit verlängertem Exspirium. Als Zeichen der Lungenüberblähung sind ein Fassthorax, assoziiert mit hypersonorem Klopfschall und verringerter Zwerchfellbeweglichkeit, zu werten. Im Anfangsstadium können diese Zeichen jedoch fehlen.

In der Literatur lassen sich die schweren Formen der COPD in zwei Typen einteilen. Beim pink puffer („rosa Schnaufer") handelt es sich um einen Typ des Lungenemphysematikers mit asthenischem Konstitutionstyp (hervorgerufen durch ständig vermehrte Muskelarbeit der Atemhilfsmuskulatur), starker Dyspnoe und trockenem Husten. Beim blue bloater („blauer Huster") handelt es sich um eine schwere Form einer chronischen Bronchitis. Diese Patienten haben oft Übergewicht und leiden unter Husten mit mehr Auswurf.

Der respiratorische Puls (die vermehrte Kontraktion der Atemhilfsmuskulatur, vor allem vom M.Scaleni) ist in der Regel in fortgeschrittenen Stadien und bei Exazerbationen zu tasten.

\subsubsection{Spirometrie}

Charakteristisch für Patienten mit COPD ist, dass nach Gabe eines Beta-2-Sympathomimetikums (z.B. $200 \mu \mathrm{g}$ Salbutamol) beziehungsweise eines Anticholinergikums (z.B. $80 \mu \mathrm{g}$ Ipratropiumbromid), 15 bzw. 30 Minuten nach Inhalation, die FEV1 um weniger als 15\% des Ausgangswertes und um weniger als 200 $\mathrm{ml}$ ansteigt (Reversibilitätstest).

Die COPD ist durch eine meist progressive Limitation der Strömung innerhalb der Atemwege gekennzeichnet. Dieses funktionelle Merkmal wird üblicherweise mit Hilfe der Spirometrie gemessen, die aufgrund der internationalen Übereinkommen nur das exspiratorische Manöver berücksichtigt. Die forciert exspirierte Vitalkapazität - FVC, das forcierte exspirierte Volumen in der ersten Sekunde der Ausatmung $\mathrm{FEV}_{1}$ und deren Verhältnis beschreiben die Atemwegsobstruktion in qualitativer und quantitativer Weise. Die Stadieneinteilung der COPD beruht auf dem Nachweis einer obstruktiven Ventilationsstörung durch eine Erniedrigung von $\mathrm{FEV}_{1} / \mathrm{FVC}<70 \%$ sowie einer definierten Erniedrigung von $\mathrm{FEV}{ }_{1}$ (Tabelle 1) [37].

\subsubsection{Diagnose der abnormen Entzündungsreaktion}

Die bislang geschilderten Befunde beruhen auf Untersuchungen von bioptisch oder chirurgisch entnommenem Lungengewebe. In den vergangenen Jahren sind aber zahlreiche Methoden zur Objektivierung der Atemwegsentzündung mit Hilfe nicht-invasiver Methoden entwickelt worden, die die Untersuchung der Atemwegsentzündung in wesentlich größeren Gruppen, bei gleichzeitig deutlich minimiertem Risiko erlauben. Zur Erfassung entzündlicher Vorgänge in den Atemwegen bei der COPD ist 
im Wesentlichen die Sputuminduktion geeignet. Die Messung von Stickstoffmonoxid in der ausgeatmeten Luft ist bei der COPD bislang nur begrenzt sinnvoll, insbesondere solange die Patienten noch rauchen.

\subsubsection{Induziertes Sputum}

Die Methodik der Sputuminduktion bei COPD ist etabliert. Es sollte jedoch berücksichtigt werden, dass die Sputuminduktion mit hypertoner Kochsalzlösung bei der Mehrzahl der Patienten mit COPD eine klinisch bedeutsame obstruktive Ventilationsstörung hervorruft, die auch durch eine vorherige Inhalation eines $\beta_{2}$-Agonisten nicht verhindert werden kann. Da Patienten mit COPD in der Regel Sputum auch spontan produzieren können, reicht meist die Induktion mit isotoner Kochsalzlösung aus, um Sputum in ausreichender Menge zu erhalten. Dennoch ist im klinischen Alltag die Sputuminduktion nur unter geeigneten Vorsichtsmaßnahmen zu empfehlen. Dieser Umstand, sowie die relativ zeitaufwändige Aufbereitung und Analyse des induzierten Sputums stehen einer größeren Verbreitung dieser Technik im klinischen Alltag entgegen [103]. Die zelluläre Zusammensetzung des induzierten Sputums zeigt Unterschiede zwischen Asthma und COPD. Im stabilen Krankheitszustand überwiegen bei der COPD die neutrophilen Granulozyten. Da der Anteil dieser Zelltypen im Sputum aber sehr variabel ist, lassen sich selten diagnostische Rückschlüsse ziehen. Eine gleichzeitig deutlich erhöhte Gesamtzellzahl/mL Sputum deutet auf eine infektive Bronchitis hin. Eine Subpopulation von Patienten mit COPD kann jedoch auch vermehrt eosinophile Granulozyten im Sputum aufweisen. Dieser Befund ist möglicherweise von Bedeutung, da er die therapeutische Effektivität von inhalativen Kortikosteroiden bei der COPD vorhersagen lässt. Eosinophile Granulozyten im Sputum nehmen auch während einer Exazerbation der COPD zu [44]. Im Sputumüberstand können auch Entzündungsmediatoren bestimmt werden, die Rückschlüsse auf die Aktivierung der Zellen zulassen. So gehen beispielsweise erhöhte Konzentrationen von IL-8 und MPO mit erhöhten Anteilen von neutrophilen Granulozyten einher. Die Messung von Mediatoren im Sputumüberstand erfordert aber in der Regel eine aufwändige Aufarbeitung und viele Mediatoren werden durch die Homogenisation des Sputums beeinflusst [60].

\subsubsection{Stickstoffmonoxid in der Ausatemluft}

Stickstoffmonoxid, NO, ist ein Gas, welches leicht in der Ausatemluft gemessen werden kann. Die Messung von NO in der Ausatemluft ist nicht-invasiv durchführbar, so dass diese Methode auch eine hohe Attraktivität für die pädiatrische Pneumologie besitzt. Es besteht eine relativ enge Korrelation zwischen der ausgeatmeten NO-Konzentration und dem Anteil der eosinophilen Granulozyten des Atemtraktes. Daher könnte die Methode bei der COPD evtl. auch zur Identifikation von Patienten dienen, die auf eine Steroidtherapie ansprechen. Bei Patienten mit COPD, die weiterhin rauchen, muss berücksichtigt werden, dass Zigarettenrauch durch seine hohe NO-Konzentration zur Abregulation der NO-Produktion in den Atemwegen führt [52]. 


\subsubsection{Atemkondensat}

Die Sammlung von Atemkondensat ist einfach und mit kostengünstigen Apparaturen durchführbar. Kommerzielle Geräte stehen für eine standardisierte Gewinnung zur Verfügung. Die Methode ist für den Patienten leicht erlernbar, da keine bestimmten Atemmanöver erforderlich sind. Die Lagerung und Analyse des gewonnenen Materials sind wesentlich komplizierter und abhängig vom Parameter, der gemessen werden soll. Der Aufwand und die Kosten sind denen der Messung eines Sputumüberstandes vergleichbar. Bei der COPD wurden bereits zahlreiche Parameter im Atemkondensat erhöht gefunden. Dies gilt insbesondere für die Exazerbation der Erkrankung. $\mathrm{H}_{2} \mathrm{O}_{2}$ wird z. B. als ein Marker des oxidativen Stresses angesehen und könnte bei der Pathogenese der COPD einen wesentlichen Faktor darstellen. $\mathrm{H}_{2} \mathrm{O}_{2}$, Isoprostane und andere Parameter der Entzündung im Atemkondensat sind allerdings auch beim Asthma oder der zystischen Fibrose erhöht gefunden worden, und somit ist eine solche Messung für die Diagnostik wenig geeignet.

Zusammenfassend kann man mit Hilfe unterschiedlicher Methoden eine abnorme Entzündungsreaktion bei der COPD nachweisen. Im Gegensatz zum Asthma bronchiale ist jedoch die Entzündungsreaktion weniger spezifisch und kann nur unvollkommen durch semi-invasive (induziertes Sputum) und nicht-invasive (Ausatemluft) Verfahren abgebildet werden [77].

\subsection{Therapie der COPD}

Die Therapie der COPD richtet sich nach dem Schweregrad der Erkrankung. Als Therapieoptionen stehen Pharmakotherapie, eine nicht-medikamenöse Behandlung und operative Verfahren zur Verfügung. Die Langzeitbehandlung der stabilen COPD ist durch eine schrittweise Erweiterung der Therapieoptionen in Abhängigkeit vom Schweregrad der Erkrankung gekennzeichnet.

Treten Exazerbationen auf, muss die Behandlung verändert werden. Etwa die Hälfte der meist leichten Exazerbationen kann ohne ärztlichen Kontakt von den betroffenen Patienten selbst bewältigt werden. Falls im Rahmen der ambulanten Therapie eine Wiederherstellung des Ausgangszustandes vor der Exazerbation nicht gelingt, ist eine stationäre Einweisung notwendig.

Der Verzicht auf Tabakrauchen ist die effektivste Einzelmaßnahme zur Reduktion des COPD-Risikos und der Progression der Erkrankung. Das Fortschreiten der Atemwegsobstruktion korreliert mit der täglich konsumierten Zigarettenzahl.

\section{Influenzaschutzimpfung:}

Die Influenzaschutzimpfung sollte jährlich bei allen Patienten mit chronischer Bronchitis beziehungsweise COPD im Herbst mit der jeweils aktuellen Vakzine durchgeführt werden. Die 
Influenzaschutzimpfung führt zu einer erheblichen Reduktion der Morbidität und ferner zu einer Abnahme von sekundär auftretenden Pneumonien [24].

\section{Pneumokokkenschutzimpfung:}

Bisher fehlt eine eindeutige Evidenz für den positiven Effekt der Pneumokokkenschutzimpfung bei COPD-Patienten im Hinblick auf die Reduktion von Exazerbationen. Wirksam ist die Impfung gegen die bakteriämische Form der Pneumokokkenpneumonie mit höherer Mortalität. Bei älteren, chronisch kranken Patienten mit und ohne COPD überwiegen jedoch die potenziellen Vorteile gegenüber den Risiken der Pneumokokkenschutzimpfung. Deshalb kann die Pneumokokkenschutzimpfung für alle COPD-Patienten empfohlen werden (Evidenzgrad D). Eine Wiederholungsimpfung sollte im Abstand von 6 Jahren nach der Erstimpfung durchgeführt werden [85].

\subsubsection{Medikamentöse Therapie}

Die Pharmakotherapie ermöglicht eine Linderung der Beschwerden, eine Besserung der körperlichen Leistungsfähigkeit, der Lebensqualität und eine Reduktion von Exazerbationen; sie kann jedoch nicht die krankheitstypische Verschlechterung der Lungenfunktion verhindern.

Bei akuter Atemnot ist die Inhalation kurz wirksamer Beta-2-Sympathomimetika mittels Dosieraerosol oder Pulver und/oder die Inhalation von kurz-wirksamen Anticholinergika zu empfehlen. Für die Dauertherapie ab dem Schweregrad II ist der regelmäßige Einsatz lang-wirksamer Beta-2Sympathomimetika (Salmeterol, Formoterol) und/oder lang wirksame Anticholinergika (Tiotropriumbromid) wegen der besseren Handhabung und besserer Effektivität zu empfehlen (Tabelle 7).

\subsubsection{Bronchodilatatoren}

Die Bronchodilatation ist der wichtigste symptomatische Ansatz in der pharmakologischen Therapie der COPD. Kurz- und langwirksame $\beta_{2}$-Agonisten und Anticholinergika ergänzen sich in ihren Wirkungen. Internationale und nationale Richtlinien empfehlen daher ihren additiven Einsatz, sofern der Patient nicht ausreichend von einer Substanzklasse allein profitiert. Für das langwirksame Anticholinergikum Tiotropium und den langwirksamen $\beta_{2}$-Agonisten Formoterol konnte gezeigt werden, dass Atemwegsobstruktion und statische Überblähung durch den additiven Einsatz eine größere Verbesserung erfahren als durch die jeweilige Einzelsubstanz [72].

Der symptomatische Therapieeffekt der Bronchodilatatoren ist unzweifelhaft. Die dauerhafte Inhalation von Bronchodilatatoren hat nach bisherigen Untersuchungen jedoch keinen wesentlichen Effekt auf den jährlichen Abfall von $\mathrm{FEV}_{1}[102]$. 


\subsubsection{Anticholinergika}

Anticholinergika sind Mittel der ersten Wahl zur Therapie der COPD [10]. Tiotropium ist ein langwirksames inhalatives Anticholinergikum für die einmal tägliche bronchodilatative Behandlung der COPD. Tiotropium ist ein langwirksamer Antagonist pulmonaler M1- und M3-Muskarinrezeptoren, der nach einmaliger Inhalation eine dosisabhängige Bronchodilatation und Bronchoprotektion gegenüber konstriktorischen Stimuli wie Methacholin über mehr als 24 Stunden bewirkt. Dabei wurde der maximale bronchodilatatorische Effekt von Tiotropiumbromid innerhalb der ersten drei Stunden nach Inhalation erreicht. Die durch Tiotropium bewirkte Bronchodilatation sinkt im Verlauf bis zur nächsten morgendlichen Inhalation nach 24 Stunden allmählich ab. Vergleicht man jedoch die maximale (peak) Bronchodilatation mit der Wirkung nach 24 Stunden (trough), so wird deutlich, dass Tiotropium in der Dauertherapie der COPD ein ausgezeichnetes „peak-to-trough”-Verhältnis besitzt, d. h. die Lungenfunktion wird langanhaltend auf einem höheren Niveau gehalten. Klinische Studien mit Tiotropium bei Patienten mit COPD über Behandlungszeiträume von bis zu einem Jahr dokumentieren eine anhaltende Bronchodilatation sowie eine verbesserung von statischen und dynamischen Lungenfunktionsparametern, Symptomen körperlicher Leistungsfähigkeit und Lebensqualität gegenüber Plazebo und Ipratropium. Darüber hinaus weisen einzelne Untersuchungen darauf hin, dass die Behandlung mit Tiotropium zu einer Reduktion der Exazerbationshäufigkeit und Hospitalisierungen bei COPD-Patienten führt [10].

\subsubsection{Beta-2-Sympathomimetika}

Die Inhalation kurzwirksamer Beta-2-Sympathomimetika mittels Dosier-Aerosol oder Pulver ist die Basistherapie bei akuter Atemnot. Trotz gewisser Bedenken bezüglich der Effekte einer Dauermedikation mit kurzwirksamen Beta-2-Sympathomimetika spricht die gegenwärtig vorliegende Studienlage nicht gegen einen derartigen Einsatz bei COPD, da bisher kaum Hinweise auf das Auftreten einer klinisch relevanten Tachyphylaxie dokumentiert sind [71]. Lang-wirksame Beta-2-Sympathomimetika (Salmeterol, Formoterol) mit einer Wirkdauer von mindestens 12 Stunden führen zu einer Reduktion der Atemnot am Tage und in der Nacht zu einer Besserung der Lungenfunktion, zu einer Steigerung der Lebensqualität und einer Reduktion von Exazerbationen [13]. Als unerwünschte Wirkungen von Beta-2Sympathomimetika sind vor allem Herzrhythmusstörungen (Vorhofflattern, ventrikuläre Extrasystolie, supraventrikuläre Tachykardien), in seltenen Fällen Angina pectoris sowie Palpitationen zu nennen, insbesondere bei Vorliegen einer chronischen Hypoxämie. Eine meist leicht beherrschbare Hypokaliämie kann auftreten. Insbesondere bei Patienten mit Herzinsuffizienz und koronarer Herzkrankheit und Neigung zu Herzrhythmusstörungen sollte der Einsatz von Beta-2-Sympathomimetika unter sorgfältiger Kontrolle von Arrhythmien und koronaren Ischämiezeichen erfolgen [19]. 


\subsubsection{Inhalative Kortikosteroide}

Inhalative Kortikosteroide (engl. inhaled corticosteroids; ICS) zusätzlich zu langwirksamen Bronchodilatatoren werden ab dem GOLD-Stadium III (FEV $1<50 \%$ ) empfohlen. Diese Empfehlung ist das Ergebnis klinischer Studien, die zeigten, dass eine ICS-Behandlung - in Kombination mit einem langwirksamen $\beta_{2}$-Agonisten - zu einer verminderten Exazerbationsrate führt. In mehreren großen Studien konnte allerdings nicht gezeigt werden, dass der beschleunigte jährliche Verlust der Lungenfunktion mit ICS beeinflusst werden kann [93]. Zwei retrospektive Auswertungen deuten zumindest an, dass ICS die Mortalität von Patienten mit COPD senken können. So war die Mortalität von ICS-behandelten COPDPatienten in der Auswertung einer großen amerikanischen Datenbank gegenüber den nicht ICSbehandelten Patienten um 29 \% geringer [93]. Klinisch-experimentell und zellbiologisch konnte bisher keine überzeugende Wirkung von inhalativen und oralen Kortikosteroiden auf die lokale Inflammation nachgewiesen werden. So blieben die Surrogatmarker der Atemwegsinflammation bei COPD nach 4wöchigen Behandlungsphasen unbeeinflusst. Während die lokale Inflammation bei der COPD als „steroid resistent" bezeichnet wird, erniedrigen systemische und inhalative Steroide das CRP (Capsel-reaktive Protein ) einen Marker der systemischen Inflammation [93].

Die TORCH-(TOwards a Revolution in COPD Health) Studie stellt die größte bisher durchgeführte COPD-Studie dar. Über einen Zeitraum von 3 Jahren wird bei Patienten mit mittel- bis schwergradiger COPD der Einfluss von inhalativem Glukokortikoid (Fluticason) und langwirksamen $\beta_{2}$-Agonist (Salmeterol), allein und in Kombination, auf die Mortalität und den Krankheitsverlauf untersucht. Weitere Endpunkte sind die Anzahl von Exazerbationen und die Lebensqualität. TORCH wurde als multizentrische, randomisierte, placebo-kontrollierte, doppelblinde Parallelgruppenstudie angelegt, wobei etwa 6200 Patienten in weltweit über 450 Zentren eingeschlossen wurden. Das Ergebniss zum primären Zielparameter (Gasamtmortalität) ergab für die Patienten unter Therapie mit Fluticason/Salmeterol eine Reduktion des Risikos zu versterben um 17,5\%, im Vergleich zu den Patienten der Kontrollgruppe. Das im Vorfeld definierte Signifikanzniveau wurde nicht erreicht $(p=0,052)$. Die Ergebnisse zu den sekundären Endpunkten zeigten unter der Kombination Fluticason/Salmeterol eine signifikante Reduktion der Anzahl von COPD-Exazerbationen um $25 \%(p<0,001)$ sowie eine signifikante Verbesserung der Lebensqualität (gemessen anhand des St. George Resiratory Questionnaire). Bei den Patienten, deren Therapie-Regime alleine inhalative Kortikoide enthielt, war ein erhöhtes Risiko für Pneumonien feststellbar [105]. 


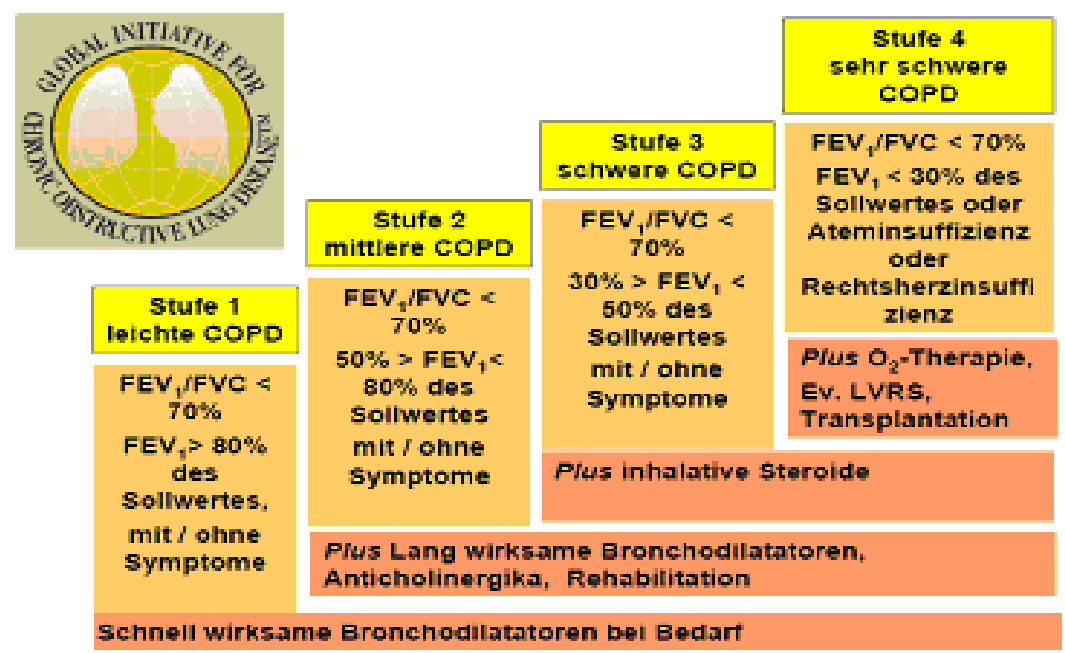

Tabelle 7: Stufentherapie der COPD nach GOLD - 2008

\subsubsection{Neue pharmakologische Ansätze - neue Ansätze mit alten Medikamenten}

\section{Theophyllin}

Theophyllin hat im Vergleich zu den $\beta_{2}$-Agonisten und Anticholinergika eine schwache bronchodilatatorische Wirkung und kann teilweise bedrohliche Nebenwirkungen aufweisen. Dennoch profitieren einzelne Patienten, wie entsprechende Auslassversuche zeigen konnten. Theophyllin kann trotz Vorbehandlung mit langwirksamen Bronchodilatatoren noch einen zusätzlichen Effekt aufweisen. In jüngster Zeit wird ein antiinflammatorischer Effekt von Theophyllin diskutiert. Im induzierten Sputum von Patienten mit COPD konnten bereits in subtherapeutischen Dosen (Plasmaspiegel $<10 \mathrm{mg} / \mathrm{l}$ ) die Anzahl der neutrophilen Granulozyten sowie die Konzentration von II-8, der Myeloperoxidase und der neutrophilen Elastase (NE) durch Theophyllin gesenkt werden. Zudem aktiviert Theophyllin die Histondeacetylase (HDAC), ein Zellkernenzym, welches in den Alveolarmakrophagen bei COPD inaktiviert ist. Die Inaktivierung der HDAC verhindert die antiinflammatorische Wirkung von Kortikosteroiden. Derzeit wird in einer Placebo-kontrollierten Studie der Effekt von Theophyllin in subtherapeutischer Dosierung $(5 \mathrm{mg} / \mathrm{l})$ in Kombination mit Kortikosteroiden auf die inflammatorischen Surrogatmarker im Sputum geprüft [9].

\section{Tetrazykline und Makrolidantibiotika}

Tetrazykline und Makrolidantibiotika haben antiinflammatorische und immunmodulatorische Effekte, die nicht auf ihre antibiotische Wirkung zurückzuführen sind. Doxycyclin ist ein unspezifischer 
Matrixmetalloproteinasen-Inhibitor (MMP-Inhibitor), und dies bereits in Dosen, die noch keine antibiotische Wirkung aufweisen. Bei Erkrankungen, die mit chronisch destruierenden Prozessen einhergehen, könnte diese Therapie von Bedeutung sein. In einer Pilotstudie an 15 Patienten mit COPD konnte nachgewiesen werden, dass der Gehalt an MMP-9 im induzierten Sputum durch Doxycyclin gesenkt werden kann [57]. Eine frühere nicht verblindete Studie hatte bereits gezeigt, dass die niedrigdosierte Gabe von Erythromycin sowohl die Anzahl der „gewöhnlichen Erkältungen” als auch Exazerbationen bei Patienten mit COPD senken kann [98].

\section{N-Acetylcystein}

N-Acetylcystein (NAC) liefert die Aminosäure Zystein als Baustein für das körpereigene Antioxidans Glutathion und wirkt so dem oxidativen Stress bei COPD entgegen. Eine plazebokontrollierte, multizentrische Studie mit $600 \mathrm{mg} / \mathrm{d}$ NAC zeigte keine Verminderung der Exazerbationen oder Beeinflussung der Lungenfunktionsverschlechterung bei Patienten mit COPD. Hingegen konnte mit 1800 mg/d NAC für die idiopathische Lungenfibrose, einem Krankheitsbild, das ebenfalls mit oxidativem Stress einhergeht, eine günstige Beeinflussung der Lungenfunktion aufgezeigt werden. Dies ist möglicherweise damit zu erklären, dass erst mit dieser Dosierung einen normalen Glutathionspiegel erreicht wurde. Es ist jedoch fraglich, ob die Dosierung mit 1800 mg/d NAC bei Patienten mit COPD in einer prospektiven Studie geprüft wird [29].

\section{Statine}

Neben der lipidsenkenden Eigenschaft weisen Statine auch eine antioxidative und antiinflammatorische Wirkung auf, die im Rahmen der vaskuloprotektiven Therapie bei kardiovaskulären Erkrankungen bereits genutzt wird. Simvastatin senkt die systemischen Inflammationsmarker hs-CRP (hochsensitives CRP), IL-6 und TNF- $\alpha$. In einer Meta-Analyse von 90056 Patienten aus 14 kontrollierten Statin-Studien konnte gezeigt werden, dass die kardiovaskuläre Mortalität um $19 \%$ und die respiratorische Mortalität um 18 \% sank [30]. Zwei retrospektive Auswertungen von Patienten mit COPD zeigten ebenfalls, dass die Mortalität dieser Patientengruppe durch Statine günstig beeinflusst wird. Diese klinischen Daten werden durch experimentelle Daten am Tiermodell der COPD gestützt. So verhindert Simvastatin in diesem Modell die Entwicklung eines Lungenemphysems und des pulmonalarteriellen Hypertonus [62]. 


\subsubsection{Nichtmedikamentöse Therapie}

\subsubsection{Ernährung}

Der Verlust von Körperzellmasse, d. h. Verlust von metabolisierendem und kontraktilem Gewebe, gilt als wichtige Systemmanifestation der COPD und ist bei ca. $50 \%$ der Patienten mit schwerer und ca. 10 $15 \%$ der Patienten mit leicht-/mittelgradiger COPD zu beobachten [88]. Der Gewichtsverlust bei COPD führt zu pulmonaler Kachexie mit zunehmender Limitierung der bereits eingeschränkten pulmonalen Leistungsfähigkeit. Gewichtsverlust wird als Abnahme der Körpermasse um $10 \%$ oder > $5 \%$ in den letzten 6 Monaten definiert. Als Grenzwert für die Kachexie wird im ATS/ERS-Positionspapier ein Body Mass-Index (BMI) von $<21 \mathrm{~kg} / \mathrm{m}^{2}$ angesehen. Ein niedriger Body Mass-Index (BMI) stellt einen Prädiktor für eine erhöhte Mortalität bei COPD-Patienten dar [66].

Augenmerk sollte aber nicht nur auf das Unter- sondern auch auf das Übergewicht $(B M I>30)$ gelegt werden, denn Letzteres führt zu einer gesteigerten Atemarbeit und hat somit ebenfalls einen negativen Einfluss auf die Belastbarkeit der Patienten [99].

Für die Ernährungstherapie ergibt sich daraus, dass Patienten mit Untergewicht geschult werden, durch Auswahl geeigneter Lebensmittel ihr Gewicht zu steigern; für Patienten mit Übergewicht müssen Lösungswege für eine Gewichtsreduktion gefunden werden. An erster Stelle der ernährungstherapeutischen Intervention stehen immer eine detaillierte Ernährungsanamnese sowie die Anamnese der Ernährungsgewohnheiten (z.B. Anzahl der Mahlzeiten). Basis der Ernährungsempfehlungen ist eine ausgewogene Mischkost, d.h. reichlich Vollkornprodukte, Obst und Gemüse. Anhand der erhobenen Daten müssen dann zusammen mit dem Patienten, eventuell auch mit den Angehörigen, Lösungswege gefunden werden, in Abhängigkeit von möglichen Begleitsymptomen Mahlzeiten energetisch aufzuwerten oder zu reduzieren bzw. die Mahlzeiten günstiger zu verteilen.

Eine Zusatznahrung sollte immer dann eingesetzt werden, wenn Patienten trotz intensiver Ernährungsberatung ihr Gewicht nicht halten können [87]. Zusatznahrung sollte jedoch immer eine zusätzliche Energiequelle darstellen und ist kein Ersatz für eine Mahlzeit.

Die Frage, welche Zusatznahrung (fett- oder kohlenhydratreich) sich für COPD-Patienten besser eignet, wird derzeit noch kontrovers diskutiert. Zusatznahrung bietet die Möglichkeit, untergewichtigen inappetenten Patienten über Getränke zusätzliche Kalorien mit hoher Energie- und Nährstoffdichte anzubieten (1,0-1,7 kcal/ml). Während Cai et al.[17] in einer randomisierten Studie an 60 COPDPatienten eine signifikant bessere Lungenfunktion unter einer fettreichen Zusatznahrung im Vergleich zu einem kohlenhydratreichen Supplement zeigten, wiesen Studien von Vermeeren et al. sowie Steiner et al. Vorteile einer kohlenhydratreichen Zusatznahrung nach [106].

In der von Vermeeren et al. durchgeführten randomisierten Studie wiesen Patienten unter einer fettreichen Zusatznahrung eine vermehrte Dyspnoe sowie eine länger andauernde Magenpassage auf. Eine eingeschränkte Zwerchfellmotorik wurde ebenfalls beobachtet [106].

Steiner et al. führten eine Doppelblindstudie durch und untersuchten den Einfluss von körperlichem Training und Ernährung auf die Belastbarkeit von COPD-Patienten [97]. 85 Patienten erhielten über einen 
Zeitraum von 7 Wochen entweder eine kohlenhydratreiche Zusatznahrung oder ein Plazebo. Es zeigte sich, dass Normalgewichtige unter Zusatznahrung im Vergleich zur Plazebogruppe eine signifikante Verbesserung der Belastbarkeit aufwiesen. Diese korrelierte mit der Kohlenhydratzufuhr. Die Autoren folgerten daraus, dass Patienten unter körperlichem Training, ebenso wie Sportler, primär auf Kohlenhydrate als Brennstoff für die Muskelkontraktion angewiesen sind.

Creutzberg et al. untersuchten im Rahmen einer Rehabilitationsmaßnahme den Einfluss von Zusatznahrung und Sport bei COPD-Patienten mit verminderter Muskelmasse. Unter täglicher Gabe von Zusatznahrung (ca. 400-600 kcal/d) sowie Sporttherapie kam es zu einem signifikanten Anstieg von Körpergewicht und Muskelmasse. Eine signifikante Verbesserung der Belastbarkeit, gemessen an der Griffstärke sowie an der 6-Minuten-Gehstrecke, konnte ebenfalls nachgewiesen werden. Diese positiven Effekte waren jedoch bei Patienten unter Glukokortikoidtherapie weniger deutlich nachweisbar [23]. Im Zusammenhang mit Zusatznahrung muss insgesamt darauf hingewiesen werden, dass untergewichtige Patienten mit Infektexazerbation einen höheren Energiebedarf bei gleichzeitig vermindertem Appetit aufweisen. Sie sprechen insgesamt schlechter auf die Gabe von Zusatznahrung an [23].

Zusammenfassend lässt sich sagen dass die Ernährungstherapie in Kombination mit körperlichem Training einen günstigen Einfluss auf Belastbarkeit, Körpergewicht, fettfreie Körpermasse sowie auf die Lungenfunktion hat. Zu Beginn einer jeden ernährungstherapeutischen Intervention gehört daher die Bestimmung des Ernährungszustands (Ermittlung des BMI und Messung der Körperzusammensetzung) [23].

\section{Ursachen einer reduzierten Nahrungsaufnahme bei COPD}

In einer von Tang et al. durchgeführten Studie zeigten 70\% der COPD-Patienten eine verminderte Energieaufnahme und damit eine negative Energiebilanz.

Die verminderte Nahrungsaufnahme bei Patienten mit fortgeschrittener Lungenerkrankung hat selten nur einen einzigen Grund. Meist tragen mehrere Faktoren dazu bei:

- zunehmende Inappetenz (infektbedingt, durch chronische Mundatmung, vermindertem Geschmacksempfinden)

- frühzeitige Sättigung

- Müdigkeit

- Dyspnoe, die oft bereits in Ruhe vorhanden ist und sich bei Belastung verstärkt, so auch durch Nahrungsaufnahme

- Medikamente, die nicht selten zu gastrointestinalen Beschwerden führen, welche mangelnden Appetit bedingen

- zunehmende Immobilität

- Depressionen (Patienten leiden unter der Behinderung durch ihre Erkrankung)

- $\quad$ schlechter Zahnstatus bzw. schlechtsitzende Zahnprothese [101]. 


\subsubsection{Rehabilitation}

Im Zentrum des Behandlungskonzeptes bei COPD steht der typische Patient, der im Verlauf seiner Krankheit vereinsamt, wegen seiner Dyspnoe immer mehr an Autonomie verliert, wegen seines schlechten Allgemeinzustandes nicht mehr außer Haus kommt und oft auch eine depressive Entwicklung durchmacht. Bei diesen COPD-Patienten sollte die pulmonale Rehabilitation zu einer besseren Lebensqualität verhelfen.

Die pulmonale Rehabilitation ist eine multidisziplinäre Behandlung von Patienten mit chronischen Lungenkrankheiten, die durch angepasstes Aufbautraining sowie umfassende Instruktion und Schulung bewirkt, dass die betroffenen Patienten ihr Leben wieder selbst gestalten und die ihrem Alter entsprechenden Tätigkeiten, trotz ihrer Behinderung, weiterhin ausführen können.

Die Rehabilitation setzt auf mehreren Ebenen an und zielt darauf, den Circulus vitiosus, der von der Dyspnoe über die Muskelatrophie zur Dekonditionierung und Isolation führt, soweit wie möglich rückgängig zu machen [79].

Da die meisten Rehabilitationsprogramme gruppenweise durchgeführt werden, haben sie auch positive psychologische und gruppendynamische Effekte. Die Patienten kommen nicht nur aus ihrer Vereinsamung heraus, sie erfahren auch, dass sie mit ihren Problemen des täglichen Lebens nicht alleine dastehen. Für die meisten Patienten ist das Rehabilitationsprogramm daher auch eine Gelegenheit, um sich mit der eventuell notwendigen Langzeitsauerstofftherapie auseinanderzusetzen und sich mit anderen Atemhilfen vertraut zu machen.

In allen nationalen und internationalen Leitlinien wird die pneumologische Rehabilitation, aufgrund der eindeutigen Evidenzlage, als essenzieller Teil des Langzeitmanagements beschrieben und gefordert [79].

Rehabilitation bei einem 45-jährigen Raucher mit beginnender COPD hat das Ziel der Verhinderung des Krankheitsprogresses, Erhalt der Erwerbsfähigkeit und Verringerung möglicherweise enormer Folgekosten. Sie wird von den Sozialsystemen als "Reha vor Rente” vergütet, während bei einem berenteten COPD-Patienten mit Schweregrad IV, Heimbeatmung, Sauerstofftherapie und schwerer sekundärer Depression die Vergütung von der gesetzlichen Krankenkasse und unter dem Begriff „Reha vor Pflege" übernommen wird. Beide Spielarten der Rehabilitation sind jedoch gleich sinnvoll und notwendig und keineswegs auf das stationäre Setting beschränkt [79].

Die pulmonale Rehabilitation ist hierbei bedeutsam und gilt als multidisziplinäres Betreuungsprogramm für chronisch lungenkranke Patienten mit dem Ziel, die physische Belastbarkeit und die Lebensqualität zu verbessern. Die positiven Effekte von Rehabilitationsmaßnahmen sind hinreichend belegt und zielen vor allem auf behandelbare Systemmanifestationen der COPD, wie muskuläre Dysfunktion und Kachexie, die einen wesentlichen Einfluss auf die Lebensqualität haben. Rehabilitationsprogramme sollten individuell dem Patienten angepasst werden und neben körperlichem Training und Ernährungstherapie auch psychosoziale Interventionsmaßnahmen enthalten [56]. 


\section{Was darf man von der COPD-Rehabilitation erwarten?}

Bisher konnte in vielen randomisierten kontrollierten Studien die Wirksamkeit der Rehabilitation bei COPD-Patienten bezüglich verschiedener objektiv messbarer Kriterien nachgewiesen werden. Die positiven Wirkungen sind, dem physiologischen Mechanismus des Trainings entsprechend, die Verbesserung der körperlichen Leistungsfähigkeit, die Verminderung der Atemnot bei täglichen Anstrengungen, eine Erleichterung bei der Ausführung der täglichen Aktivitäten und - allgemeiner - eine Steigerung der Lebensqualität [56].

In einigen kleineren Studien wurde es gezeigt, dass die Rehabilitation unmittelbar nach einer Exazerbation das Risiko einer weiteren Exazerbation, die zu einer Hospitalisation führt, vermindert und auch die Mortalität reduziert. Diese Studien legen nahe, dass mit der Rehabilitation eine Reihe von Risikofaktoren für Exazerbationen und eine hohe Mortalität günstig beeinflusst werden können [75].

\subsubsection{Langzeit-Sauerstofftherapie}

Die Langzeit-Sauerstofftherapie (LTOT) ist bei chronischer Hypoxämie (arterieller Sauerstoffpartialdruck $\leq 55 \mathrm{mmHg}$ ) indiziert; bei Cor pulmonale bereits bei einem pO2< $60 \mathrm{mmHg}$. Die Anwendungsdauer sollte mindestens 16 Stunden pro Tag betragen.

Die etablierte medikamentöse Therapie mit Bronchodilatatoren (Anticholinßrgika, 2-Agonisten, Theophyllin) hat nur symptomlindernden Charakter, ohne dass die Langzeitprognose der COPD wesentlich beeinflusst wird. Auch der Versuch, die durch Granulozyten und aktivierte Alveolarmakrophagen getragene Entzündung durch Kortikosteroide zu günstig zu beeinflussen, muss als gescheitert angesehen werden [39]. Somit ist die Langzeitsauerstofftherapie bislang die einzige Maßnahme, die einen Überlebensvorteil für COPD-Patienten belegen konnte. Dies gilt allerdings nur dann, wenn sie mindestens 15, besser mehr als 18 Stunden pro Tag angewendet wird [81].

\subsubsection{Heimbeatmung}

Patienten mit schwerer COPD entwickeln langsam, aber progredient eine respiratorische Insuffizienz mit einer zunehmenden Erschöpfung der Atemmuskulatur. Insbesondere bei akuter Exazerbation dekompensieren die Patienten und zeigen eine respiratorische Insuffizienz bis hin zum respiratorischen Versagen. In diesem Fall ist die akute nichtinvasive Beatmung mittels Nasenmaske oder mit Gesichtsmaske Mittel der Wahl. Der Vorteil der nichtinvasiven Beatmung in dieser Situation ist unzweifelhaft nachgewiesen, und sie kann heute als Standard bezeichnet werden. Nichtinvasive Beatmung verhindert nicht nur signifikant die Notwendigkeit einer endotrachealen Intubation, sondern verbessert zudem das Überleben der Patienten im Vergleich zu einer konservativen Therapie [78].

Dagegen ist eine häusliche und intermittierende nichtinvasive Beatmung bei chronischer hyperkapnischer respiratorischer Insuffizienz bisher nicht durch kontrollierte Studien gesichert. 
Die intermittierende nichtinvasive Beatmung über eine Nasenmaske entlastet die Atempumpe und führt zu einer Reduktion der Überblähung. Eine Reihe von prospektiven, allerdings nicht kontrollierten Untersuchungen, hat einen günstigen Effekt auf die Belastungsdyspnoe und Lebensqualität gefunden [18].

Die meisten der bisher publizierten Studien weisen eine Reihe von methodischen Schwächen auf, so dass eine abschließende Beurteilung der Effizienz dieser Therapieform nicht möglich ist. Insbesondere sind die in den meisten Studien verwendeten Beatmungseinstellungen nicht geeignet, eine effektive Beatmung durchzuführen. Eine effektive Beatmung zeigt sich an einer Reduktion der CO2-Werte um mindestens 10\%. Die Patienten mit schwerer hyperkapnischer Insuffizienz profitieren von dieser Therapie hinsichtlich Belastbarkeit, Lebensqualität und Exazerbationsrate, wenn eine effektive Beatmung durchgeführt wurde. Patienten, bei denen es gelingt, die schwere Hyperkapnie anhaltend zu verbessern, haben zudem nach einer retrospektiven Analyse ein verbessertes Überleben im Vergleich zu den Patienten, bei denen eine effiziente Reduktion der CO2-Werte nicht möglich war. Allerdings fehlen bisher prospektive und gesicherte Daten zur Mortalität [14].

Je ausgeprägter die Hyperkapnie im Verlauf der Erkrankung wird, umso schwieriger wird eine ausreichend dosierte Sauerstofftherapie, da mit dem $\mathrm{PaO}_{2}$ gleichzeitig der $\mathrm{PaCO}_{2}$ ansteigt. Dies hat, neben negativen Effekten auf den Atemantrieb, erhäbliche Konsequenzen auf das kardiovaskuläre System. Kohlendioxid führt über eine Aktivierung von Chemorezeptoren zu einem Anstieg des peripheren und des pulmonalarteriellen Widerstands mit nachfolgender arterieller und pulmonaler Hypertonie, gleichzeitig steigt der Hirndruck an und es kommt zur Verschlechterung der zerebralen Perfusion. Darüber hinaus könnte die Hyperkapnie die Prognose der Patienten negativ beeinflussen [50].

Meecham-Jones untersuchte 18 Patienten mit schwerer COPD und respiratorischer Globalinsuffizienz über drei Monate; zuerst wurde eine Sauerstofftherapie alleine, dann nichtinvasive Beatmung (pressure

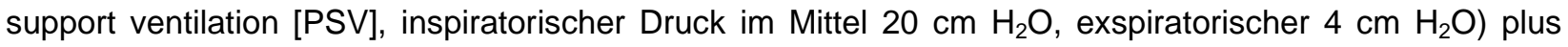
Sauerstofftherapie verabreicht. Er zeigt sowohl deutliche Veränderungen der Blutgase $\left(\mathrm{PaO}_{2}-\mathrm{Anstieg}\right.$, $\mathrm{PaCO}_{2}$-Abfall gegenüber dem Ausgangswert nach zwölf Stunden Beatmungspause), als auch Verbesserungen der Schlaf- und der Lebensqualität [64].

Auch wenn eine allgemeine Empfehlung für die Einleitung einer nichtinvasiven Beatmung nach der aktuellen Datenlage nicht gegeben werden kann, zeigt doch die wachsende und breite klinische Erfahrung, dass diese Therapieform bei schwerer hyperkapnischer und respiratorischer Insuffizienz im individuellen Fall sinnvoll und effizient sein kann. 


\subsubsection{Operative Therapieverfahren}

\subsubsection{Bullektomie}

Bei großen Bullae, die mehr als $1 / 3$ eines Lungenflügels einnehmen und das benachbarte Gewebe komprimieren, kann die Bullektomie zu einer Besserung der Lungenfunktion und Abnahme der Dyspnoe führen (Evidenzgrad B). Gelegentlich kann die Indikation auch bei Hämoptysen oder rezidivierenden Infektionen gestellt werden. Vor der Entscheidung zur Bullektomie sollten eine Bronchoskopie, ein Computertomogramm des Thorax (HR-CT, High Resolution Computertomographie), ein Lungenfunktionstest unter Einschluss der arteriellen Blutgase, die Messung der CO-Diffusionskapazität, und ein Perfusionsszintigramm der Lunge durchgeführt werden. Gute Ergebnisse des chirurgischen Eingriffs sind bei normaler oder nur gering reduzierter Diffusionskapazität und beim Fehlen einer signifikanten Hypoxämie zu erwarten.

Die Bullektomie kann im Rahmen einer videoassistierten Thorakotomie durchgeführt werden. Eine offene Thorakotomie mittels Sternotomie erfolgt in der Regel bei beidseitigen Bullae. Bei schwerem, generalisiertem Lungenemphysem ist dieser Eingriff nicht indiziert [47].

\subsubsection{Lungenvolumenreduktion (LVR)}

Das von Cooper etablierte Konzept der operativen Lungenvolumenreduktion (LVR) beim Lungenemphysem beinhaltet die Resektion von stark emphysematös veränderten Lungenarealen mit dem Ziel, die Lungenüberblähung zu reduzieren, die Dyspnoe zu lindern und die Lungenfunktion zu verbessern [22].

Im „National Emphysema Treatment Trial” (NETT), sind die Ergebnisse der LVR und der bestmöglichen medizinischen Behandlung miteinander verglichen worden. Die Untersuchung hat klare Überlebensvorteile und funktionelle Verbesserungen über mindestens zwei Jahre für die Subgruppe von Patienten mit apikalen Defektzonen und geringer Belastungskapazität $\leq 25 \mathrm{~W}$ für Frauen, $\leq 40$ Watt für Männer) gegenüber dem rein medizinisch behandelten Kontrollkollektiv gezeigt [70].

Für die Gesamtgruppe aller operierten Patienten fand sich kein Überlebensvorteil, obwohl funktionelle Verbesserungen auch zwei Jahre nach der Operation noch nachgewiesen werden konnten. Da sich bei Patienten mit schwerer Obstruktion ( $\mathrm{FEV}_{1}<20 \%$ des Sollwertes), homogenem Emphysem und erniedrigtem Transferfaktor für Kohlenmonoxid (TLCO $<20 \%$ des Sollwertes) eine extrem hohe 90-TageMortalität fand, sind diese Patienten von der LVR definitiv auszuschließen.

Eine LVR ist zu empfehlen wenn keine sonstigen gravierenden Erkrankungen vorliegen und von einer guten Langzeitcompliance in der Zeit nach der Operation auszugehen ist, denn für die langfristige Stabilisierung des Behandlungserfolges nach erfolgter LVR ist eine konsequente Fortsetzung der medikamentösen Behandlung, der Physiotherapie und der Tabakabstinenz von zentraler Bedeutung [70]. 
Als Alternative zur chirurgischen LVR wurde in den letzten Jahren die Möglichkeiten der bronchoskopischen Lungenvolumenreduktion (BLVR) geprüft.

Es gibt zwei Prinzipien: die endobronchiale Okklusion durch Implantation von Ventilsystemen oder die Schaffung eines Bypass zur kollateralen Ventilation (Exhale-Stents). Im ersten Fall bewirkt man eine Lungenvolumenreduktion und einen regionalen Lungenkollaps durch den Verschluss eines Bronchus, welcher einen überblähten, emphysematösen Teil der Lunge versorgt. Im zweiten Fall werden extraanatomische Verbindungen zwischen Segmentbronchien und überblähten Lungengewebe über Stents geschaffen, um eine Abnahme der dynamischen Hyperinflation zu erreichen [104],[107], [113].

Die korrekte Lage der Stents ist wesentlich für eine gute Funktionsfähigkeit. Wilkens zeigte dass sich die Niedrigdosis-Dünnschicht-Multislice-CT als sehr hilfreich zur Verlaufskontrolle der Lokalisation nach bronchoskopischer Platzierung von Exhale-Stents erwiesen hat [113].

\subsubsection{Lungentransplantation}

Für Patienten mit schwerem Lungenemphysem steht als Ultima Ratio die Lungentransplantation (LTx) zur Verfügung. Dabei muss zwischen der einseitigen (SLT = single lung transplantation) und beidseitigen Lungentransplantation (BLT: bilateral lung transplantation) unterschieden werden.

Die einseitige Transplantation kommt nur für Patienten mit COPD infrage, bei denen sich keine Bronchiektasen finden. Bei geeigneter Auswahl der Patienten können primär die Lebensqualität und Belastbarkeit, nicht jedoch die statistische Lebenserwartung der Patienten verbessert werden. Die mittlere 3-Jahres-Überlebensrate liegt bei etwa $60 \%$ [46].

Funktionsanalytische Einschlusskriterien für eine Lungentransplantation sind eine $\mathrm{FEV}_{1}<20-25 \%$ des Sollwertes, ein arterieller Sauerstoffpartialdruck in Ruhe bei Raumluftatmung $<55 \mathrm{~mm} \mathrm{Hg}$, eine persistierende Hyperkapnie mit $\mathrm{PaCO}_{2}$-Werten $>55 \mathrm{~mm} \mathrm{Hg}$, eine rasche Verschlechterung der $\mathrm{FEV}_{1}$ und eine Häufung schwerer Exazerbationen sowie von Hospitalisationen mit rascher Verschlechterung der Lebensqualität. Ausschlusskriterien sind ein biologisches Alter von mehr als 65 Jahren, schwere Funktionsstörungen anderer Organe, eine stark eingeschränkte Kreatinin-Clearance von $<50 \mathrm{mg} / \mathrm{ml} / \mathrm{min}$, HIV-Infektion, maligne Tumoren, der Nachweis von Hbs-Antigen bzw. einer Hepatitis-C mit histologisch nachgewiesener Lebererkrankung.

$\mathrm{Zu}$ den relativen Kontraindikationen gehören ein schlechter Ernährungszustand mit einem BMI < 18 $\mathrm{kg} / \mathrm{m}^{2}$, Systemerkrankungen, Kollagenosen, eine symptomatische Osteoporose, schwere Kyphoskoliosen, Suchterkrankungen, erhebliche psychosoziale Probleme bzw. die Beatmungspflichtigkeit des Patienten [46].

Limitiert wird die Lungentransplantation durch die geringe Zahl der Spender. Eine immunsuppressive Therapie ist während oder direkt nach dem chirurgischen Eingriff einzuleiten und lebenslang fortzusetzen. Die LVR kann bei Patienten mit schwerem Lungenemphysem als lebensrettende therapeutische Intervention während der Wartezeit auf die Lungentransplantation genutzt werden [92]. 


\section{Material und Methodik}

\subsection{Die Bioimpedanzanalyse - BIA}

\subsubsection{Einleitung}

\subsubsection{Die Entwicklung der Bioimpedanzanalyse}

Die Geschichte der Bioimpedanzanalyse begann bereits 1786, als der italienische Physiker Galvani den Einfluss elektrischen Stroms auf Gewebsstrukturen des Frosches beobachtete. Konkrete Formen nahmen die Experimente jedoch erst Jahre später um 1960 an. Der französische Arzt Thomasset war davon überzeugt, dass der elektrische Widerstand den Flüssigkeitsgehalt des menschlichen Körpers widerspiegelt. Er und seine Kollegen entwickelten 1962 einen der ersten Impedanzanalysatoren für Messungen an biologischen Geweben. Den Grundstein für die heute bekannte Form der Impedanzanalyse legte 1970 der amerikanische Forscher Nyboer. Ihm gelang es nachzuweisen, dass Impedanzwerte Rückschlüsse auf unsere Körperzusammensetzung zulassen.

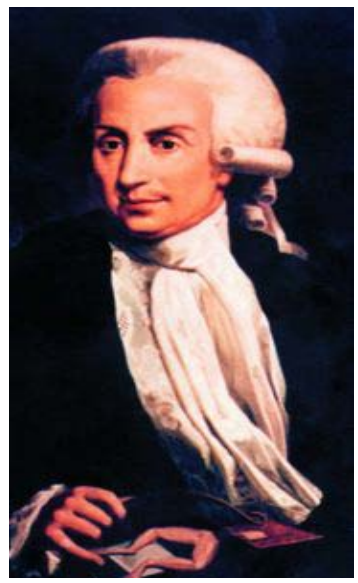

Ihre endgültige Bezeichnung erhielt die Bioimpedanzanalyse in den 80iger Jahren. Im Laufe der Jahre setzte sie sich gegen eine Vielzahl ähnlicher Diagnoseformen durch und gilt heute als international anerkannte Methode für die Messung der Körperzusammensetzung in unterschiedlichsten Bereichen der Ernährungsmedizin oder Anthropologie. Einfach, zuverlässig und kostengünstig ist die Impedanzanalyse eine Methode unserer Zeit. Sie bietet Medizinern die Möglichkeit differenzierter Diagnostik und damit die Grundlage gezielter langfristiger Therapieansätze. Ein immer vielfältigeres Spektrum an Geräten und Software für spezifische Einsatzbereiche gewährleistet Präzision und Sicherheit [66]. 
Die Wertigkeit der Bioimpedanzmesung wurde 1994 in einer Konferenz der National Institutes of Health Technology und 1999 in einer Expertendiskussion in der Evangelischen Akademie Loccum so beurteilt: "die bioelektrische Impedanzanalyse bietet eine reliable Schätzung des Körperwassers. Die Methode ist nützlich zur Analyse der Körperzusammensetzung bei Gesunden und bei einigen chronischen Affektionen wie z.B. der leichten oder mäßigen Adipositas, dem Diabetes mellitus und anderen internistischen Erkrankungen, bei denen es nicht zu extremen Störungen der Flüssigkeitsverteilung im Organismus kommt "[66].

Die BIA ist eine nicht-invasive und preisgünstige Methode zur Messung der Körperzusammensetzung, welche die elektrischen Eigenschaften des Körpers nutzt. Dazu wird ein schwacher Wechselstrom von $50 \mathrm{kHz}$ über 4 Hautelektroden, die an Hand- und Fußgelenk des Probanden befestigt werden, durch den Körper geleitet und der Spannungsabfall gemessen. Der beobachtete frequenzabhängige Widerstand, die Impedanz, besteht aus 2 Komponenten: Resistance und Reactance. Jeder Parameter wird im Einzelnen im nächsen Kapitel definiert. Anders gesagt ist die Impendanz der Gesamtwiderstand eines biologischen Leiters gegen Wechselstrom. Dieser unterteilt sich in den Widerstand des elektrolythaltigen Körperwassers (Resistance) und den Widerstand der Körperzelle (Reactance).

Zur Berechnung der Körperzusammensetzung mit der BIA ist es notwendig, das TBW (total body water) möglichst genau zu bestimmen, da dieses für die Berechnung aller weiteren Messwerte benötigt wird. Das TBW wird mittels validierter gerätespezifischer Formeln aus den Messwerten Resistence und Reaktanz berechnet. Durch die Bestimmung des PA (Phasenwinkel) ist es möglich, die LTM (Lean Tissue Mass) in die Bestandteile ECM (extracellular mass) und Körperzellmasse - so genannte BCM (body cell mass) - zu unterteilen [38].

\subsubsection{Durchführung der Messung}

Um möglichst genaue Ergebnisse zu erhalten, sollten folgende Regeln beachtet werden:

1. Allgemeine Regeln vor der Messung:

- keine schweren Mahlzeiten vor der Messung

- die letzte sportliche Betätigung sollte 12 Stunden zurückliegen

- der letzte Alkoholkonsum sollte 24 Stunden zurückliegen

2. Während der Messung im Liegen:

- die Elektroden an der dominanten Seite anbringen

- die Arme sollten neben dem Körper liegen, ohne diesen zu berühren

- Ohrringe, Uhren etc. dürfen anbehalten werden 
Rote Electrode (signal electrode) distal

Schwarze Electrode (measuring electrode) - proximal

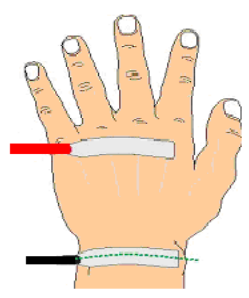

Rote Electrode (signal electrode) distal

Schwarze Electrode (measuring electrode) - proximal

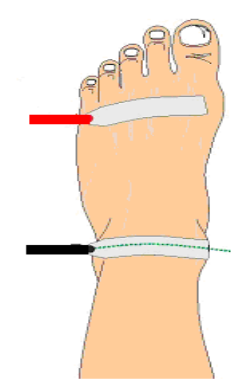

Abbildung 9: Positionierung der Elektroden bei Bioimpedanzmessung

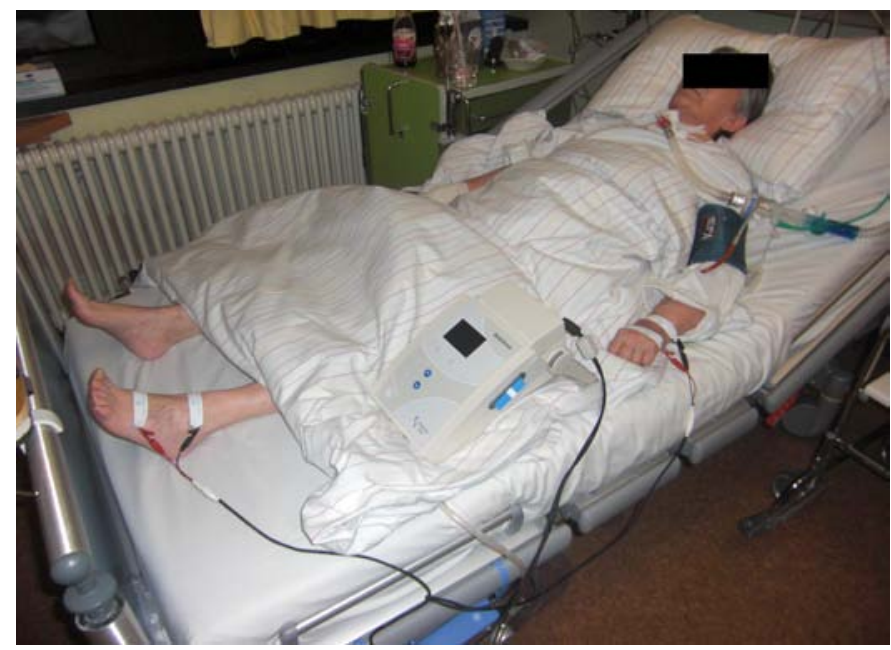

Abbildung 10: Durchführung der Bioimpedanzanalyse

Für die Messung wurde ein Multifrequenzanalysator (BIA SCOUT, Fresenius Kabi, Bad Homburg, Deutschland) benutzt. Zur Durchführung der Bioimpedanzmessung werden je zwei Elektroden auf den Hand- und Fußrücken der dominanten Körperseite angelegt. Die richtige Platzierung der Elektroden ist ein entscheidender Punkt (Abbildung 10). Die Elektroden sollen möglichst auf frisch entfetteter Haut angebracht werden, um maximalen Kontakt zu erhalten. Es werden zwei Elektroden verwendet: eine Stromeingabeelektrode - signal electrode, die distal platziert wird und eine sensible Messelektrode measuring electrode, die proximal platziert wird. 


\subsubsection{Körperkompartimente}

Die Einteilung verschiedener Kompartimente ist aus Sicht der diagnostischen Abgrenzung verschiedener Ernährungszustände berechtigt.

\begin{tabular}{|l|l|}
\hline Lean Tissue Mass (LTM) & Magermasse, fettfreie Masse des Körpers \\
\hline Körperzellmasse (BCM) & $\begin{array}{l}\text { die Summe aller aktiv am Stoffwechsel beteiligten Zellen, im } \\
\text { wesentlichen Muskelmasse }\end{array}$ \\
\hline Extrazelluläre Masse (ECM) & $\begin{array}{l}\text { Skelett und Bindegewebe, interstitieller und transzellulärer } \\
\text { Raum }\end{array}$ \\
\hline Intrazelluläres Wasser (ICW) & Intrazelluläres Wasser - ICW: ca. 66 \% des Ganzkörperwassers \\
\hline Extrazelluläres Wasser (ECW) & $\begin{array}{l}\text { Extrazelluläres Wasser - ECW ca. 33 \% des } \\
\text { Ganzkörperwassers }\end{array}$ \\
\hline
\end{tabular}

Tabelle 8: Terminologie der Körperzusammensetzung

Das Einkompartiment-Modell als gröbster Parameter entspricht der Gewichtsmessung des Körpers. Man erhält einen genau bestimmbaren, sehr wichtigen Messwert, kann aber bei Änderungen des Gewichts keine Aussagen über die Ursache (Wasser-/ Fettveränderung) treffen.

In der 2 - Kompartiment - Messung wird der Körper in Fett und Magermasse, Lean Tissue Mass (LTM) unterteilt. Diese Einteilung ist historisch auf Anthropometrie zurückzuführen. Mit Hilfe eines Calipers werden Hautfaltendicken über definierten Körperstellen bestimmt (meist an Bizeps und Trizeps sowie subscapulär und suprailiakal). Aus der Dicke der Hautfalten wird mit Hilfe standardisierten Tabellen das Körperfett berechnet. Aus praktischer Sicht ist ein 2-Kompartiment-Modell in der Klinik häufig nicht ausreichend, da klinisch relevante Verschiebungen zwischen der Körperzellmasse - Body Cell Mass $(B C M)$ und Extrazelluläre Masse (ECM) bei gleichzeitig konstanter Magermasse nicht erfasst werden.

In der Adipositastherapie reicht zunächst ein 2-Kompartimenten - Modell, um die Energiespeicher in Form der Fettmasse zu charakterisieren. In der Ernährungsmedizin sind Muskel-, Fett- und Knochenmasse wichtige Komponenten, da sie therapeutisch relevante Veränderungen zeigen. 


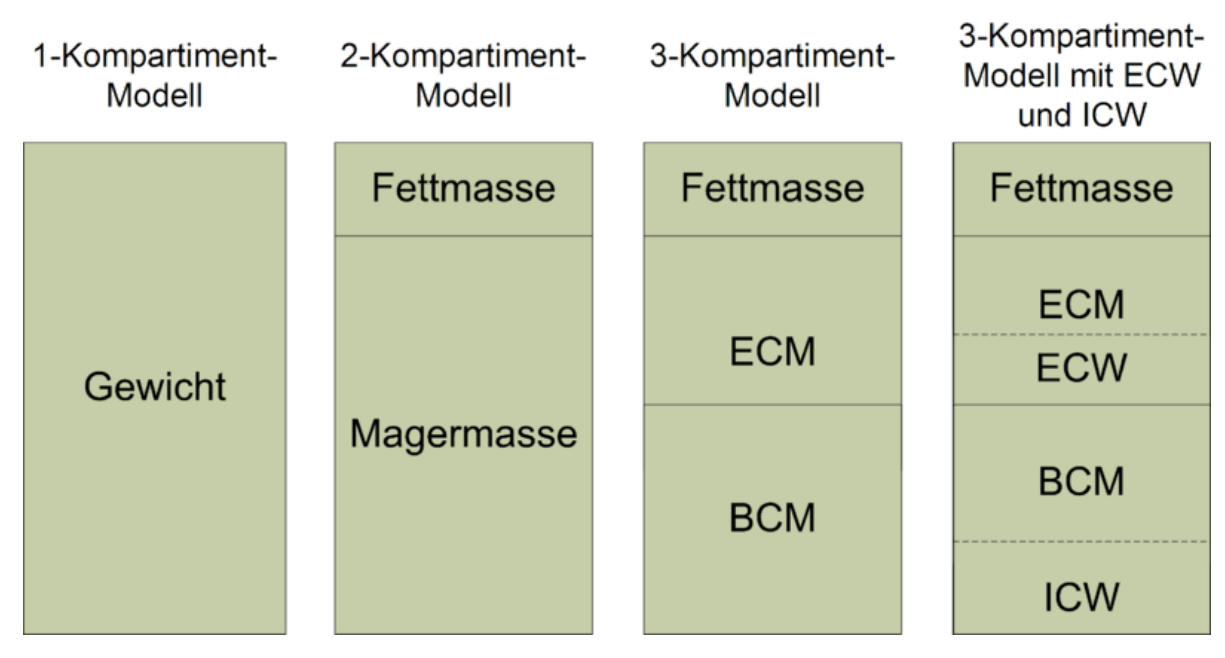

Abbildung 11: Einteilung in verschiedenen Kompartimenten der Körperzusammensetzung

Das 3-Kompartiment-Modell entsteht durch die Unterteilung der Magermasse in die Körperzellmasse BCM und die Extrazelluläre Masse - ECM. Die BCM ist die Summe aller sauerstoffoxidierenden stoffwechselaktiven Zellen, also Muskulatur, innere Organe und ZNS. Zur Extrazellulären Masse ECM gehören der interstitielle und transzelluläre Raum sowie Skelett und Bindegewebe. Massive Verschiebungen zwischen BCM und ECM können ohne Änderungen von Gewicht und Magermasse einhergehen. Bestimmungen im 3-Kompartiment- Modell sind mit der Bioimpedanzanalyse möglich [69].

\subsubsection{Die Messparameter der BIA, die Impedanz}

Die Impedanz ist definiert als Gesamtwiderstand eines biologischen Leiters gegen Wechselstrom. Sie besteht aus zwei Komponenten, Resistance (R) und Reactance (Xc).

\subsubsection{Resistance - R}

Die Resistance ist der reine ohmsche Widerstand eines Leiters gegen Wechselstrom und ist daher umgekehrt proportional zum Gesamtkörperwasser. Durch den hohen Anteil an Wasser und Elektrolyten ist die Magermasse ein guter Leiter für den Strom, während die Fettmasse einen hohen Widerstand besitzt.

Die Resistance steigt mit der Länge eines Zylinders (= Körpergröße oder bei segmentaler Messung Länge der Gliedmaßen) und sinkt mit dem Durchschnitt derä fhe (d. h. R ist invers proportional zum Durchmesser des Zylinders). "Dicke" Menschen haben im Vergleich zu gleichgroßen Schlanken einen niedrigeren R-Wert, größere Menschen haben einen höheren R-Wert als kleinere Menschen [38]. 


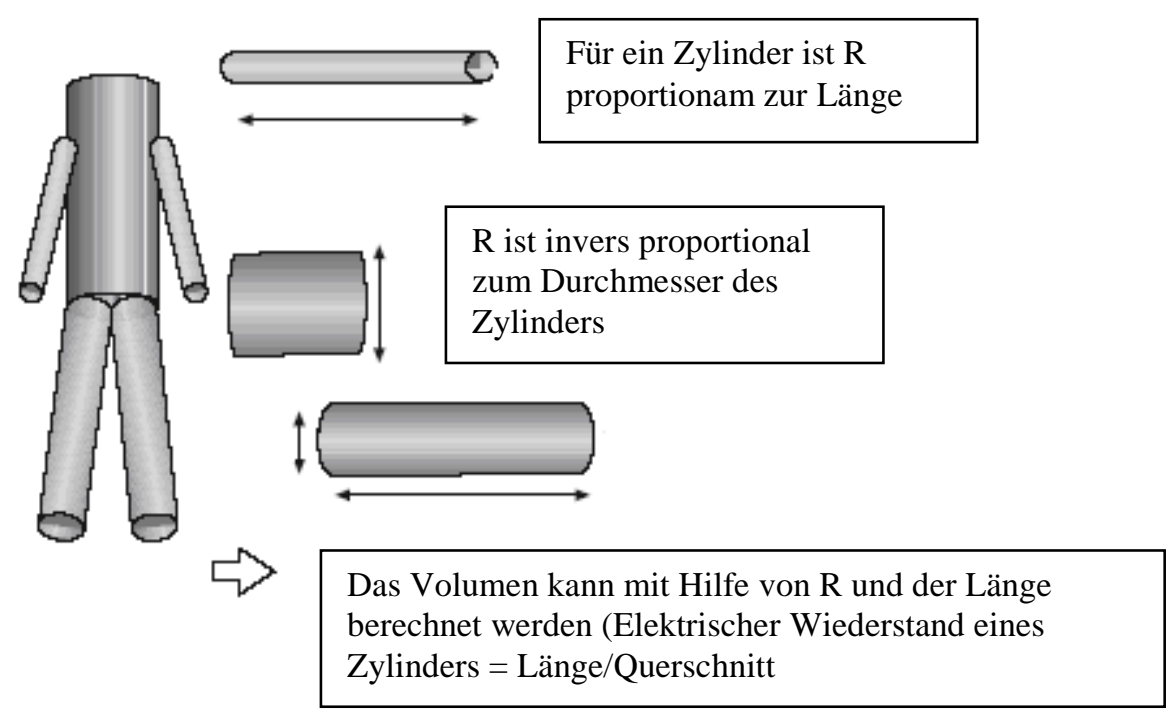

Abbildung 12: Einfluss der Körperformen auf die Resistance (R) [52]

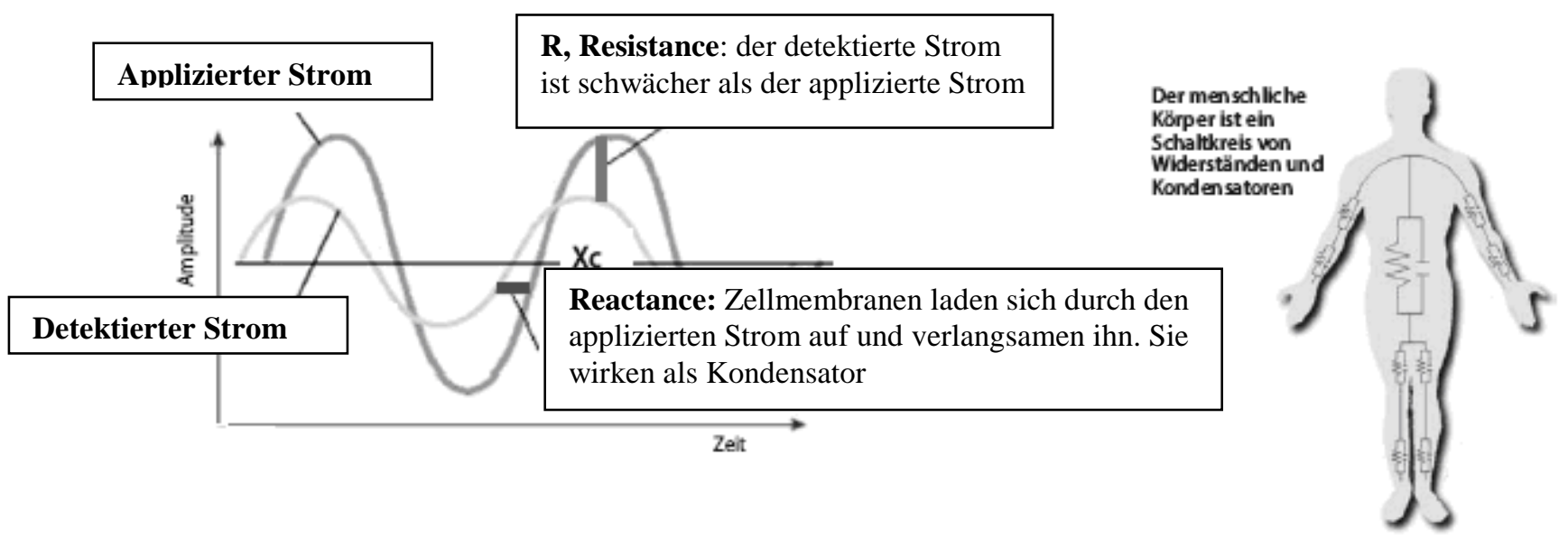

Abbildung 13: Messgrößen der Bioelektrischen Impedanz Analyse: $\mathbf{R}$ und $\mathbf{X c}$ [52] 
Die Resistance entsteht zu etwa 95\% an den Extremitäten und wird durch Veränderungen im Wassergehalt der Extremitäten entsprechend beeinflusst. Hierdurch erklären sich die gelegentlich auftretenden überproportionalen Schwankungen der Resistance, da die Durchblutung und damit der Flüssigkeitsgehalt der Extremitäten von äußeren Bedingungen (Umgebungstemperatur, Luftdruck) und inneren Bedingungen (körperliche Aktivität, krankheitsbedingte Stauung) abhängig ist. Liegt eine Resistance-Messung sehr weit oberhalb des normalen Bereichs, wie es bei extrem niedrigem Wassergehalt der Extremitäten vorkommt (Kälte, hoher Druck), so wird nach dem Berechnungsschema das Körperwasser und damit die Magermasse tendenziell zu niedrig und das Körperfett zu hoch berechnet. Bei verstärkter Extremitätendurchblutung oder -stauung weicht die Resistance nach unten ab und Körperwasser und Magermasse werden zu hoch, das Körperfett zu niedrig berechnet [69].

Mehrere Verlaufs- oder Wiederholungsmessungen einer Person verbessern die Beurteilung der Körperzusammensetzung durch die BIA [38].

3.1.3.2 Reactance - Xc, ist der kapazitive Widerstand, der durch die Kondensatoreigenschaften der Körperzellen entsteht.

Die Unterscheidung und Bestimmung dieser beiden Komponenten der Impedanz wird durch die Messung des Phasenwinkels ermöglicht.

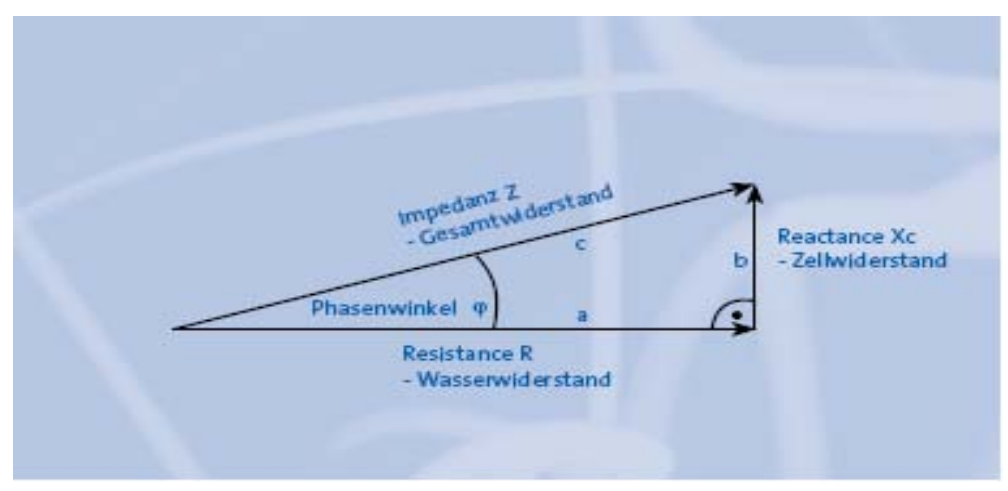

Abbildung 14: Die Bestimmung von R und Xc aus Impedanz und Phasenwinkel [38]

Fur eine Gruppe normalgewichtiger und gesunder Menschen gelten folgende Normwerte: $R=474 \pm 52$ Ohm, Xc = 59,4 $\pm 7,1$ Ohm [69]. 


\subsubsection{Die Größen der BIA}

\subsubsection{Lean Tissue Mass (LTM) - Magermasse}

Die Magermasse - LTM stellt die fettfreie Masse des Körpers dar. Im wesentlichen wird die Magermasse von der Muskulatur, den Organen, dem Skelettsystem und dem ZNS gebildet. Die morphologisch sehr unterschiedlichen Organsysteme sind funktionell identisch aufgebaut und bestehen aus Zellen, in denen Stoffwechselarbeit und Syntheseleistungen durchgeführt werden, sowie aus extrazellulärer Flüssigkeit und Matrixsubstanz, mit deren Hilfe der Substrattransport und Stoffaustausch stattfindet.

Die Komponenten der Magermasse sind die Körperzellmasse - BCM, die Summe aller aktiv am Stoffwechsel beteiligten Zellen und extrazelluläre Masse - ECM (Stützgewebe und Transport). Eine Differenzierung der Magermasse in diesen beiden Komponenten ist mit mehreren Verfahren möglich: DXA (Dual X-ray Absorptiometry), MRT/CT (Magnetresonanztomographie/ Computertomographie) und BIA.

Nach Pace und Rathburn hat die Magermasse einen Wassergehalt von 72\%. Die Magermasse könnte daher aus dem berechneten Körperwasser auf der Grundlage: LTM = 0,72 / TBW abgeleitet werden. Bei dieser Kalkulation geht man von einem konstanten Hydrierungswert der Magermasse aus, was bei einer gesunden, homogenen Population auch zutrifft. Der Wassergehalt kann aber variieren; so wurden zum Beispiel Werte zwischen 85\% bei Anasarka und 67\% bei Exsikkose gemessen. Kinder haben ebenfalls einen höheren prozentualen Wassergehalt. Bei pathologischem Hydratationsgrad der Magermasse kann

es zu abweichenden Berechnungen für Magermasse, Körperzellmasse und Extrazelluläre Masse kommen [55].

Mittels Bioimpedanz wird die Magermasse computerunterstützt anhand der Formel von Lukaski berechnet (s. Kap. 3.2).

Ein Verlust an Magermasse wird im Alter und bei chronischen Erkrankungen beobachtet. Ein Verlust von $>40 \%$ der Magermasse ist mit dem Leben nicht vereinbar [55].

\subsubsection{Body Cell Mass (BCM) - Körperzellmasse}

Die Körperzellmasse ist die Summe aller aktiv am Stoffwechsel beteiligten Zellen. Sie ist kein anatomisches, sondern ein funktionell definiertes Kompartiment und besteht vor allem aus den Zellen der Muskulatur und der inneren Organe.

Die BCM ist die Summe der kaliumreichen sauerstoffverbrauchenden Zellen des Körpers. Sie umfasst im 3-Kompartiment-Modell sowohl das proteinreiche und die Körperfunktionen bestimmende Gewebe als auch das intrazelluläre Wasser. 
Jedes Gewebe des menschlichen Organismus enthält einen Teil der BCM. Bindegewebe mit vielen Fibrozyten hat nur einen geringen Anteil an der Gesamt-BCM, während die zellreiche Muskulatur die Hauptmasse der BCM stellt. Die Adipozyten werden wegen ihres geringen Energiestoffwechsels nicht zur BCM gerechnet, sondern bilden als Summe ein eigenes Kompartiment [33].

Die BCM ist heterogen zusammengesetzt. Sie besteht aus Skelettmuskulatur und den inneren Organen (Leber, Herz, Nieren, Lunge, Milz, Gehirn, Blutzellen, Immunsystem etc.), welche als Nicht Muskel - BCM bezeichnet werden können. Das Verhältnis von Muskel- zu Nicht-Muskel-BCM betragt bei gesunden und normalgewichtigen Menschen 3,5:1 bis 4:1. Bei untergewichtigen und kachektischen Patienten wird das Verhältnis von Muskel zu Nicht-Muskel-BCM zu den inneren Organen hin verschoben. Umgekehrt kommt es bei Kraftsportlern oder auch nach Anabolikaeinnahme zu einer disproportionalen Zunahme der Muskelmasse [55].

Die BCM ist die zentrale Größe bei der Beurteilung des Ernährungszustandes eines Patienten, da die Stoffwechselarbeiten des Organismus innerhalb der Zellen der BCM geleistet werden. Die BCM ist die entscheidende Determinante des Energieverbrauchs, des Stoffwechsels energiereicher Substrate und des Eiweißumsatzes. In der BCM finden etwa 99\% der Stoffwechselprozesse statt. Aufgrund ihrer zentralen Bedeutung für Körperfunktionen hat die BCM z.B. bei Schwerkranken eine eigenständige prognostische Bedeutung [69].

Die BCM bestimmt den Kalorienbedarf des Organismus. Neben dem Betriebsstoffwechsel umfasst die Arbeitsleistung der BCM den Baustoffwechsel zum Erhalt der Zellstrukturen und die Syntheseaufgaben für die ECM, wie z.B. die Bildung von Bindegewebsfasern, Knochen- und Knorpelsubstanzen, Transportproteinen und Enzymen.

Für die individuell vorhandene BCM spielen genetische Faktoren (Konstitutionstyp), Lebensalter und Trainingszustand eine Rolle. Jugendliche mit starker körperlicher Aktivität (z.B. Leistungssportler) trainieren ihre Muskulatur in der Reifungsphase des Organismus. Häufig findet man bei diesen Personen zeitlebens einen höheren Anteil von Körperzellmasse in der Magermasse (persistierende Hypertrophie der Muskelzellen).

Wenn ein temporärer intrazellulärer Wasserverlust entsteht, könnten durch Bioimpedanz-Messung ungenaue Werte der BCM gemessen werden. Um einen echten BCM-Verlust handelt es sich aber erst dann, wenn gleichzeitig der Phasenwinkel sinkt [38].

\subsubsection{Phasenwinkel}

Zur Unterscheidung der beiden Komponenten Resistance und Reactance aus dem gemessenen Gesamtwiderstand verfügen moderne BIA-Geräte über eine phasensensitive Elektronik. Das Messprinzip beruht darauf, dass durch Kondensatoren im Wechselstromkreis eine Zeitverschiebung $\Delta$ t entsteht. Jede stoffwechselaktive Zelle des Körpers besitzt eine Zellmembran, die wie ein Kondensator aufgebaut ist. Diese Membran lässt die Zelle in einem Wechselstromfeld als Kugelkondensator wirken. 
Da Wechselstrom eine Sinusform hat, wird diese Verschiebung in ${ }^{\circ}$ (Grad) gemessen und als Phasenwinkel (phi) oder a (alpha) bezeichnet. Bildlich ausgedrückt haben intakte, pralle Zellen mit stabilem Membranpotential einen hohen Phasenwinkel, während geschädigte Zellen einen entsprechend niedrigen Phasenwinkel zeigen.

Der Phasenwinkel ist bei einer Frequenz von $50 \mathrm{kHz}$ am höchsten und am aussagekräftigsten. Eine reine Zellmembranmasse hätte einen Phasenwinkel von $90^{\circ}$, reines Elektrolytwasser hat einen Phasenwinkel von $0^{\circ}$ [65].

Der Phasenwinkel ist direkt proportional zur Menge der BCM (Body Cell Mass), bzw. zur Gesamtoberfläche und zum elektrischen Potential der darin enthaltenen Membranen. Im Gegensatz zu den Zellen der Body Cell Mass sind Fettzellen als reine Speicherzellen kaum stoffwechselaktiv, besitzen nur ein minimales Membranpotential und werden bei der phasensensitiven Messung nicht erfasst.

Der Phasenwinkel ist als direkter Messparameter bzw "Rohwert“ weniger von messtechnischen Problemen oder anderen Fehlerquellen abhängig. Er ist ein generelles Mass für die Zelldichte und die Membranintegrität der Zellen und lässt Aussagen über den Zustand der Zelle und den Gesundheitszustand des Organismus zu [66].

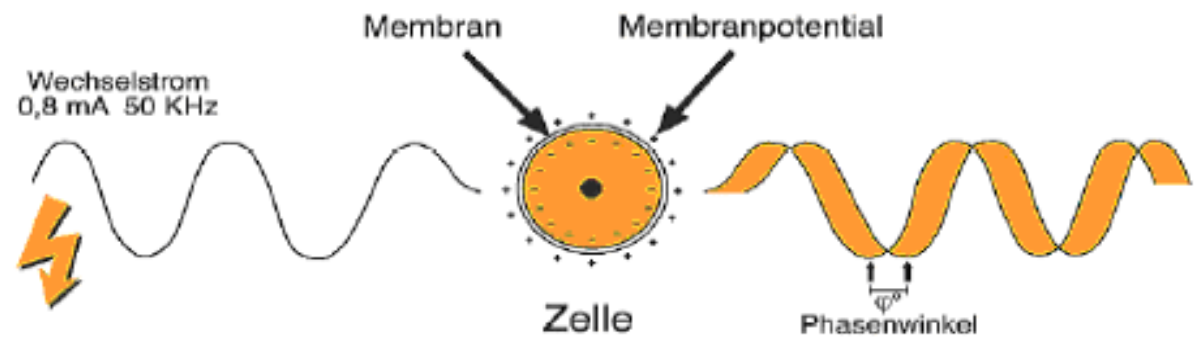

Abbildung 15: Intakte Zelle mit hoher Membranintegrität oder "'hohe Zelldichte" - hoher Phasenwinkel [52]

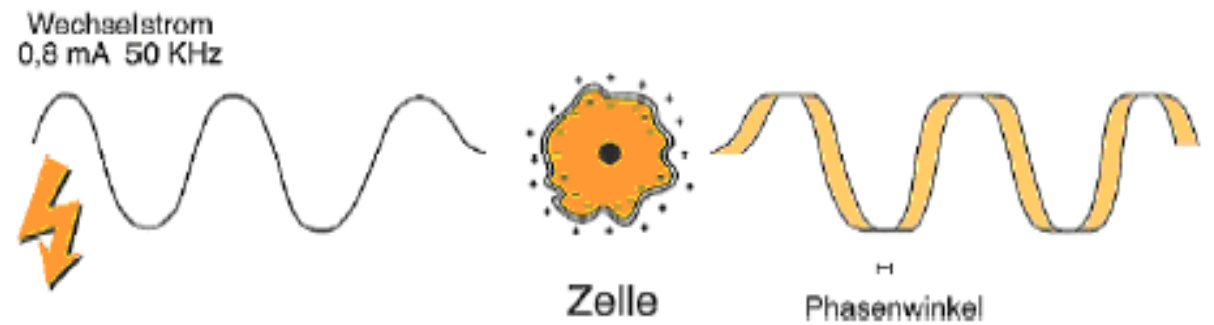

Abbildung 16: Geschädigte Zelle oder niedrige Zelldichte - niedriger Phasenwinkel [52] 


\subsubsection{Total Body Water (TBW) - Ganzkörperwasser}

Bei der Impedanzmessung wird das in den Geweben enthaltene Elektrolytwasser sehr genau erfasst. Oral aufgenommenes Wasser, welches noch nicht vom Körper resorbiert wurde, wird nicht gemessen, während i.v. applizierte Lösungen erfasst werden. Aszitesflüssigkeit wird nicht gemessen, da sie sich außerhalb des Gewebes der Magermasse befindet [65].

Das Ganzkörperwasser wird wie folgt verteilt:

- Extrazelluläres Wasser - ECW: ca. 33 \% des TBW (Lymphe, interstitiell, transzellulär, Plasma)

- Intrazelluläres Wasser - ICW: ca. 66 \% des TBW

Die Menge des Körperwassers eines Organismus wird in erster Linie über die Körperzellmasse BCM und damit primär über die Muskelmenge determiniert. Der Wassergehalt eines $70 \mathrm{~kg}$ schweren Mannes beträgt etwa 42-45 I (0,6-0,65 l/kg Körpergewicht bzw. 68-73\% des Körpergewichts). Davon befinden sich ca. 30 I intrazellulär $(0,4 \mathrm{l} / \mathrm{kg}$ Körpergewicht bzw. ca. $40 \%$ des Körpergewichts) und ca.15 I extrazellulär (0,2 l/kg Körpergewicht bzw. ca. 23\% des Körpergewichts). Ein Drittel des extrazellulären Volumens entfallen auf das Plasmavolumen (5\% des Körpergewichts) [69].

Der Elektrolytgehalt der intrazellulären Flüssigkeit beträgt $8 \mathrm{mMol}$ Natrium und $152 \mathrm{mMol}$ Kalium pro Liter. In der extrazellulären Flüssigkeit befinden sich $140 \mathrm{mMol} / \mathrm{l}$ Natrium und $4 \mathrm{mMol} / \mathrm{l} \mathrm{Kalium}$. Bei Säuglingen und Kleinkindern ist der Anteil des Gesamtkörperwassers mit 80\% des Körpergewichts höher. Hier finden sich 45\% des Wassers extra- und 55\% intrazellulär [55].

Ein Flüssigkeitsverlust in der Größenordnung von 1-2\% des Körpergewichts beeinträchtigt bereits die körperliche und geistige Leistungsfähigkeit. Eine Bestimmung des Körperwassers bzw. der intra- und extrazellulären Volumina ist sinnvoll bei Störungen der Wasserbilanz und -verteilung. Der durchschnittliche Wasserumsatz beträgt bei einem Erwachsenen ca. 1/30 des Körpergewichts. Beim Säugling sind dies $3 / 10$ des Körpergewichts. Dies erklärt, warum Säuglinge sehr empfindlich auf Störungen der Wasserbilanz reagieren.

Die Flüssigkeitsbilanz errechnet sich aus der täglichen Wasserzufuhr (0,5-1,5 I durch Getränke, 1-1,2 I durch feste Speisen, 0,3 I als endogenes Stoffwechselprodukt) und der Wasserausscheidung bzw. den Flüssigkeitsverlusten (0,6-1,5 I Urin, 1-1,5 I Schwei $\beta$, ca. 0,4 $\mathbf{u}$ ber die Lunge (Perspiratio insensibilis), $<0,2$ I über den Stuhl). Die Wasserbilanz ist normalerweise ausgeglichen. Die Wasserbilanz kann durch fortlaufende Messung des Körpergewichts und gleichzeitige Protokollierung von Ein- und Ausfuhr erfasst werden. Aufgrund des möglichen kumulativen Fehlers (z. B. ungenaue Angaben zum Wassergehalt von Lebensmitteln, Fehler beim Sammeln des Urins oder nicht erfasste Verluste, z. B. Durchfälle, Schwitzen) sind Bilanztechniken mit möglichen Fehlern behaftet. 
In der Klinik werden hämodynamische Parameter wie der Blutdruck, die Herzfrequenz, der zentrale Venendruck oder der pulmonalarterielle Druck zur Beurteilung der Flüssigkeitsbilanz und z. B. zur Einschätzung des adäquaten Infusionsvolumens im Rahmen einer künstlichen Ernährung herangezogen. Diese intensivmedizinisch relevanten Kenngfën erfassen das i ntravasale Volumen und nicht das gesamte ECW. Die Prävention einer Expansion des ECW's ist ein wesentliches Ziel der Behandlung Schwerkranker auf der Intensivstation. Frühzeitige Veränderungen des ECW's sind schwer nachweisbar. Wird ein Ödem manifest, so hat das ECW in der Regel um mehr als 10\% des Körpergewichts zugenommen. Ein $60 \mathrm{~kg}$ schwerer Patient mit einem ECW von 12 I wird so erst bei einem ECW von 18 I ein klinisch manifestes Ödem aufweisen [66]. In einer von uns durchgeführten Studie haben wir gezeigt dass es bei kritisch kranken Patienten nach 5 Tagen Aufenthalt auf der Intensivstation zu einer Zunahme des ECW's auf dem Boden einer ausgeprägten Abnahme des intrazellulären Wassers - ICW kommt [63].

Bei Dehydratation beträgt das Verhältnis von Gesamtkörperwasser zur fettfreien Masse <0,72. Klinische Zeichen des Wassermangels sind Hypovolämie oder Blutdruckabfall. Flüssigkeitsverluste werden nach ihrem Ausma $\beta$ bzw. den klinischen Zeichen in leï̈łsig(keitsverluste: $3 \quad-5 \%$ des Körpergewichts; Symptome: Durst, verminderter Hautturgor, trockene Schleimhäute), mittel (Flüssigkeitsverluste: 5-10\% des Körpergewichts; Symptome: Blutdruckabfall, Tachykardie, Oligurie) und schwer (Flüssigkeitsverluste: $>10 \%$ des Körpergewichts; Symptome: Schock, Bewusstlosigkeit) eingeteilt.

Die Veränderungen vom ICW könnten frühzeitige Veränderungen des Ernährungszustands, der Flüssigkeitshomöostase und auch des Stoffwechsels charakterisieren.

Probleme bei der Interpretation der Ergebnisse von BIA-Messungen bestehen bei Expansion des Extrazellulärraums (z. B. bei Leberzirrhose, Herzinsuffizienz oder Nierenversagen). Zur Erkennung der Malnutrition bei eingelagertem Wasser wird der Phasenwinkel beurteilt [52].

\subsubsection{Extra Cellular Mass ( ECM) - Extrazelluläre Masse}

Der Teil der Magermasse außerhalb der Zellen der BCM wird als extrazelluläre Masse - ECM bezeichnet. Feste Bestandteile der ECM sind die bindegewebigen Strukturen: Collagen, Elastin, Haut, Sehnen, Faszien und Knochen.

Der flüssige Anteil besteht aus Plasma, interstitiellem und transzellulärem Wasser. Als transzelluläres Wasser bezeichnet man Flüssigkeiten in Körperhöhlen. Dazu zählt zum Beispiel der Liquor spinalis oder der Inhalt des gastrointestinalen Lumen.

Unphysiologische transzelluläre Flüssigkeit kommt als Pleura- bzw. Perikarderguss oder als Aszites vor. Transzelluläres Wasser kann von der BIA-Messung nicht erfaßt werden. Das liegt daran, dass ca. 95\% des gemessenen elektrischen Widerstandes in den Extremitäten entstehen. Der Torso geht mit nur ca. 5\% Widerstandsanteil in die Berechnung des Körperwassers ein. Da zum Beispiel ein Aszites von ca. 5 Litern den Widerstand des Torso um nur wenige Ohm ändert, wird der Gesamtwiderstand praktisch gar nicht beinflusst. 


\subsubsection{ECM / BCM-Index}

Der ECM/BCM-Index ist der zweitwichtigste Parameter zur Beurteilung des Ernährungszustandes. Beim Gesunden ist die Body Cell Mass (BCM) stets deutlich größer als die Extrazelluläre Masse (ECM), so dass der Index kleiner 1 beträgt.

Im Frühstadium der Malnutrition ist eine Abnahme der BCM bei gleichzeitiger Vergrößerung des Extrazellulärraumes charakteristisch; Magermasse und Gewicht können dabei konstant bleiben. Der steigende ECM/BCM-Index macht dann frühzeitig auf eine Verschlechterung des Ernährungszustandes aufmerksam [38].

Ein ansteigender ECM/BCM Index kann zwei Ursachen haben:

\section{a. Katabolie der BCM:}

Bei katabolen Veränderungen jedweder Genese kommt es zur Reduktion der Body Cell Mass. Aufgrund des intrazellulären Proteinverlustes lagert der Körper kompensatorisch Wasser im Extrazellulärraum ein.

\section{b. Wassereinlagerung in der ECM:}

Ein erhöhter ECM/BCM-Index ist für die Beurteilung einer Malnutrition von Bedeutung. Bei Nahrungsoder Nährstoffmangel mobilisiert der menschliche Organismus zur Glukosehomöostase intrazelluläres Protein und bildet daraus Glucose. Der intrazelluläre Proteinverlust führt zu einer Verkleinerung der BCM. Gleichzeitig kommt es durch Abgabe des proteingebundenen intrazellulären Wassers zu einer Vergrößerung des Extrazellulärraumes. Die Masse von BCM und ECM verändert sich in dieser Situation gegenläufig. Die BCM fällt dabei überproportional ab. Verminderung der BCM und die extrazelluläre Überwässerung (ohne sichtbare periphäre Ödeme) sind typische Merkmale der Malnutrition [65].

\subsubsection{Body Fat - Körperfett}

Körperfett hat eine Dichte von $0,9 \mathrm{~g} / \mathrm{cm}^{3}$. Das Fett wirkt als Isolator für Wechselstrom. Fettzellen besitzen nicht die typischen Eigenschaften der Zellen der BCM (Körperzellmasse) und haben daher auch kaum kapazitiven Widerstand (Reactance). Die Fettmasse wird aus der Gewichtsdifferenz von Magermasse und Körpergewicht berechnet.

Normwerte Männer: 10 - $15 \%$ des Gesamtkörpergewichtes

Normwerte Frauen: 20 - 25 \% des Gesamtkörpergewichtes [69] 


\subsubsection{Andere Untersuchungsmethoden zur Bestimmung der Körperzusammensetzung}

Die Erfassung einzelner Kenngrößen der Korperzusammensetzung ist mit verschiedenen Methoden möglich. Diese haben jeweils verschiedene Zielgrößen und sind unterschiedlich genau. Ein direkter Vergleich der Methoden untereinander (z. B. Anthropometrie versus Bbioelektrische Impedanzmessung versus Neutronenaktivierung) ist deshalb nicht immer sinnvoll.

Die bioelektrische Impedanzmethode misst elektrische Phänomene (Widerstand, Leitfahigkeit), welche vom Wasser- und Elektrolytgehalt und den Zellmembranen abhängig sind.

Mit Neutronenaktivierung können Elemente wie N, K, Cl, C erfasst und z. B. der Stickstoffgehalt des Körpers und somit ebenfalls die BCM bestimmt werden. Die Berechnung des Körperproteins folgt der Annahme eines mittleren Stickstoffgehalts im Körpereiweiß (16\%). Diese Annahme ist allgemein richtig, sie unterliegt jedoch multiplen Variationen [66].

Auch die Messung des Gesamtkörperkaliums erlaubt die Erfassung der BCM. 98\% des Gesamtkörperkaliums befinden sich intrazellulär. Die Umrechnung von den Kaliumwerten zur BCM beruht auf folgenden Annahmen:

— einer konstanten intrazellulären Kaliumkonzentration von $150 \mathrm{mmol}$ Kalium/l

- eines konstanten intrazellulären Wassergehalts von $72 \%$

Der prozentuale Wassergehalt weicht aber bei Kindern, Schwangeren, älteren Menschen oder auch Schwerkranken von dem genannten Wert ab. So beträgt z. B. die Hydration der FFM während der Schwangerschaft $76 \%$ [88].

\begin{tabular}{|l|l|}
\hline \multicolumn{1}{|c|}{ Methode } & \multicolumn{1}{c|}{ Zielgrössen } \\
\hline BIA & $\begin{array}{l}\text { Gesamtkörperwasser, BCM, Phasenwinkel, } \\
\text { ECW, ICW }\end{array}$ \\
\hline Neuronenaktivierung & $\begin{array}{l}\text { Calcim, Natrium, Stickstoff, Wasserstoff, } \\
\text { Sauerstoff, Chlor, Phosphor }\end{array}$ \\
\hline Gesamtkörperkalium & BCM, Magermasse \\
\hline Anthropometrie & Fettmasse, Fettverteilung, Muskelmasse \\
\hline Isotopendilution & Gesamtkörperwasser \\
\hline DXA & $\begin{array}{l}\text { Knochenmineralgehalt, Knochendichte, } \\
\text { Fettmasse }\end{array}$ \\
\hline
\end{tabular}

Tabelle 9: Methoden und ihre primären Zielgrößen der Körperzusammensetzung [38] 


\begin{tabular}{|c|c|}
\hline BIA & $\begin{array}{l}\text { Probleme bei veränderten Flüssigkaitsräumen, } \\
\text { z.B. bei Aszites Herz-und Niereninsuffizienz }\end{array}$ \\
\hline Neutronenaktivierung & $\begin{array}{l}\text { Apparativ afwändig, in wenigen Kliniken } \\
\text { verfügbar, hohe Kosten, Strahlenbelastung }\end{array}$ \\
\hline Gesamtkörperkalium & $\begin{array}{l}\text { Diuretikaeinnahme, Leber- und } \\
\text { Nierenerkrankungen, Abhängig vom } \\
\text { Hydratationszustand }\end{array}$ \\
\hline Anthropometrie & $\begin{array}{l}\text { Abhängig vom Hydratationszustand, ungenau, } \\
\text { Berechnungsformeln }\end{array}$ \\
\hline Isotopendilution & Probleme bei Aszites, teuer, aufwändig \\
\hline Dual-energy x-ray absorptiometry - DXA & $\begin{array}{l}\text { Röntgenstrahlenbelastung, aufwendige } \\
\text { Prozessierung der Messdaten, hohe Kosten }\end{array}$ \\
\hline
\end{tabular}

Tabelle 10: Nachteile verschiedener Untersuchungsmethoden zur Bestimmung der Körperzusammensetzung [38]

Die Anthropometrie umfasst die Messungen der "Dicke" von Hautfalten, Umfänge und Abstände. Es handelt sich um die Messungen zur Bestimmung des Unterhautfettgewebes und der Muskelmasse. Hautfalten und Umfänge werden an definierten Referenzpunkten des Körpers gemessen. Abweichungen vom Referenzpunkt führen zu Ungenauigkeiten in der Bestimmung der Fettmasse (z. B. eine Abweichung von bis zu $2 \mathrm{~mm}$ bedeutet einen Fehler der Fettmasse von bis zu 3\%). Gegebenfalls wird die Hautfaltendicke vom Hydratationszustand beeinflusst. Bei Ödemen und auch Dehydratation sind die Messungen von zweifelhaftem Wert. Die bedeutensten Probleme jeder Untersuchungsmethode sind in Tab.10 dargestellt [38].

Die Messungen der Hautfalten erfolgen mit einer Kaliperzange. Der Kaliper übt eine definierte und konstante Kraft aus. Die Kontaktfläche beträgt 20-40 mm². Für die Bestimmung der Trizepshautfalte (TSF) wird im Stehen am Mittelpunkt der Verbindungslinie zwischen Akromion und Olekranon bei gebeugtem Ellenbogengelenk und entspannter Muskulatur gemessen. Eine Hautfalte wird zwischen Finger und Daumen der linken Hand gefasst und von der Muskelfaszie abgehoben. Mit der Kaliperzange werden nur Haut und Unterhautfettgewebe "gefasst". Die Kaliperzange hat keinen wesentlichen Druck auf die Hautfalte. Die Messung erfolgt innerhalb von 5 Sekunden nach Schließen der Zange. Der Mittelwert aus 3 Messungen ergibt das endgültige Ergebnis. Normalwerte für die TSF sind für Männer $12 \mathrm{~mm}$ und für Frauen 16,5 mm. Da die Fettmasse mit dem Alter zunimmt, sind alterskorrigierte Referenzbereiche zu verwenden. Die anthropometrische Erfassung des Konstitutionstyps wird heute nicht mehr regelhaft durchgeführt [66]. 


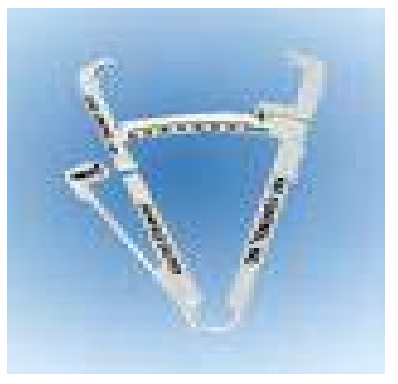

Abbildung 17: Kaliperzange

Eine weitere Möglichkeit zur Messung der Körperzusammensetzung ist die Isotopendilution. Die Bestimmung beruht auf dem Prinzip der Isotopenverdünnung. Mittels Isotopendilution wird das Gesamtkörperwasser gemessen. Die Messung erfolgt mit radioaktiven oder stabilen Isotopen. Radioaktive tracer dürfen bei Kindern und Jugendlichen sowie jungen Frauen, Schwangeren und Stillenden nicht angewendet werden. Heute werden nahezu ausschließlich stabile Isotope verwendet [38].

Mit der Methode der Isotopendilution wird der Wassergehalt des Körpers erfasst. Da die Fettmasse wasserfrei ist, ist das Gesamtkörperwasser (total body water; TBW) ein Index der fettfreien Masse - FFM. Bei normalgewichtigen und gesunden Menschen ist der Wasseranteil der fettfreien Masse relativ konstant (73\%). Aus der Differenz von Körpergewicht und FFM wird die Fettmasse berechnet.

Substanzen zur Bestimmung des Gesamtkörperwassers sollten sich nur im Wasserraum verteilen und schnell mit dem Körperwasser equilibrieren, sie dürfen im Untersuchungszeitraum nicht verstoffwechselt oder ausgeschieden werden, nicht-toxisch sein und physiologische Vorgänge nicht beeinträchtigen [38].

Dual-energy x-ray absorptiometry - DXA wird heute routinemäßig zur Untersuchung der Knochendichte bzw. des Knochenmineralgehaltes im Rahmen der Osteoporosediagnostik angewendet. Dabei werden gezielt bestimmte Referenzpunkte (z. B. Lendenwirbelkörper, Schenkelhals, Calcaneus) gemessen. Als Ganzkörpermessung kann mittels DXA eine differenzierte Untersuchung der Körperzusammensetzung durchgeführt werden. Dabei wird die gesamte Knochenmasse des Körpers nach folgender Formel berechnet:

$$
\text { Gesamte Knochenmasse }=\text { Knochenmineralgehalt } \times \text { 3,571 [108] }
$$

Eine Untersuchung der Körperzusammensetzung mit DXA wird mit einem Röntgengerät bei sehr niedriger Strahlendosis durchgeführt. Die bei der dual-photon-absorptiometry (= DPA) benutzte Radionuklidquelle wird bei der DXA durch eine Röntgenröhre ersetzt, welche Photonen mit höher Geschwindigkeit erzeugt. Die Röntgenröhre emittiert Photonenstrahlen verschiedener Energien (40 keV, $80 \mathrm{keV}$ ). Beim Durchdringen der Körpergewebe verliert die Röntgenstrahlung je nach Gewebeart unterschiedlich an Energie. Die Abschwächung der Photonen dient zur Ermittlung eines Gewebe spezifischen R-Wertes. Der R-Wert ergibt sich aus dem Verhältnis der Photonenabschwächung bei niedriger gegenüber höher Energie. Jeder Bildpunkt (Pixel) hat einen gemessenen R-Wert (z. B. R-Wert 
für Fett, R-Wert für Weichteile, sog. lean tissue, R-Wert für Knochenmineralien). Die R-Werte sind abhängig von der Gewebezusammensetzung, z.B. 1,21 für Triglyceride, 1,37-1,38 fur extra- und intrazelluläre Flüssigkeiten und 2,68 für Knochenmineralien. Der Anteil der Komponenten wird durch den gemessenen R-Wert berechnet. Die Reststrahlung wird von dem Detektorsystem (DXA) erfasst. Eine Ganzkörpermessung dauert zwischen 5 und 20 min und ist mit einer geringen Strahlenbelastung verbunden [108].

Die Anwendung verbietet sich bei Kindern, Jugendlichen und Schwangeren. Es wird eine aufwendige Prozessierung der Messdaten benötigt. Die Computer-gestützte Bildanalyse erfolgt mit Hilfe spezifischer R-Werte für Fett, Magermasse ohne Knochen und Knochenmineralien. Die DXA-Methode unterteilt so den menschlichen Körper in 3 Kompartimente: die Fettmasse, die Knochenmasse und die fettfreie Masse[108].

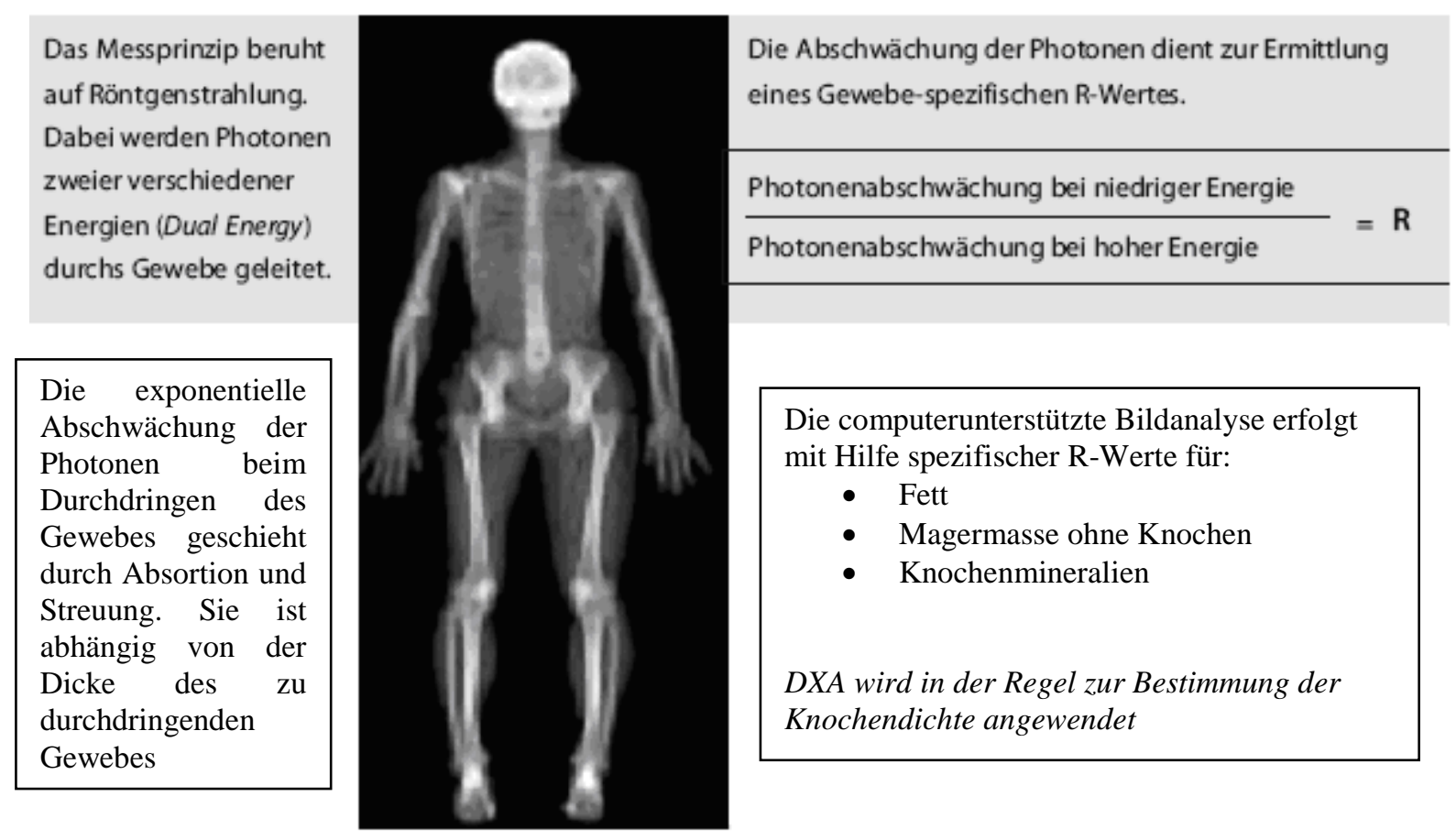

Abbildung 18: Messung der Körperzusammensetzung mit '’Dual-energy x-ray absorptiometry'” [66]

Zusammenfassend lässt sich feststellen, dass die richtige Entscheidung für eine Methode sich aus der Fragestellung und der Zielgß̈̈ ergibt. Im klinischen Altag ist die Praktikiabolèr Methode zu berücksichtigen. In der ernährungsmedizinischen Routine sind heute anthropometrische Methoden, die bioelektrische Impedanznalyse (BIA) und die DXA (= Dual energy x-ray absorptiometry) etabliert. In wenigen Einrichtungen können die Körperdichte, der Gesamtkörperkaliumgehalt oder die Elemente analysiert werden. Die aufwändigen Methoden werden ausschliesslich im Rahmen der Forschung angewendet. 
Die Körperzusammensetzung kann grundsätzlich mit allen genannten Methoden erfasst werden, es gibt jedoch keinen Goldstandard. So werden z. B. fehlernährte Patienten unabhängig von der Methode als solche identifiziert. Die Wahl der Methode hängt also sowohl von der jeweils interessierenden Zielgrße als auch von der erforderlichen Genauigkeit ab.

Eine Kombination verschiedener Methoden ist möglich. Dieses Vorgehen kann die individuellen Fehler einzelner Methoden reduzieren [38].

\subsection{Durchführung der Messungen}

In unserer Untersuchung haben wir eine Gruppe von 47 COPD-Patienten (24 Männer; 23 Frauen) im Bezug auf Parameter der BIA charakterisiert. Die Patienten waren stationär in der pneumologischen Abteilung der Uniklinik Homburg und in der geriatrischen Abteilung der Fachklinik Quierschied.

Die Messung erfolgte mittels Bioelektrischer Impedanz Analyse (BIA). Für die Messung wurde ein Multifrequenzanalysator (BIA SCOUT, Fresenius Kabi, Bad Homburg, Deutschland) verwendet. Die Messung fand unter standardisierten Bedingungen direkt vor oder nach der anthropometrischen Datenerhebung statt. Für die Messung wurden die Patienten in flacher Rückenlage ohne Kopfkissen so auf die Liege gelegt, dass Beine und Arme weder einander noch den Rumpf berührten. Zwischen der Lagerung und der Messung lagen etwa 5 min. Es wurden dann jeweils zwei Einmalklebeelektroden an definierten Stellen auf der Haut der Hand und des unbekleideten Fußes der dominanten Körperseite befestigt. An der Hand wurde die Messelektrode auf Höhe des Ulnarköpfchens, die Signalelektrode nahe den Fingergrundgelenken zwischen dem 2. und 3. Strahl der Hand geklebt. Am Fuß wurden die Elektroden an anatomisch entsprechenden Punkten angebracht: die Messelektrode wurde zwischen den Malleoli medialis und lateralis geklebt, die Signalelektrode nahe den Zehengrundgelenken zwischen dem 1. und 2. Strahl des Fußes. Dann wurden Messungen bei $50 \mathrm{kHz}$ vorgenommen. Die Messergebnisse wurden in ein Computerauswertungsprogramm (Nutrition Management Tool Version 2.0.293) eingegeben, das von der Herstellerfirma des Analysators mitgeliefert wurde. Das Programm berücksichtigt auch Alter, Geschlecht, Körpergröße und -gewicht des Patienten.

Die Beurteilung des pathologischen Ernährungs- und Trainingszustandes erfolgte durch Bestimmung von Phasenwinkel, ECM/BCM, Muskelmasse und Gesammtkörperwasser. Die Messung der meisten Parameter ergab ein statistisch signifikantes Resultat $(p<0.05)$. 
Die BIA - Parameter sind computerunterstützt anhand der Formel von Lukaski berechnet worden:

1. $\operatorname{LTM}=0,756 \times\left(\right.$ Größe in $\left.\mathrm{cm}^{2} / R\right)-(0,11 \times$ Gewicht in $\mathrm{kg})+(0,107 \times \mathrm{Xc})-5,463$

2. Fettmasse $=$ Körpergewicht - LTM

3. $\mathrm{ECW}(\mathrm{I})=0,189 \times \mathrm{GrQ \beta e}^{2}(\mathrm{~cm} 2) / \mathrm{R}(\mathrm{Ohm})+0,052 \times$ Gewicht $(\mathrm{kg}) \quad-0,0002 \mathrm{Größe}^{2}\left(\mathrm{~cm}^{2}\right) / \mathrm{Xc}(\mathrm{Ohm})+$ 1,03

4. $B C M(\mathrm{~kg})=\mathrm{LTM}(\mathrm{kg})-\mathrm{ECW}(\mathrm{kg}) / 0,73$

5. TBW $=0,277 \times\left(\right.$ Größe in $\left.\mathrm{cm}^{2} / R\right)-(0,14 \times$ Gewicht in kg $)-(0,08 \times$ Alter in Jahre $)+(2,9 \times$ Geschlecht (Frauen 0, Männer 1) $+4,65$

\section{3 Überprüfung der Testbedingungen}

\subsubsection{Test der Prüfgrößen auf Normalverteilung nach Shapiro \& Wilk}

Alle Prüfgrößen wurden mit dem Shapiro-Wilk-Test auf Normalverteilung getestet. Der Test prüft die Nullhypothese, dass eine Stichprobe $x_{1}, \ldots, x_{n}$ aus einer Normalverteilung stammt und eignet sich für Stichprobengrößen $<50$. Die Prüfgröße $W$ wird berechnet nach:

$W=\frac{\left(\sum_{i=1}^{n} a_{i} x_{(i)}\right)^{2}}{\sum_{i=1}^{n}\left(x_{i}-\bar{x}\right)^{2}}$

Der Test weist die Nullhypothese (H0) zurück, wenn die Prüfgröße $W$ zu klein ist.

\subsubsection{Testbedingungen}

Folgende Testbedingungen und Hypothesen wurden formuliert Irrtumswahrscheinlichkeit $(\alpha)$

$=1 \%$

Nullhypothese $(\mathrm{HO})$

$=\quad$ Prüfgrösse ist normalverteilt

Alternativhypothese $(\mathrm{H} 1)$

$=\quad$ Prüfgröße ist nicht normalverteilt

Testentscheidung

$=\quad \mathrm{H} 0$ wird abgelehnt, wenn die Teststatistik $\boldsymbol{W}<$ ist als der kritische $\mathrm{W}$-Wert $\boldsymbol{W p}$ 


\subsubsection{Ergebnisse}

Prozentwerte

\begin{tabular}{|c|c|c|c|c|c|c|c|}
\hline \multirow{2}{*}{ Prüfgrösse } & \multirow{2}{*}{ Einheit } & \multicolumn{3}{|c|}{ COPD-Männer ( $n=24)$} & \multicolumn{3}{|c|}{ COPD-Frauen $(n=23)$} \\
\hline & & $p$ & W & TE & $p$ & W & TE \\
\hline ECW & $\%$ von $\mathrm{KG}$ & $2,84 \times 10^{-13}$ & 0,9002 & $\mathrm{HO}$ & $1,37 \times 10^{-3}$ & 0,9562 & $\mathrm{HO}$ \\
\hline ICW & $\%$ von $\mathrm{KG}$ & $3,97 \times 10^{-2}$ & 0,8958 & $\mathrm{HO}$ & $4,99 \times 10^{-2}$ & 0,9470 & $\mathrm{HO}$ \\
\hline TBW & $\%$ von $\mathrm{KG}$ & $8,47 \times 10^{-5}$ & 0,9018 & $\mathrm{HO}$ & $1,34 \times 10^{-2}$ & 0,9630 & $\mathrm{HO}$ \\
\hline LTM & $\%$ von $\mathrm{KG}$ & $2,28 \times 10^{-4}$ & 0,8969 & $\mathrm{HO}$ & $4,26 \times 10^{-4}$ & 0,9497 & $\mathrm{HO}$ \\
\hline $\mathrm{BCM}$ & $\%$ von $K G$ & $1,41 \times 10^{-3}$ & 0,9164 & $\mathrm{HO}$ & $2,24 \times 10^{-3}$ & 0,9391 & $\mathrm{HO}$ \\
\hline FAT & $\%$ von $\mathrm{KG}$ & $8,93 \times 10^{-4}$ & 0,9027 & $\mathrm{HO}$ & $2,04 \times 10^{-2}$ & 0,9608 & $\mathrm{HO}$ \\
\hline FFM & $\%$ von $\mathrm{KG}$ & $8,93 \times 10^{-4}$ & 0,9027 & $\mathrm{HO}$ & $2,04 \times 10^{-2}$ & 0,9608 & $\mathrm{HO}$ \\
\hline
\end{tabular}

$\mathrm{HO}=$ Nullhypothese (Normalverteilung); $\mathrm{H} 1=$ Alternativhypothese (keine Normalverteilung);

$\mathrm{TE}=$ Testentscheidung (anzunehmende Hypothese)

Index-Werte

\begin{tabular}{|c|c|c|c|c|c|c|c|}
\hline \multirow{2}{*}{ Prüfgrösse } & \multirow{2}{*}{ Einheit } & \multicolumn{3}{|c|}{ COPD-Männer $(n=24)$} & \multicolumn{3}{|c|}{ COPD-Frauen $(n=23)$} \\
\hline & & $P$ & $\mathbf{w}$ & TE & $P$ & W & TE \\
\hline ECW-I & Liter $/ \mathrm{m}^{2}$ & $3,03 \times 10^{-5}$ & 0,9446 & $\mathrm{HO}$ & $1,44 \times 10^{-4}$ & 0,9013 & $\mathrm{HO}$ \\
\hline ICW-I & Liter $/ \mathrm{m}^{2}$ & $3,91 \times 10^{-1}$ & 0,9374 & $\mathrm{HO}$ & $8,58 \times 10^{-2}$ & 0,9368 & $\mathrm{HO}$ \\
\hline TBW-I & Liter $/ \mathrm{m}^{2}$ & $1,60 \times 10^{-2}$ & 0,9485 & $\mathrm{HO}$ & $5,13 \times 10^{-3}$ & 0,8725 & $\mathrm{H} 1$ \\
\hline LTM-I & $\mathrm{kg} / \mathrm{m}^{2}$ & $7,22 \times 10^{-11}$ & 0,9274 & $\mathrm{HO}$ & $9,21 \times 10^{-5}$ & 0,9594 & $\mathrm{HO}$ \\
\hline BCM-I & $\mathrm{kg} / \mathrm{m}^{2}$ & $8,99 \times 10^{-5}$ & 0,9166 & $\mathrm{HO}$ & $8,12 \times 10^{-5}$ & 0,9545 & $\mathrm{HO}$ \\
\hline FAT-I & $\mathrm{kg} / \mathrm{m}^{2}$ & $6,68 \times 10^{-8}$ & 0,9569 & $\mathrm{HO}$ & $1,15 \times 10^{-6}$ & 0,9406 & $\mathrm{HO}$ \\
\hline FFM-I & $\mathrm{kg} / \mathrm{m}^{2}$ & $5,96 \times 10^{-2}$ & 0,9430 & $\mathrm{HO}$ & $1,68 \times 10^{-2}$ & 0,8887 & $\mathrm{HO}$ \\
\hline
\end{tabular}

$\mathrm{HO}=$ Nullhypothese (Normalverteilung); $\mathrm{H1}=$ Alternativhypothese (keine Normalverteilung);

$\mathrm{TE}=$ Testentscheidung (anzunehmende Hypothese)

\section{Sonstige Werte}

\begin{tabular}{|l|l|c|c|c|c|c|c|}
\hline \multirow{2}{*}{ Prüfgrösse } & \multirow{2}{*}{ Einheit } & \multicolumn{4}{|l|}{ COPD-Männer $(\mathbf{n}=\mathbf{2 4})$} & \multicolumn{2}{l|}{ COPD-Frauen (n = 23) } \\
\cline { 3 - 7 } & & $\boldsymbol{P}$ & $\mathbf{W}$ & $\mathrm{TE}$ & $\boldsymbol{p}$ & $\mathbf{W}$ & TE \\
\hline BMI & $\mathrm{kg} / \mathrm{m}^{2}$ & $1,90 \times 10^{-22}$ & 0,9511 & $\mathrm{H} 0$ & $7,41 \times 10^{-18}$ & 0,9147 & $\mathrm{H} 0$ \\
\hline E/B & Liter $/ \mathrm{kg}$ & $1,97 \times 10^{-4}$ & 0,9322 & $\mathrm{H} 0$ & $8,71 \times 10^{-11}$ & 0,9319 & $\mathrm{H} 0$ \\
\hline Hyd-FFM & $\%$ & $1,09 \times 10^{-1}$ & 0,9160 & $\mathrm{H} 0$ & $5,49 \times 10^{-3}$ & 0,9427 & $\mathrm{H} 0$ \\
\hline Phi & Grad $\left[^{\circ}\right]$ & $5,30 \times 10^{-3}$ & 0,9490 & $\mathrm{H} 0$ & $4,04 \times 10^{-3}$ & 0,9550 & $\mathrm{H} 0$ \\
\hline Xc & Ohm & $2,43 \times 10^{-1}$ & 0,9021 & $\mathrm{H} 0$ & $9,14 \times 10^{-2}$ & 0,8843 & $\mathrm{H} 0$ \\
\hline
\end{tabular}

$\mathrm{HO}=$ Nullhypothese (Normalverteilung); $\mathrm{H} 1=$ Alternativhypothese (keine Normalverteilung);

$\mathrm{TE}=$ Testentscheidung (anzunehmende Hypothese) 


\subsection{Beschreibung der Referenzpopulation}

Alters- und geschlechtsspezifische Referenzwerte aller Prüfgrößen aus einer Population gesunder und normalgewichtiger Probanden wurden von Fresenius Kabi (Bad Homburg) zur Verfügung gestellt.

Der Altersmedian der Referenzpopulation lag bei den Männern bei 56,90 Jahren mit einer Standardabweichung von 11,23 Jahren. Das mittlere Gewicht der Männer lag bei 78,84 Kg mit einer Standardabweichung von 9,31 Kg. Bei den Frauen lag das mittlere Gewicht bei 66,59 $\mathrm{Kg}$ mit einer Standardabweichung von 7,33 Kg.

Der mittlere BMI der Männer lag bei 25,22 kg/m². Bei Frauen war der mittlere BMI 24,92 kg/m².

Bezüglich der Parameter der Bioimpedanz wurden bei der Referenzpopulation folgende Mittelwerte gemessen:

- Intrazelluläres Wasser - Index ( ICW-I ): 8,82 Liter / $\mathrm{m}^{2}$ bei Männern und 6,18 Liter $/ \mathrm{m}^{2}$ bei Frauen

- Lean Tissue mass - Index ( LTM-I ): $19,14 \mathrm{~kg} / \mathrm{m}^{2}$ bei Männern und 12,46 $\mathrm{Kg} / \mathrm{m}^{2}$ bei Frauen

- Body Cell Mass - Index (BCM-I): 15,61 kg / $\mathrm{m}^{2}$ bei Männern und 11,62 $\mathrm{Kg} / \mathrm{m}^{2}$ bei Frauen

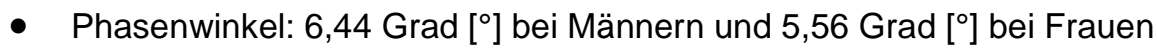

- ECM/BCM-Index: 0,63 Liter / kg bei Männern und 0,78 Liter / $\mathrm{kg}$ bei Frauen

Populationsdaten $\left(\mathrm{MW}_{\text {Ref }}=\right.$ Mittelwert; $\mathrm{ST}_{\text {Ref }}=$ Standardabweichung $)$

\begin{tabular}{|l|l|l|l|l|l|l|l|l|c|}
\hline \multirow{2}{*}{ Prüfgrösse } & \multirow{2}{*}{ Einheit } & \multicolumn{4}{|c|}{ Referenz-Männer (n= 292) } & \multicolumn{4}{|c|}{ Referenz-Frauen (n = 237) } \\
\cline { 3 - 10 } & $\mathrm{MW}_{\text {Ref }}$ & $\mathrm{ST}_{\text {Ref }}$ & Min & Max & $\mathrm{MW}_{\text {Ref }}$ & $\mathrm{ST}_{\text {Ref }}$ & Min & Max \\
\hline Alter & Jahre & 56,90 & 11,23 & 40,00 & 84,00 & 62,71 & 6,88 & 50,00 & 77,00 \\
\hline Körpergewicht & $\mathrm{kg}$ & 78,84 & 9,31 & 49,50 & 111,00 & 66,59 & 7,33 & 48,40 & 83,90 \\
\hline Körperlänge & $\mathrm{cm}$ & 176,67 & 7,63 & 150,00 & 119,40 & 163,42 & 6,09 & 146,50 & $\begin{array}{l}179,1 \\
0\end{array}$ \\
\hline
\end{tabular}

Prozentwerte $\left(\mathrm{MW}_{\text {Ref }}=\right.$ Mittelwert $; \mathrm{ST}_{\text {Ref }}=$ Standardabweichung $)$

\begin{tabular}{|l|l|l|l|l|l|l|l|l|c|}
\hline \multirow{2}{*}{ Prüfgrösse } & \multirow{2}{*}{ Einheit } & \multicolumn{4}{|c|}{ Referenz-Männer (n= 292) } & \multicolumn{3}{|c|}{ Referenz-Frauen (n = 237) } \\
\cline { 3 - 10 } & $\mathrm{MW}_{\text {Ref }}$ & $\mathrm{ST}_{\text {Ref }}$ & Min & Max & $\mathrm{MW}_{\text {Ref }}$ & $\mathrm{ST}_{\text {Ref }}$ & Min & Max \\
\hline ICW & \% von KG & 31,23 & 3,92 & 15,34 & 41,08 & 25,96 & 3,17 & 19,19 & 38,85 \\
\hline LTM & \% von KG & 67,87 & 11,27 & 21,69 & 96,44 & 52,46 & 9,21 & 33,06 & 89,53 \\
\hline BCM & \% von KG & 39,44 & 7,64 & 7,41 & 58,88 & 28,66 & 6,19 & 15,35 & 54,27 \\
\hline FFM & \% von KG & 76,75 & 7,78 & 43,64 & 97,12 & 34,52 & 6,67 & 9,26 & 48,46 \\
\hline
\end{tabular}


Index-Werte $\left(\mathrm{MW}_{\text {Ref }}=\right.$ Mittelwert; $\mathrm{ST}_{\text {Ref }}=$ Standardabweichung $)$

\begin{tabular}{|l|l|l|l|l|l|l|l|l|l|}
\hline \multirow{2}{*}{ Prüfgrösse } & \multirow{2}{*}{ Einheit } & \multicolumn{3}{|c|}{ Referenz-Männer (n = 292) } & \multicolumn{3}{|c|}{ Referenz-Frauen (n = 237) } \\
\cline { 3 - 10 } & & $\mathrm{MW}_{\text {Ref }}$ & $\mathrm{STA}_{\text {Ref }}$ & Min & Max & MW $_{\text {Ref }}$ & STA $_{\text {Ref }}$ & Min & Max \\
\hline ICW-I & Liter $/ \mathrm{m}^{2}$ & 8,82 & 1,25 & 4,42 & 12,12 & 6,18 & 0,74 & 3,94 & 9,03 \\
\hline $\mathrm{LTM}-\mathrm{I}$ & $\mathrm{kg} / \mathrm{m}^{2}$ & 19,14 & 3,23 & 6,24 & 28,05 & 12,46 & 1,95 & 7,42 & 20,12 \\
\hline $\mathrm{BCM}-\mathrm{I}$ & $\mathrm{kg} / \mathrm{m}^{2}$ & 15,61 & 2,16 & 2,13 & 16,92 & 11,12 & 1,68 & 10,08 & 21,19 \\
\hline FFM-I & $\mathrm{kg} / \mathrm{m}^{2}$ & 21,69 & 2,76 & 12,56 & 29,67 & 6,80 & 1,33 & 3,49 & 12,37 \\
\hline
\end{tabular}

Sonstige $\left(\mathrm{MW}_{\text {Ref }}=\right.$ Mittelwert $; \mathrm{ST}_{\text {Ref }}=$ Standardabweichung $)$

\begin{tabular}{|c|c|c|c|c|c|c|c|c|c|}
\hline \multirow{2}{*}{ Prüfgrösse } & \multirow{2}{*}{ Einheit } & \multicolumn{4}{|c|}{ Referenz-Männer (n = 292) } & \multicolumn{4}{|c|}{ Referenz-Frauen $(n=237$ ) } \\
\hline & & $\mathrm{MW}_{\text {Ref }}$ & STA $_{\text {Ref }}$ & Min & Max & $\mathrm{MW}_{\text {Ref }}$ & $\mathrm{STA}_{\mathrm{Ref}}$ & Min & Max \\
\hline BMI & $\mathrm{kg} / \mathrm{m}^{2}$ & 25,22 & 2,18 & 19,68 & 28,89 & 24,92 & 2,24 & 19,57 & 29,54 \\
\hline $\mathrm{E} / \mathrm{B}$ & Liter / kg & 0,63 & 0,16 & 0,43 & 2,45 & 0,78 & 0,13 & 0,46 & 1,32 \\
\hline Phi & $\operatorname{Grad}\left[{ }^{\circ}\right]$ & 6,44 & 0,82 & 2,61 & 8,78 & 5,56 & 0,68 & 3,77 & 9,15 \\
\hline
\end{tabular}

\subsection{Beschreibung der COPD-Population}

Die COPD-Männer waren 42,11 - 81,57, im Mittel 67,87 Jahre alt während die COPD-Frauen 50,17 77,19, im Mittel 63,82 Jahre alt waren. Das Körpergewicht der Männer mit COPD lag zwischen 40,50 Kg und 121,0 Kg, im Mittel 75,69 Kg mit einer Standardabweichung von 20,92 Kg. Das Körpergewicht der Frauen mit COPD lag zwischen 38,70 und $104,50 \mathrm{Kg}$, im Mittel 60,30 Kg mit einer Standardabweichung von $16,07 \mathrm{Kg}$.

Der BMI der COPD-Männer lag zwischen 14,88 und 40,90 kg/m ${ }^{2}$, im Mittel bei $25,54 \mathrm{~kg} / \mathrm{m}^{2}$. Bei Frauen war der BMI zwischen 15,50 und $38,85 \mathrm{~kg} / \mathrm{m}^{2}$, im Mittel bei $23,79 \mathrm{~kg} / \mathrm{m}^{2}$.

Populationsdaten $\left(\mathrm{MW}_{\mathrm{COPD}}=\right.$ Mittelwert; $\mathrm{ST}_{\mathrm{COPD}}=$ Standardabweichung $)$

\begin{tabular}{|l|l|l|l|l|l|l|l|l|l|}
\hline \multirow{2}{*}{ Prüfgrösse } & \multirow{3}{*}{ Einheit } & \multicolumn{4}{|l|}{ COPD-Männer (n = 24) } & \multicolumn{3}{l|}{ COPD-Frauen (n = 23) } \\
\cline { 3 - 10 } & & $\mathrm{MW}_{\text {COPD }}$ & $\mathrm{ST}_{\text {COPD }}$ & Min & Max & MW $_{\text {COPD }}$ & ST $_{\text {COPD }}$ & Min & Max \\
\hline Alter & Jahre & 67,87 & 9,64 & 42,11 & 81,57 & 63,82 & 6,82 & 50,17 & 77,19 \\
\hline Körpergewicht & $\mathrm{kg}$ & 75,69 & 20,92 & 40,50 & 121,00 & 60,30 & 16,07 & 38,70 & 104,5 \\
\hline Körperlänge & $\mathrm{cm}$ & 171,70 & 6,48 & 164,00 & 189,00 & 159,37 & 7,02 & 145,00 & 176,0 \\
\hline
\end{tabular}


Prozentwerte $\left(\mathrm{MW}_{\mathrm{COPD}}=\right.$ Mittelwert $\mathrm{ST}_{\mathrm{COPD}}=$ Standardabweichung $)$

\begin{tabular}{|l|l|l|l|l|l|l|l|l|l|}
\hline \multirow{2}{*}{ Prüfgrösse } & \multirow{2}{*}{ Einheit } & \multicolumn{4}{|l|}{ COPD-Männer (n = 24) } & \multicolumn{4}{l|}{ COPD-Frauen (n = 23) } \\
\cline { 3 - 10 } & & $M^{\text {COPD }}$ & $\mathrm{ST}_{\text {COPD }}$ & Min & Max & MW $_{\text {COPD }}$ & ST $_{\text {COPD }}$ & Min & Max \\
\hline ICW & \% von KG & 25,46 & 5,18 & 18,20 & 36,73 & 23,02 & 4,17 & 16,96 & 33,02 \\
\hline LTM & \% von KG & 51,65 & 15,34 & 30,51 & 84,98 & 44,30 & 12,33 & 26,26 & 73,58 \\
\hline BCM & \% von KG & 27,53 & 9,34 & 15,17 & 49,09 & 21,99 & 7,34 & 12,44 & 38,74 \\
\hline FFM & \% von KG & 66,96 & 12,05 & 51,62 & 92,62 & 60,84 & 9,22 & 46,55 & 82,53 \\
\hline
\end{tabular}

Index-Werte $\left(\mathrm{MW}_{\mathrm{COPD}}=\right.$ Mittelwert; $\mathrm{ST}_{\mathrm{COPD}}=$ Standardabweichung $)$

\begin{tabular}{|l|l|l|l|l|l|l|l|l|l|}
\hline \multirow{2}{*}{ Prüfgrösse } & \multirow{2}{*}{ Einheit } & \multicolumn{4}{|l}{ COPD-Männer (n = 24) } & \multicolumn{4}{l|}{ COPD-Frauen (n = 23) } \\
\cline { 3 - 10 } & & $\mathrm{MW}_{\text {COPD }}$ & $\mathrm{ST}_{\text {COPD }}$ & Min & Max & MW $_{\text {COPD }}$ & $\mathrm{ST}_{\text {COPD }}$ & Min & Max \\
\hline ICW-I & Liter $/ \mathrm{m}^{2}$ & 6,59 & 1,40 & 4,53 & 10,41 & 4,89 & 0,94 & 3,63 & 7,09 \\
\hline LTM-I & $\mathrm{kg} / \mathrm{m}^{2}$ & 13,14 & 3,01 & 8,56 & 20,43 & 9,27 & 1,95 & 6,28 & 14,08 \\
\hline $\mathrm{BCM}-\mathrm{I}$ & $\mathrm{kg} / \mathrm{m}^{2}$ & 7,03 & 2,09 & 3,87 & 12,27 & 4,62 & 1,36 & 2,57 & 7,87 \\
\hline FFM-I & $\mathrm{kg} / \mathrm{m}^{2}$ & 17,38 & 3,56 & 11,87 & 26,69 & 12,97 & 2,34 & 10,16 & 17,89 \\
\hline
\end{tabular}

Sonstige $\left(\mathrm{MW}_{\mathrm{COPD}}=\right.$ Mittelwert $; \mathrm{ST}_{\mathrm{COPD}}=$ Standardabweichung $)$

\begin{tabular}{|l|l|l|l|l|l|l|l|l|l|}
\hline \multirow{2}{*}{ Prüfgrösse } & \multirow{2}{*}{ Einheit } & \multicolumn{4}{|l|}{ COPD-Männer (n = 24) } & \multicolumn{3}{l|}{ COPD-Frauen (n = 23) } \\
\cline { 3 - 11 } & & $\mathrm{MW}_{\text {COPD }}$ & $\mathrm{ST}_{\text {COPD }}$ & Min & Max & $\mathrm{MW}_{\text {COPD }}$ & $\mathrm{ST}_{\text {COPD }}$ & Min & Max \\
\hline $\mathrm{BMI}$ & $\mathrm{kg} / \mathrm{m}^{2}$ & 25,54 & 6,52 & 14,88 & 40,90 & 23,79 & 6,26 & 15,50 & 38,85 \\
\hline $\mathrm{E} / \mathrm{B}$ & Liter $/ \mathrm{kg}$ & 1,03 & 0,22 & 0,62 & 1,39 & 1,09 & 0,30 & 0,68 & 1,70 \\
\hline Phi & Grad $\left[^{\circ}\right]$ & 4,49 & 0,89 & 2,89 & 6,51 & 4,11 & 0,76 & 2,89 & 5,56 \\
\hline
\end{tabular}

Bezüglich der Parameter der Bioimpedanz wurden bei der Referenzpopulation folgende Mittelwerte gemessen:

- Intrazelluläres Wasser - Index ( ICW-I ): 6,59 Liter $/ \mathrm{m}^{2}$ bei Männern und 4,89 Liter $/ \mathrm{m}^{2}$ bei Frauen

- Lean Tissue mass - Index ( LTM-I ): 13,14 kg / $\mathrm{m}^{2}$ bei Männern und 9,27 $\mathrm{Kg} / \mathrm{m}^{2}$ bei Frauen

- Body Cell Mass - Index (BCM-I): 7,03 kg / $\mathrm{m}^{2}$ bei Männern und 4,62 $\mathrm{Kg} / \mathrm{m}^{2}$ bei Frauen

- Phasenwinkel: 4,49 $\mathrm{Grad}\left[{ }^{\circ}\right]$ bei Männern und 4,11 $\mathrm{Grad}\left[{ }^{\circ}\right]$ bei Frauen

- ECM/BCM-Index: 1,03 Liter / kg bei Männern und 1,09 Liter / kg bei Frauen 


\section{Ergebnisse}

\subsection{Lean Tissue mass - Index ( LTM - I), die Magermasse}

LTM stellt die fettfreie Masse des Körpers dar. Im wesentlichen wird die Magermasse von der Muskulatur, den Organen, dem Skelettsystem und dem ZNS gebildet. Mit Lean Tissue Mass als fettfreier Körpermasse lässt sich die Muskelmasse abschätzen. Mittels bioelektrischem Impedanzverfahren gelingt dies mit geringem Zeit-Kostenaufwand und ohne Patienten-Belastung. Bei den COPD-Patienten nützen LTM-Werte zur Beurteilung einer möglichen Mangelernährung.

In unserer Untersuchung hatten 73,91\% der Frauen und 70,83\% der Männer eine verminderte Magermasse, dargestellt durch den LTM-Index. Auf der anderen Seite wiesen 21,73\% der Frauen und 29,17\% der Männer einen normalen LTM-I auf. Lediglich bei einer Patientin (4,34\%) wurde ein großer LTM-I gemessen. Die Messungen waren statistisch signifikant $(p<0,001)$.

\section{LTM - Index bei Frauen mit COPD im Vergleich zur Referenzpopulation}

- COPD, ----10\% Quantile, ---- $90 \%$ Quantile

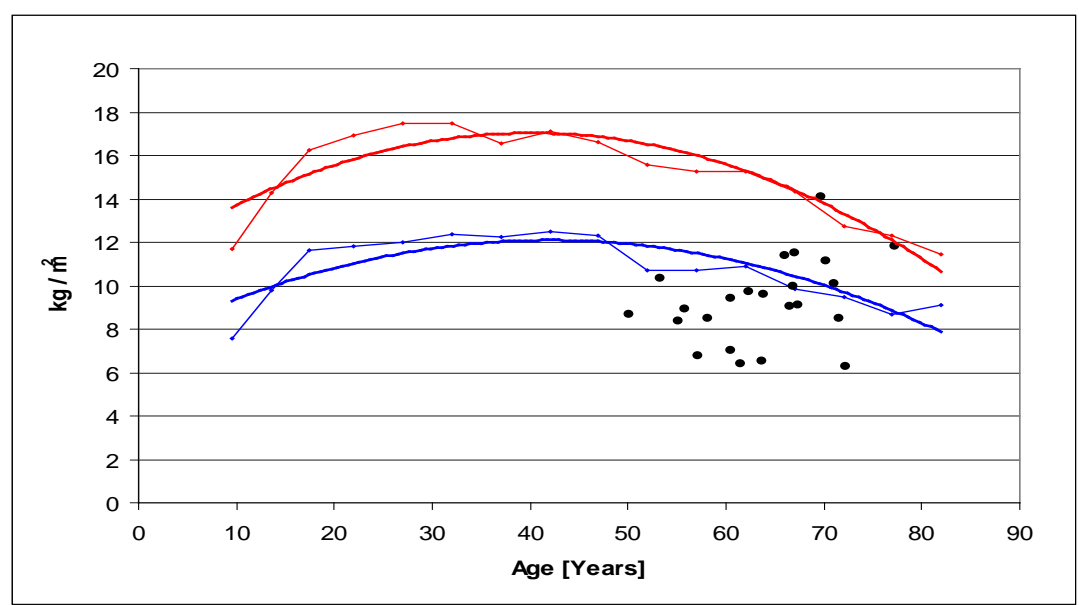




\section{LTM - Index bei Männern mit COPD im Vergleich zur Referenzpopulation}

- COPD, ----10 \% Quantile, ---- 90 \% Quantile

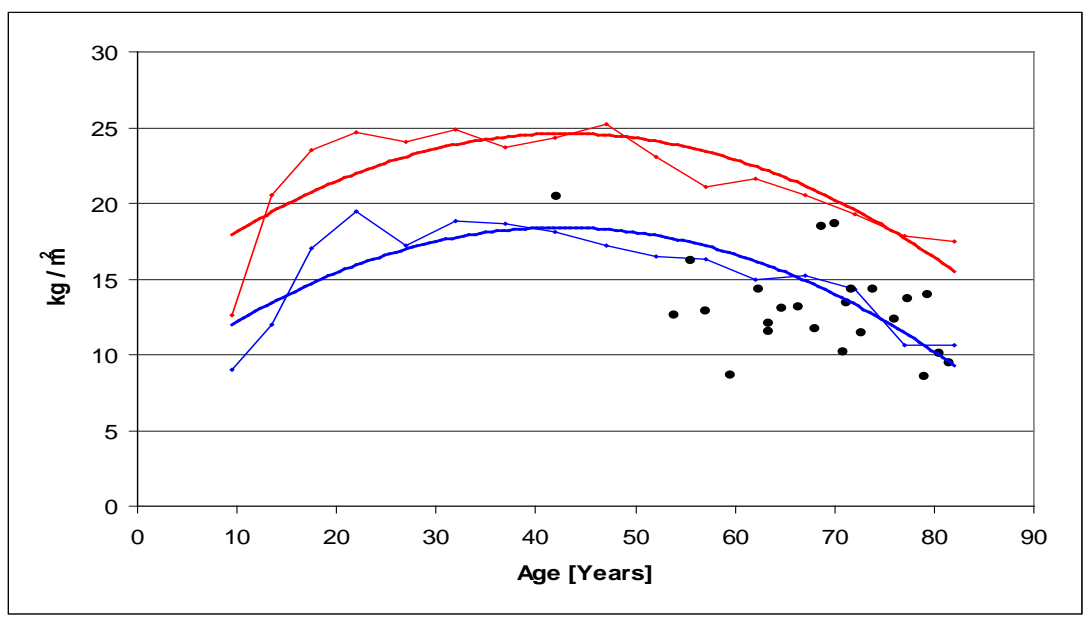

\subsection{Body Cell Mass - Index (BCM - I)}

Body Cell Mass, BCM (Körperzellmasse) ist die Summe aller aktiv am Stoffwechsel beteiligten Zellen. Sie ist kein anatomisches, sondern ein funktionell definiertes Kompartiment und besteht vor allem aus den Zellen der Muskulatur. Die BCM ist die Regelgröße des Energieverbrauches und bestimmt den Kalorienbedarf des Organismus. 78,26\% der Frauen und 75\% der Männer hatten eine reduzierte Körperzellmasse, also eine reduzierte Muskelmasse. 21,74\% der Frauen und 25\% der Männer wiesen eine normale BCM auf. Die Messungen waren statistisch signifikant $(p<0,05)$.

\section{BCM - Index bei Frauen mit COPD im Vergleich zur Referenzpopulation}

- COPD, ----10\% Quantile, --- $90 \%$ Quantile

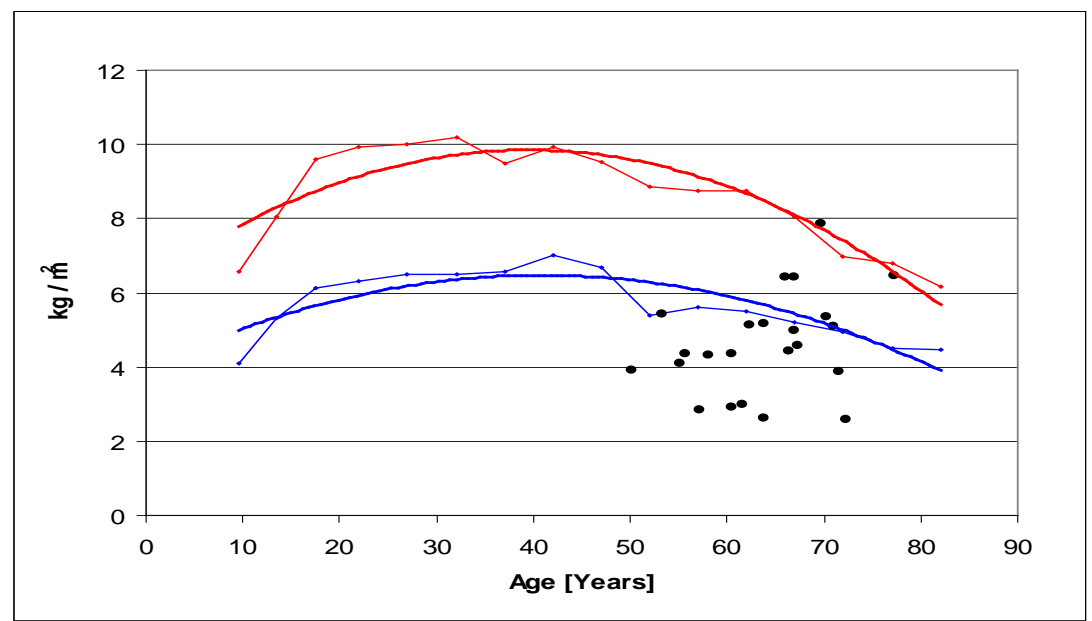




\section{BCM - Index bei Männern mit COPD im Vergleich zur Referenzpopulation}

- COPD, ----10\% Quantile, ---- $90 \%$ Quantile

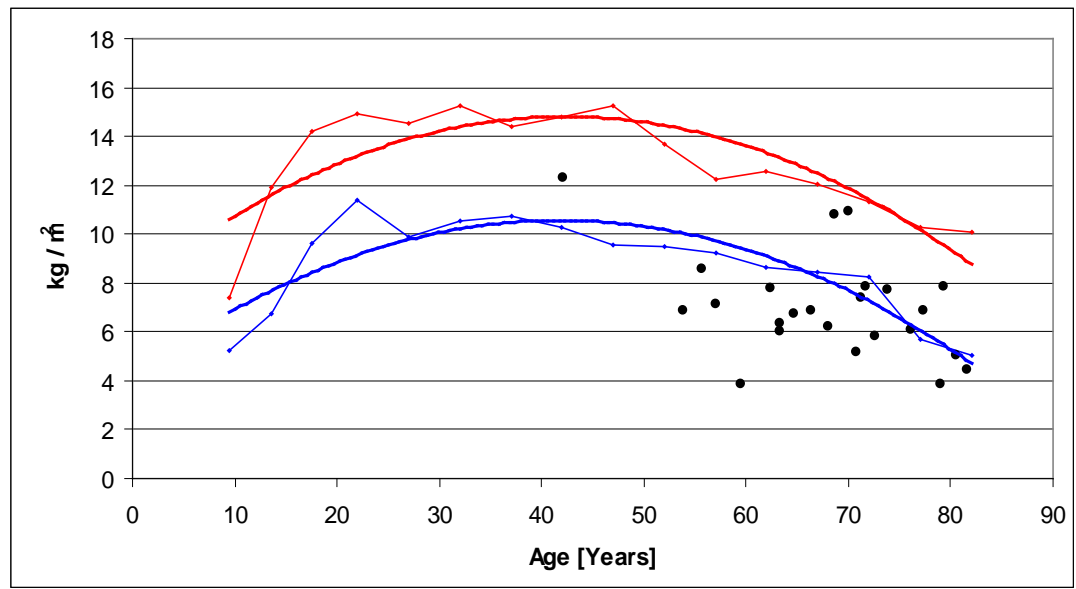

\subsection{Phasenwinkel}

Der Phasenwinkel ist ein Maß für die Zelldichte und für die Membranintegrität der Zellen. Desweiteren lässt er Aussagen über den Zustand der Zelle zu. Er ist direkt proportional zur Gesamtoberfläche und zum elektrischen Potential der darin enthaltenen Membranen. In unserer Studie geht hervor, dass 82,60\% der Frauen und 75\% der Männer einen erniedrigten Phasenwinkel aufweisen $(p<0,05)$. Bei 13,04 \% der Frauen und bei $25 \%$ der Männer wurde ein normaler Phasenwinkel gemessen. Bei einer Patientin $(4,34 \%)$ war der Phasenwinkel erhöht.

\section{Phasenwinkel bei Frauen mit COPD im Vergleich zur Referenzpopulation}

- COPD, ----10\% Quantile, ---- $90 \%$ Quantile

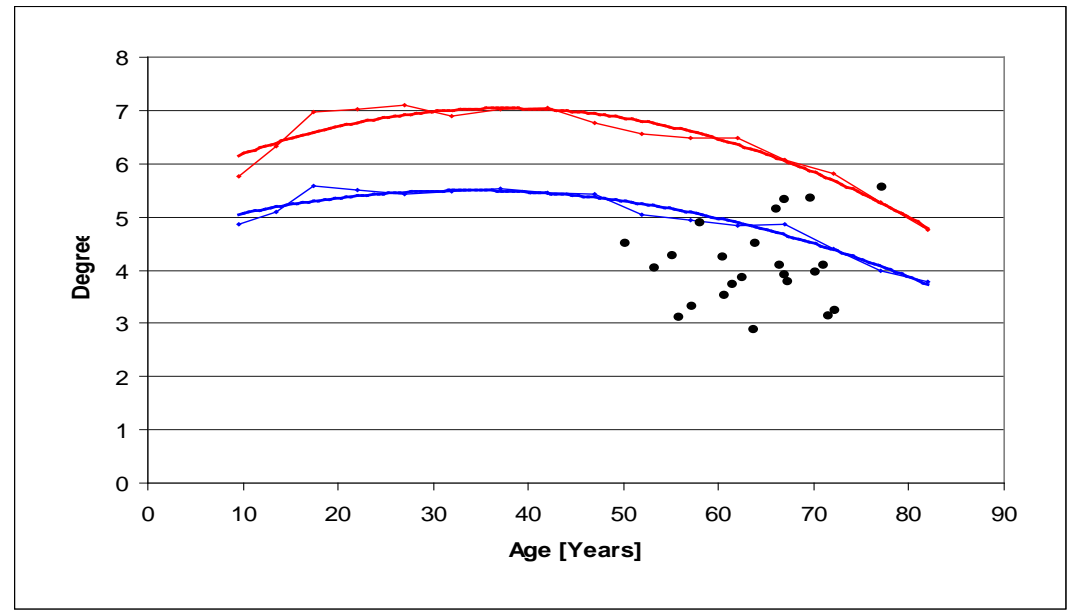




\section{Phasenwinkel bei Männern mit COPD im Vergleich zur Referenzpopulation}

- COPD, ----10\% Quantile, ---- $90 \%$ Quantile

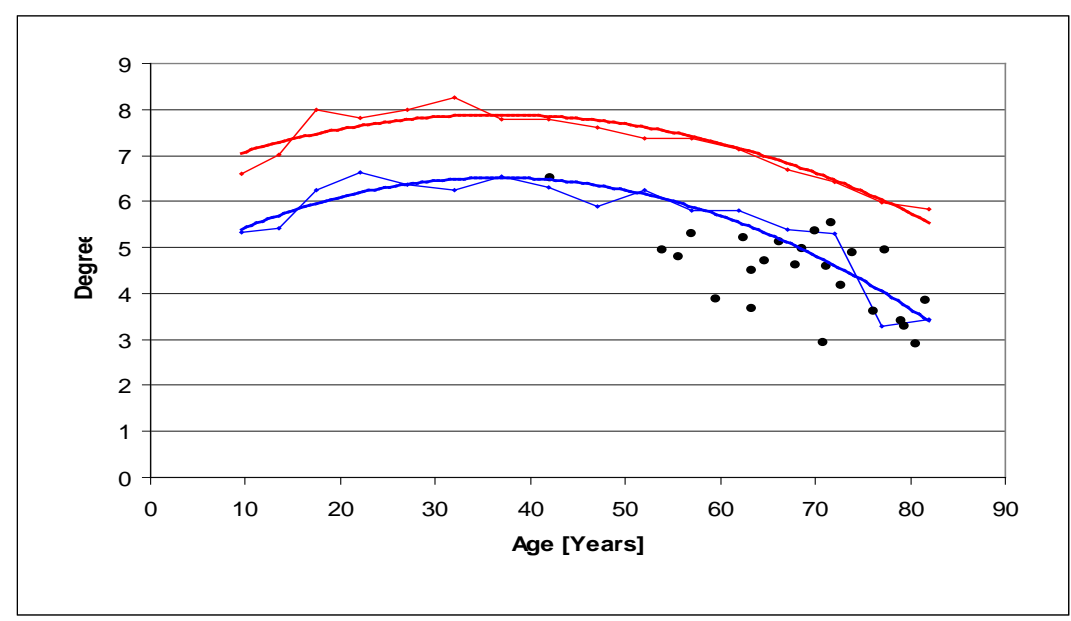

\subsection{Intrazelluläres Wasser, ICW - Index}

Intrazelluläres Wasser wird als Marker des Hydratationsgrades der Zellen bezeichnet. Die Menge des intrazellulären Körperwassers eines Organismus wird in erster Linie über die Körperzellmasse BCM und damit primär über die Muskelmenge determiniert. Ein Flüssigkeitsverlust von 1-2\% des Körpergewichts beeinträchtigt bereits die körperliche und geistige Leistungsfähigkeit. In unserer Untersuchung wurde bei 73,91\% der Frauen und 70,83\% der Männer ein pathologisch verminderter Hydratationsgrad der Körperzellmasse gemessen. 21,73\% der Frauen und 16,66\% der Männer wiesen eine normale Hydratation auf. Bei einer Patientin (4,34\%) war das intrazelluläre Wasser erhöht.

Die Messungen waren bei Männern statistisch nicht signifikant $(p=0,391)$. Bei Frauen betrug der $p$ Wert 0,085, was uns ebenfalls keine statistische Signifikanz ergibt. 
Intrazelluläres Wasser - Index bei Frauen mit COPD im Vergleich zur Referenzpopulation - COPD, ----10\% Quantile, ---- $90 \%$ Quantile

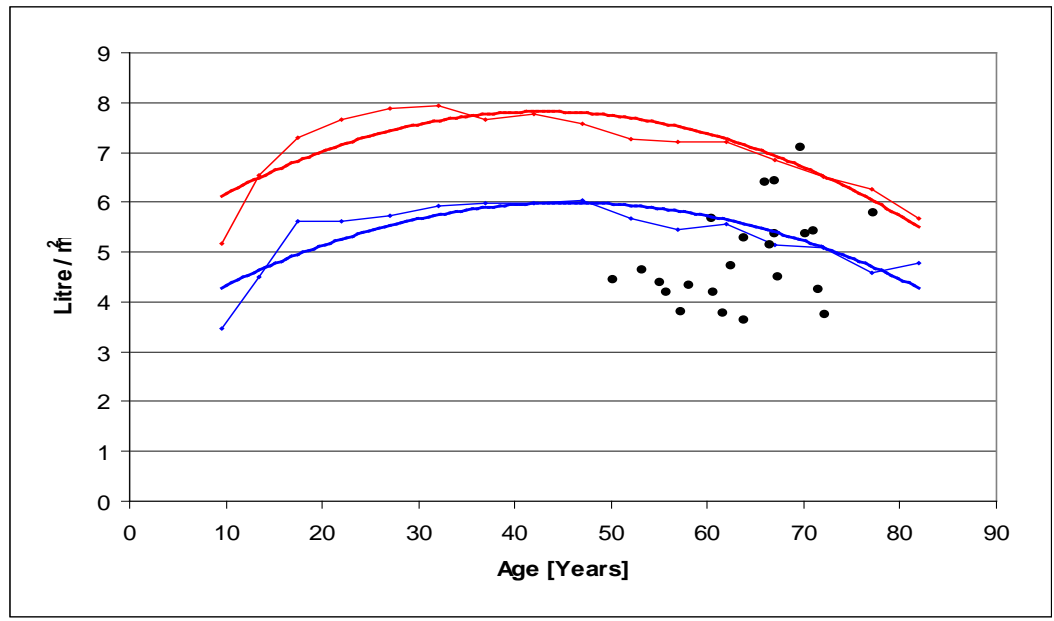

Intrazelluläres Wasser - Index bei Männern mit COPD im Vergleich zur Referenzpopulation - COPD, ----10\% Quantile, ---- 90 \% Quantile

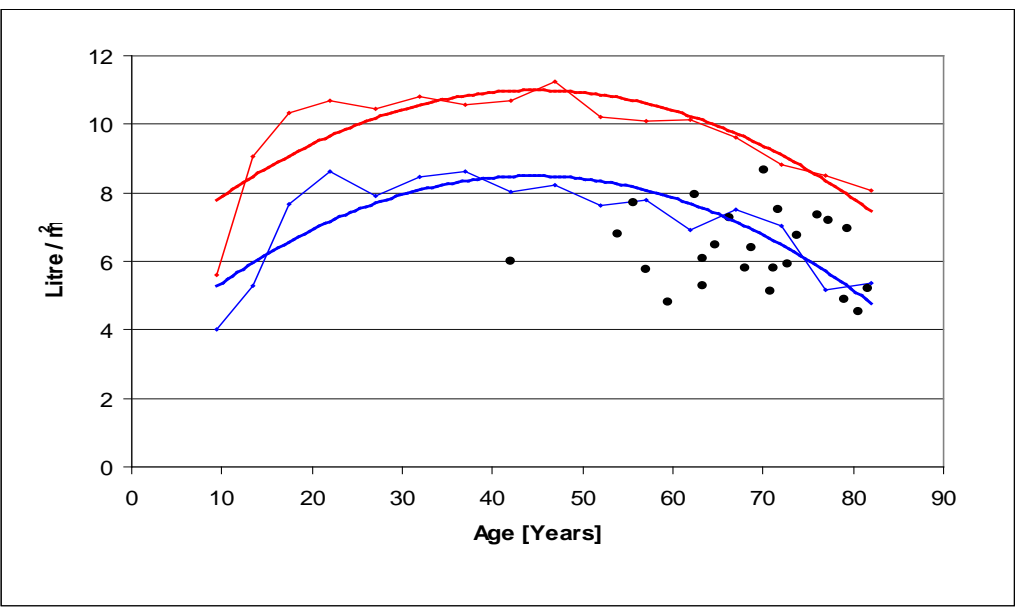




\subsection{ECM / BCM - Index}

Der ECM/BCM-Index ist der zweitwichtigste Parameter zur Beurteilung des Ernährungszustandes. Beim Gesunden ist die Body Cell Mass (BCM) stets deutlich größer als die Extrazelluläre Masse - ECM, so dass der Index $<1$ ist. Ein ECM/BCM-Index $>1$ ist für die Beurteilung einer Malnutrition von grosser Bedeutung. In unserem Kollektiv wurde bei $69,56 \%$ der Frauen und bei $75 \%$ der Männer ein ECW/ BCM Index $>1$ gemessen. Bei den anderen Patienten (30,44\% der Frauen und 25\% der Männer) lag der ECM/BCM-Index im Normbereich. Die Messungen waren statistisch signifikant. $(p<0,001)$.

ECM I BCM - Index bei Frauen mit COPD im Vergleich zur Referenzpopulation

- COPD, ----10\% Quantile, ---- $90 \%$ Quantile

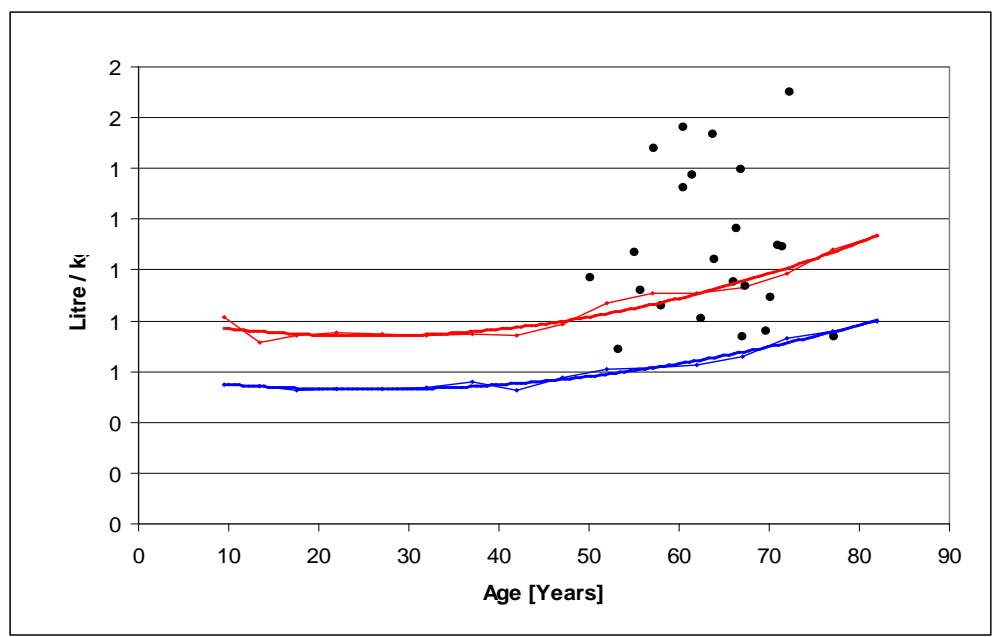

ECM I BCM - Index bei Männern mit COPD im Vergleich zur Referenzpopulation - COPD, ----10\% Quantile, ---- $90 \%$ Quantile

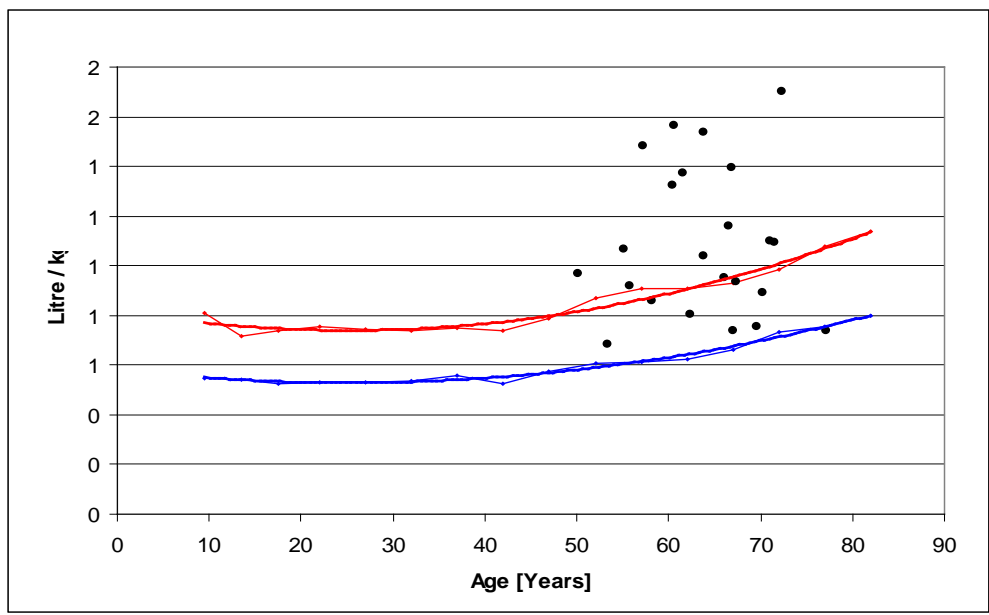




\subsection{Body mass index, BMI}

In unserer Untersuchung wiesen 30,78\% der Frauen einen normalen BMI auf; bei 26,08\% war der BMI erhöht und bei $43.47 \%$ der Patientinen wurden erniedrigte BMI-werte gemessen. Bei Männern ist die Situation ähnlich: 37,50\% der COPD-Männer hatten einen normalen BMI; bei 29,16\% waren die Werte erhöht und bei 33,33\% war der BMI im Vergleich zur Referenzpopulation erniedrigt.

\section{BMI bei Frauen mit COPD im Vergleich zur Referenzpopulation}

- COPD, ----10\% Quantile, ---- 90 \% Quantile

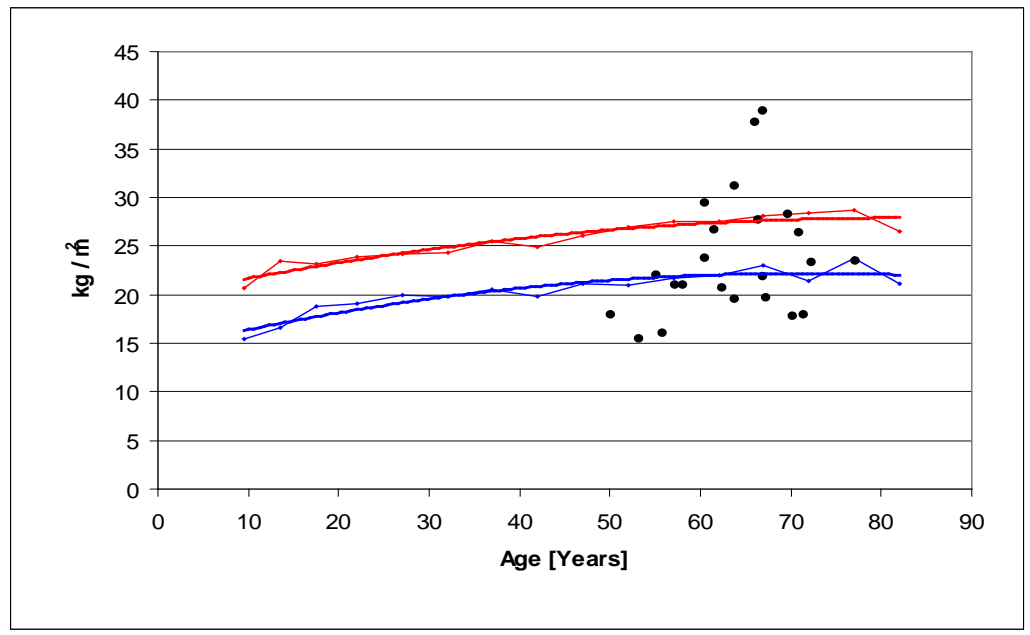

BMI bei Männern mit COPD im Vergleich zur Referenzpopulation

- $\quad$ COPD, ----10 \% Quantile, ---- 90 \% Quantile

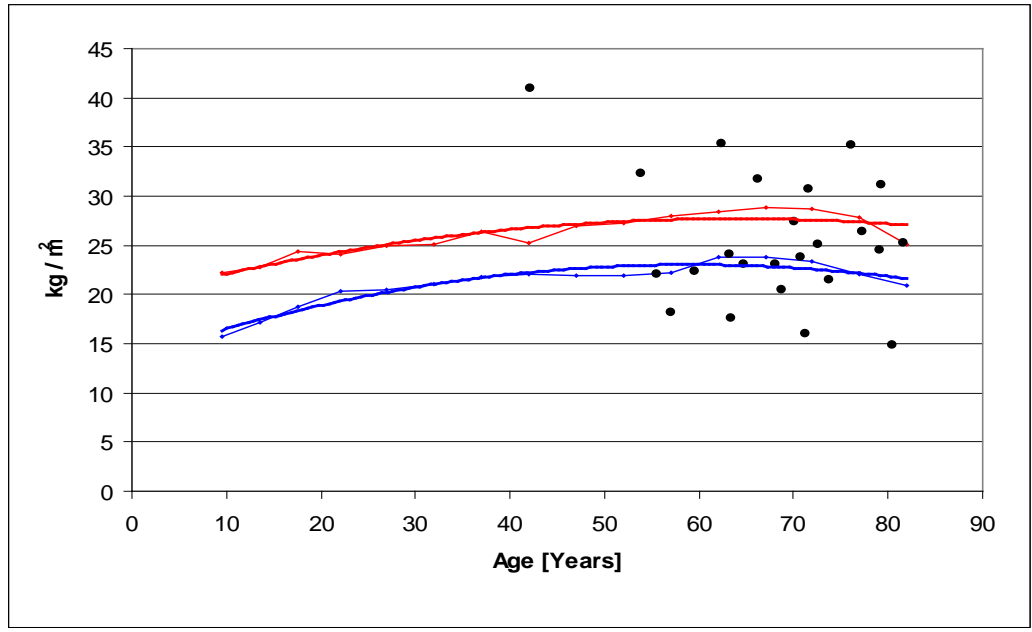




\subsection{Gewicht bei COPD - Patienten}

Weiterhin haben wir das Gewicht von COPD-Patienten analysiert. Es ergaben sich folgende Ergebnisse: 33,33\% der COPD-Männer waren untergewichtig; 41,60\% hatten ein normales Gewicht und $25 \%$ waren übergewichtig.

Der größte Teil der COPD-Patientinen war untergewichtig: 13 Patientinen, 56,52\%.

$26,08 \%$ hatten ein normales Gewicht und $17,39 \%$ waren übergewichtig.

Gewicht bei Frauen mit COPD im Vergleich zur Referenzpopulation

- COPD, ----10\% Quantile, ---- 90 \% Quantile

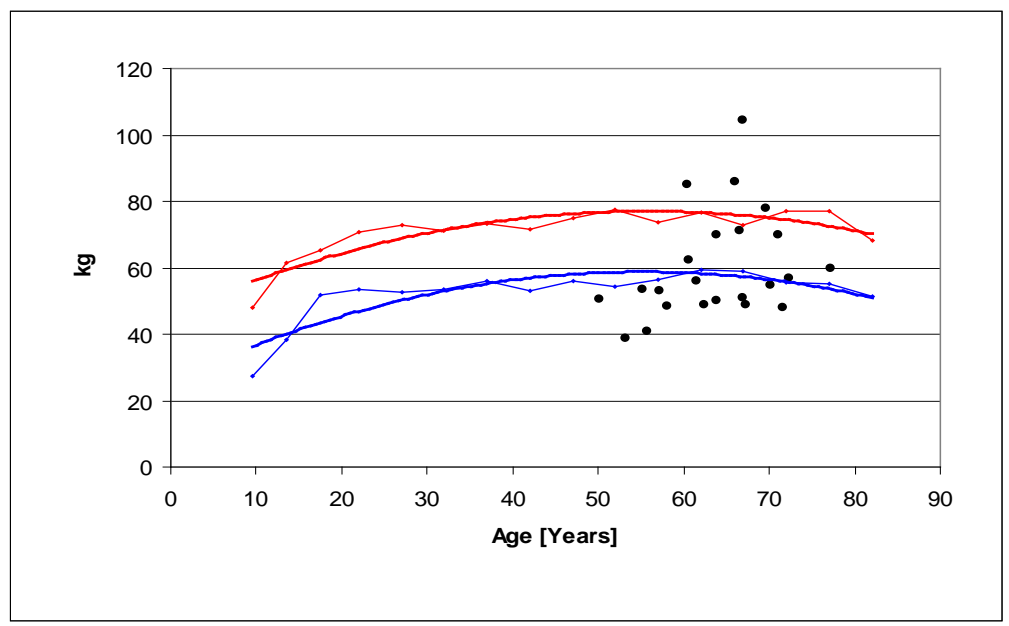

Gewicht bei Männern mit COPD im Vergleich zur Referenzpopulation

- COPD, ----10\% Quantile, ---- 90 \% Quantile

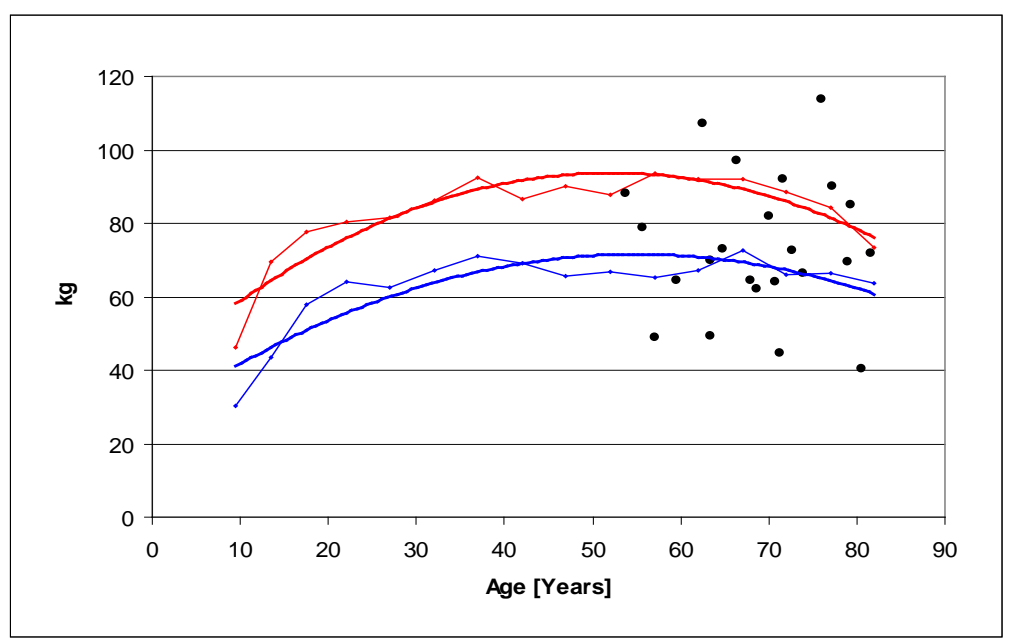




\subsection{FEV1 versus BCM}

Im Verlauf der Untersuchung haben wir versucht zu beweisen, dass eine Korrellation zwischen den Mittelwerten (MW) von BCM und den Mittelwerten von FEV1 bei den Frauen mit COPD bestehet.

Bei 12 Patientinen war der gemessene BCM-I unter dem MW $\mathrm{MW}_{\text {COPD-Frauen }}\left(4,62 \mathrm{~kg} / \mathrm{m}^{2}\right) .75 \%$ von diesen Frauen hatten ein FEV1 unter dem gemessenen Mittelwert - $530 \mathrm{ml}$ und lediglich 25\% der Patientinen hatten ein FEV1 > $530 \mathrm{ml}$.

Bei den anderen 11 Frauen mit COPD war der BCM-I größer als 4,62 kg/m ${ }^{2}$. Diese Patientinen schneiden lungenfunktionell besser ab. Bei 81\% wurden FEV1-Werte von über $530 \mathrm{ml}$ gemessen. 19\% von diesen Patientinen wiesen ein niedriges FEV1 $(<530 \mathrm{ml})$ auf.

Die FEV1-Werte sind deutlich besser bei den COPD-Patienten, die mehr Muskelmasse aufweisen im Vergleich zur Patienten mit einer reduzierten Körperzellmasse.

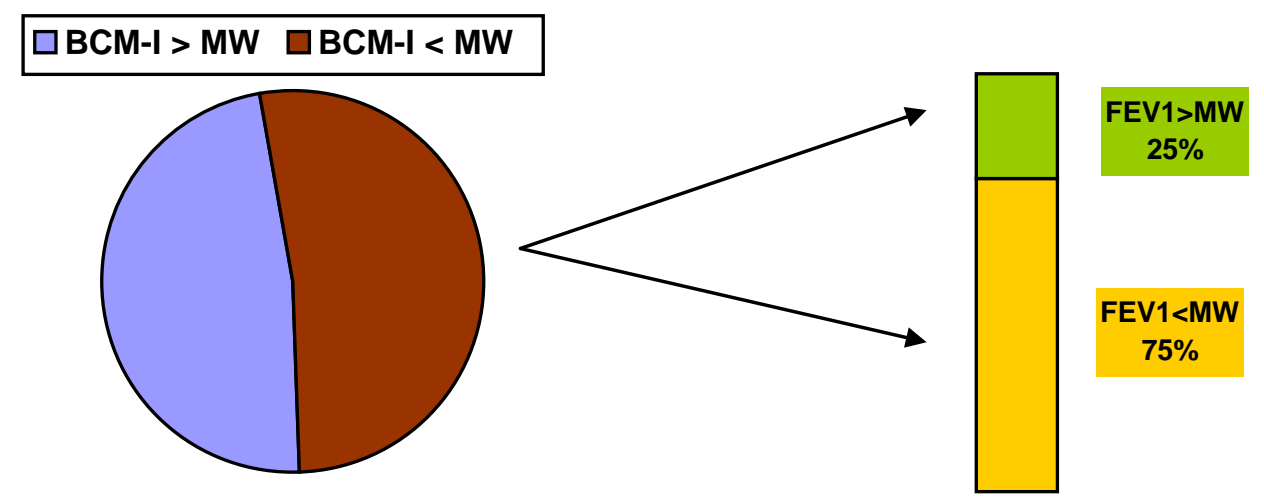

Abb. 14.1. 75\% der Patientinen mit niedrigem BCM-I haben ein reduziertes FEV1 ( $\left.<530 \mathrm{ml}=M W_{\text {CoPD-Frauen }}\right)$

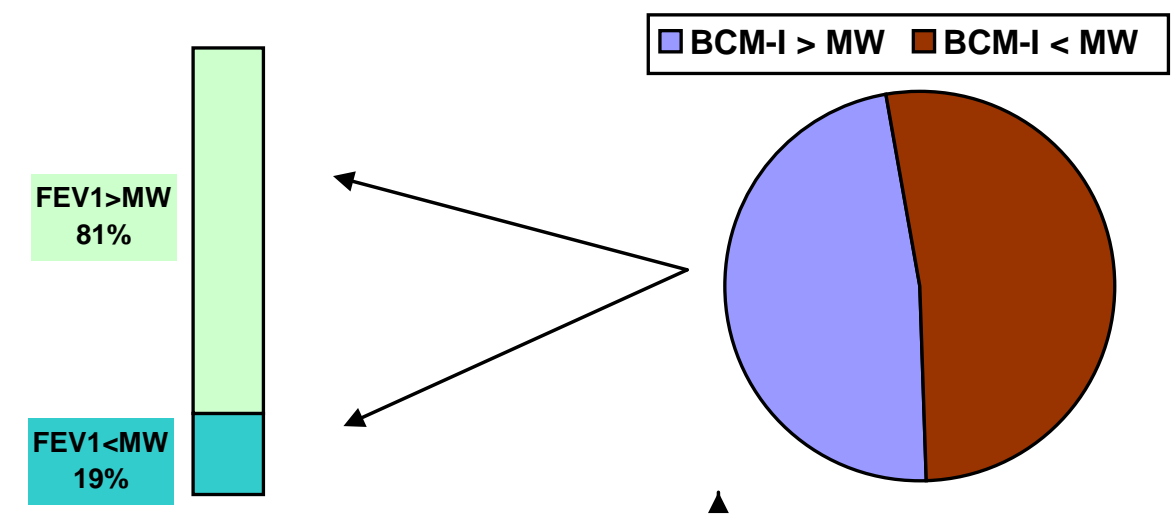

Abb. 14.2. $81 \%$ der COPD-Frauen mit besserem BCM-I wiesen ein erhöhtes FEV1 $\left(>530 \mathrm{ml}=\mathrm{MW}_{\text {COPD- }}\right.$ Frauen) 
Bei Männern waren die Ergebnisse ähnlich. Bei 14 Patienten war der gemessene BCM-I unter dem MW ${ }_{\text {COPD-Männer }}\left(7,03 \mathrm{~kg} / \mathrm{m}^{2}\right) .86 \%$ von diesen Männern hatten ein FEV1 unter dem Mittelwert - $880 \mathrm{ml}$.

Die Männer, die mehr Muskelmasse hatten (BCM-Index größer als 7,03 kg/m ${ }^{2}$ ), wiesen eine bessere pulmonale Leistung, dargestellt durch FEV1, auf. Bei 80\% wurden FEV1-Werte von über 880ml gemessen und nur 20\% wiesen ein niedrigeres FEV1 $(<880 \mathrm{ml})$ auf.

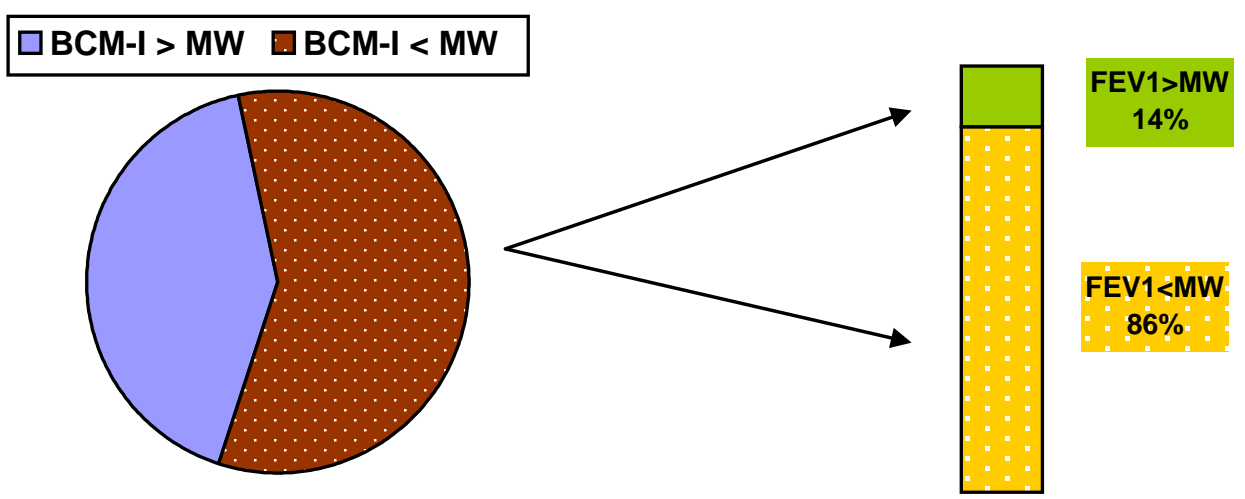

Abb. 14.1. 86\% der Patienten mit niedrigem BCM-I haben ein reduziertes FEV1 (<880mI =MW

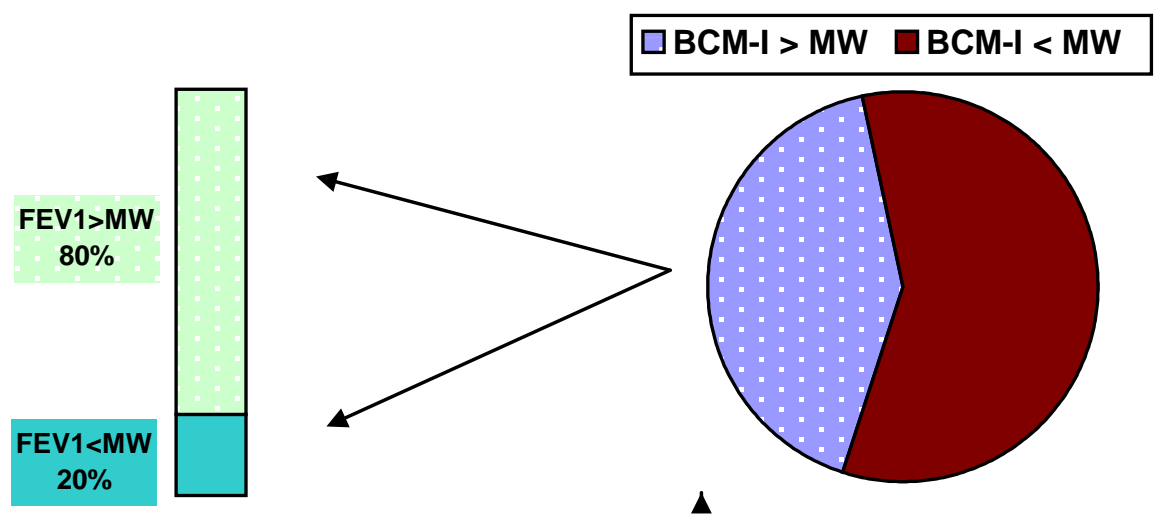

Abb. 14.2. 80\% der Männer mit besserem BCM-I wiesen ein erhöhtes FEV1 ( $\left.>880 m l=M W_{\text {COPD-Männern }}\right)$ 


\section{$\underline{\text { 5. Diskussion }}$}

In den letzten Jahren ist zunehmend deutlich geworden, dass es sich bei der COPD nicht um eine reine Lungenerkrankung handelt, sondern dass multiple systemische Veränderungen vorliegen. Insbesondere die systemische Inflammation und die Belastung mit Sauerstoffradikalen führen zu Veränderungen in der Muskulatur, im Endokrinium und in den Knochen und Gefäßen.

Der Verlust an Muskelmasse, verursacht durch unterschiedliche Faktoren, hat einen direkten Einfluss auf die Belastbarkeit der COPD-Patienten. Sowohl der Gewichtsverlust als auch ein Verlust an Muskelmasse wirken sich ungünstig auf die Mortalität und Morbidität von COPD-Patienten aus [8].

In dieser Arbeit wurde die Körperzusammensetzung von 47 COPD-Patienten (24 Männer und 23 Frauen) mittels Bioimpedanzanalyse - BIA bestimmt. Die Beurteilung des pathologischen Ernährungsund Trainingszustandes erfolgte durch Bestimmung von Phasenwinkel, ECM/BCM, Muskelmasse und Gesamtkörperwasser. Die Messung der meisten Parameter ergab ein statistisch signifikantes Resultat $(p<0.05)$.

\subsection{Lean tissue mass ( LTM ) - die Magermasse}

LTM stellt die fettfreie Masse des Körpers dar. Die Lean tissue mass wird von der Muskulatur, den Organen, dem Skelettsystem und dem ZNS gebildet. Die morphologisch sehr unterschiedlichen Organsysteme sind funktionell identisch aufgebaut und bestehen aus Zellen, in denen Stoffwechselarbeit und Syntheseleistungen durchgeführt werden, sowie aus extrazellulärer Flüssigkeit und Matrixsubstanz, mit deren Hilfe der Substrattransport und Stoffaustausch stattfindet.

Die Komponenten der Magermasse sind die Körperzellmasse - BCM, die Summe aller aktiv am Stoffwechsel beteiligten Zellen und die extrazelluläre Masse - ECM (Stützgewebe und Transport). Es gibt somit eine enge Korelation zwischen Lean tissue mass und Körperzellmasse.

Im Vergleich zu unseren Referenzpopulationen wiesen die COPD-Patienten eine verminderte Magermasse auf. Der Mittelwert des LTM-l's bei der COPD - Population beträgt 13,14 Kg/ $\mathrm{m}^{2}$ bei Männer und $9,27 \mathrm{~kg} / \mathrm{m}^{2}$ bei Frauen. In den Messungen der Referenzpopulationen zeigten sich deutlich höhere

Mittelwerte: $19,14 \mathrm{~kg} / \mathrm{m}^{2}$ bei Männer und $12,46 \mathrm{~kg} / \mathrm{m}^{2}$ bei Frauen. Prozentuall hatten $73,91 \%$ der Frauen und 70,83\% der Männer eine verminderte fettfreie Masse - dargestellt durch LTM - I $(p<0,001)$.

In der Literatur wird bei COPD-Patienten auch eine Inzidenz von 40-60\% von Untergewicht bzw. Mangelernährung angegeben [12]. Die Ursache des Untergewichts bzw. des Gewichtsverlusts ist bislang noch unklar. Im Allgemeinen ist der Gewichtsverlust, insbesondere der Verlust an Muskelmasse, jedoch das Ergebnis einer negativen Energiebilanz. Die erhöhte Atemarbeit ist eine der wesentlichen Ursachen für einen höheren Ruhe-Energieverbrauch bei respiratorisch eingeschränkten Patienten. Im Gegensatz zu Gesunden, deren Gesamtenergie für die Atmung in Ruhe ca. 2-3\% beträgt, benötigen Patienten mit COPD aufgrund der verminderten Elastizität des Thorax und der mechanisch ungünstigeren Ausgangslage bei Überblähung deutlich mehr Energie [12]. 
Parallel dazu könnte der Verlust an Muskelmasse eine andere Genese habenwie z.B. die systemische Inflammation. Hierbei spielen neben der direkten Aktivierung von Neutrophilen und Makrophagen die Imbalance zwischen Oxidanzien und Antioxidanzien und das fehlende Gleichtgewicht zwischen Proteasen und Antiproteasen eine bedeutsame Rolle.

Es gibt Studien, die zeigen dass auch bei stabilen COPD-Patienten die Serumspiegel einiger inflammatorischer Zytokine erhöht ist und diese für einen Hypermetabolismus verantwortlich sind. Insbesondere der Tumor-Nekrose-Faktor - (TNF $\alpha$ ) wurde untersucht. Es zeigte sich, dass Patienten mit Untergewicht und Gewichtsverlust höhere Werte von TNF- $\alpha$ aufweisen als Gewichtsstabile [31].

\subsection{BCM - Zu wenig Körperzellmasse bei den Patienten mit COPD}

Der Verlust von Körperzellmasse, $d$. h. Verlust von metabolisierenden und kontraktilen Geweben gilt als Systemmanifestation der COPD und ist in unserer Untersuchung sowohl bei Patienten mit schwerer als auch bei Patienten mit leicht-/mittelgradiger COPD zu beobachten. 78,26\% der Frauen und 75\% der Männer hatten eine reduzierte Körperzellmasse. Der Mittelwert des BCM - l's bei der COPD - Population beträgt 7,03 kg $/ \mathrm{m}^{2}$ bei Männern und 4,62 $\mathrm{kg} / \mathrm{m}^{2}$ bei Frauen. In der Messungen der Referenzpopulationen zeigten sich deutlich erhöhte Mittelwerte: $15,61 \mathrm{~kg} / \mathrm{m}^{2}$ bei Männer und $11,12 \mathrm{~kg} / \mathrm{m}^{2}$ bei Frauen. Die Messungen waren statistisch relevant $(p<0,05)$.

Die BCM ist die Summe der kaliumreichen, sauerstoffverbrauchenden Zellen; sie ist die „activity metabolizing tissue" des Körpers. Die BCM ist heterogen zusammengesetzt. Sie besteht aus Skelettmuskulatur und den inneren Organen (Leber, Herz, Nieren, Lunge, Milz, Gehirn, Blutzellen, Immunsystem etc.), welche als Nicht-Muskel-BCM bezeichnet werden können. Das Verhältnis von Muskel zu Nicht-Muskel-BCM beträgt bei gesunden und normalgewichtigen Menschen 5:1 bis 6:1. Bei untergewichtigen und kachektischen Patienten wird das Verhältnis von Muskel zu Nicht-Muskel-BCM zu den inneren Organen verschoben. Umgekehrt kommt es bei Kraftsportlern, oder auch nach Anabolikaeinnahme zu einer disproportionalen Zunahme der Muskelmasse. [66]

Die BCM ist die zentrale Größe bei der Beurteilung des Ernährungszustandes eines Patienten, da die Stoffwechselarbeiten des Organismus innerhalb der Zellen der BCM geleistet werden. Die BCM ist die entscheidende Determinante des Energieverbrauchs, des Stoffwechsels energiereicher Substrate und des Eiweißumsatzes. In der BCM finden etwa 99\% der Stoffwechselprozesse statt. Aufgrund ihrer zentralen Bedeutung für Körperfunktionen hat die BCM z. B. bei Schwerkranken eine eigenständige prognostische Bedeutung.

Die Körperzellmasse ist auch abhängig vom Lebensalter. Bei Kindern und Jugendlichen ist die Zellmasse des Organismus noch nicht ausgereift. Der Anteil der BCM in der Magermasse ist meistens kleiner als 50\%. Erst nach Abschluss des Längenwachstums differenzieren sich die Muskelzellen endgültig. Erwachsene mit normalem Ernährungszustand haben mehr als 50\% BCM in der Magermasse. Im hohen Lebensalter verringert sich die BCM meist durch körperliche Inaktivität, oft bis auf $45-40 \%$. Bei körperlich aktiven älteren Menschen bleibt die BCM jedoch weitgehend erhalten. Normalwerte für die 
Körperzellmasse lassen sich über den Anteil der Zellmasse in der Magermasse definieren. Im Altersbereich von 18 - 75 Jahren sollten Männer ca. 53 - 59\%, Frauen ca. $50-56 \%$ BCM in der Magermasse haben (Idealwerte). Bei Leistungssportlern kann die BCM bis zu 60\% der Magermasse betragen.

Die Erhaltung der BCM ist die zentrale Aufgabe bei allen Formen der Ernährungstherapie. Auch bei Reduktionsdiäten sollte der BCM-Verlust keinesfalls mehr als $20 \%$ der BCM betragen, da eine BCMReduktion wesentlich langsamer vom Körper kompensiert wird als Z.B. eine Reduktion des Körperfettes. Aus ernährungsmedizinischer Sicht ist ein Verlust an BCM ein schlechtes Zeichen. Dieses gilt nicht nur für Schwerkranke, sondern auch z. B. für Übergewichtige, welche unter einer Diät Gewicht, Fettmasse und BCM abnehmen. [38].

Mittels Bioimpedanzmessung haben wir gezeigt, dass die Mehrheit der CPOD-Patienten eine verminderte Körperzellmasse aufweist. Diese Tatsache ist auch von Bernard et al. mittels Kernspintomographie gezeigt worden. Im MRT war die Muskelfläche am Oberschenkel bei Gesunden im Vergleich zur COPD - Patienten deutlich größer [11].

In einer von uns durchgeführten Studie haben wir gezeigt, dass es bei kritisch kranken Patienten zu einer ausgeprägten Abnahme der Körperzellmasse kommt. Nach 5 Tage Aufenthalt auf der Intensivstation haben mehr als 84\% der kritisch kranken Patienten über 20\% der BCM verloren [63].

\subsection{Pathologische Membranintegrität bei COPD - Patienten.}

Der Phasenwinkel ist direkt proportional zur Gesamtoberfläche der Zellen und zum elektrischen Potential der Membranen. Er ist ein Referenzwert für die Membranintegrität der Zellen. Im Gegensatz zu den Zellen der Body Cell Mass sind Fettzellen als reine Speicherzellen kaum stoffwechselaktiv, besitzen nur ein minimales Membranpotential und werden bei der phasensensitiven Messung nicht erfaßt [38].

Unter den direkt mit der BIA erhobenen Messwerten (Resistance, Reactance und Phasenwinkel jeweils bei $50 \mathrm{kHz}$ ) zeigte sich der Phasenwinkel bei der COPD-Gruppe deutlich reduziert. Aus unserer Untersuchung geht deutlich hervor, dass die Mehrheit der COPD-Patienten (82,60\% der Frauen und 75\% der Männer) eine erniedrigte Zelldichte haben. Der Mittelwert des Phasenwinkels bei der COPDPopulation beträgt $4,49^{\circ}$ bei Männern und $4,11^{\circ}$ bei Frauen. In den Messungen der Referenzpopulationen zeigten sich deutlich höhere Mittelwerte: $6,44^{\circ}$ bei Männern und $5,56^{\circ}$ bei Frauen.

Der Phasenwinkel ist bei vielen chronischen Erkrankungen vermindert und könnte uns eine prognostische Information bzgl. des weiteren Krankheitsverlaufs anbieten. In einer Untersuchung an 1186 geriatrischen Patienten konnten Wirth et al. einen signifikant niedrigeren Phasenwinkel bei im Krankenhaus verstorbenen geriatrischen Patienten in Vergleich zu den Überlebenden zeigen, was auf den prognostischen Wert des Phasenwinkels bei multimorbiden Patienten hinweist. [112] 


\subsection{Der Hydratationszustand einer Zelle beeinflusst den Zellstoffwechsel. Bei COPD - Patienten ist das intrazelluläre Wasser (ICW) vermindert}

Ein anderer wichtiger Parameter, der von uns gemessen wurde, ist das intrazelluläre Wasser (ICW). ICW wird als Marker des Hydratationsgrades der Zellen bezeichnet. Die Menge des Körperwassers eines Organismus wird in erster Linie über die Körperzellmasse BCM und damit primär über die Muskelmenge determiniert.

Das Ganzkörperwasser wird bei gesunden Erwachsen wie folgt verteilt:

- Extrazelluläres Wasser - ECW: ca. 33 \% vom Ganzkörperwasser - TBW (Lymphe, interstitiell, transzellulär, Plasma)

- Intrazelluläres Wasser - ICW: ca. 66 \% vom Ganzkörperwasser - TBW [69]

In unserer Untersuchung wurde bei $73,91 \%$ der Frauen und 70,83\% der Männer ein verminderter Hydratationsgrad der Körperzellmasse gemessen. Der Mittelwert des ICW-I's bei der COPD - Population beträgt $6,59 \mathrm{~kg} / \mathrm{m}^{2}$ bei Männern und $4,89 \mathrm{~kg} / \mathrm{m}^{2}$ bei Frauen. In den Messungen der Referenzpopulationen zeigten sich deutlich höhere Mittelwerte: $8,82 \mathrm{Kg} / \mathrm{m}^{2}$ bei Männer und 6,18 $\mathrm{Kg} / \mathrm{m}^{2}$ bei Frauen.

Bei Gesunden besitzt die Magermasse einen hohen Anteil an Wasser und Elektrolyten und sie ist daher ein sehr guter Leiter für den Strom, während die Fettmasse einen hohen Widerstand hat. Ein geringer Anteil an Wasser zeigt uns eine pathologische Zusammensetzung der Magermasse. Die Magermasse mit "wenig" Wasser wird bei den Patienten mit terminalen malignen Erkrankungen und bei den Patienten mit einer ausgeprägten Malnutrition diagnostiziert [38].

Bei Schwerkranken, welche sich regelhaft in einer katabolen Stoffwechsellage befinden und Zeichen einer beginnenden Mangelernährung zeigen können, kommt es regelhaft zu einer Abnahme vom ICW [63]. Diese Veränderung der Körperzusammensetzung erfolgt meist vor der Abnahme des Körpergewichts und der Magermasse; insofern kann die Abnahme des ICW's die Verluste der BCM vorhersagen, da das intrazelluläre Wasser durch den intrazellulären Proteinverlust nach extrazellulären Raum mobilisiert wird [69].

Der Hydratationszustand einer Zelle beeinflusst den Zellstoffwechsel (z.B. Proteinumsatz, Glykogensynthese). Wenn der Hydratationszustand abnimmt und somit das ICW sinkt, kommt es zur Steigerung der extrazellulären Natriumkonzentration, zellulärer Kaliumverluste, Insulinresistenz mit einer verminderten zellulären Glukoseaufnahme und Azidose, bei der die Wasserstoffionen in die Zelle gelangen und Kaliumionen verloren gehen [55].

Die Veränderungen der ICW könnten frühzeitige klinisch-relevante Störungen des Ernährungszustands, der Flüssigkeitshomoostase und des Stoffwechsels charakterisieren. 


\subsection{Ein erhöhter ECM/BCM-Index ist für die Beurteilung einer Malnutrition von grosser Bedeutung}

Die Magermasse im Zweikompartimenten-Modell ist für eine subtile Beurteilung des Ernährungszustandes unzureichend, da die enthaltene Extrazellulärmasse infolge eingelagerter Flüssigkeit relativ erhöht sein kann. Es ist daher sinnvoll, die Magermasse weiter in die Extrazellulärmasse (ECM) und die sogenannte Körperzellmasse (BCM) aufzuschlüsseln. Aus metabolischer Sicht ist allein die Körperzellmasse für Stoffwechselaktivität und Kalorienverbrauch des Organismus - „containing the oxygen exchanging, potassium rich, glucose oxidising, work performing tissue" - entscheidend [65].

Malnutrition ist durch eine Abnahme der Körperzellmasse gekennzeichnet, welche häufig mit einer Zunahme der Extrazellulärmasse einhergeht. Das Verhältnis von ECM/BCM ist somit ein geeigneter Parameter für die Beschreibung des Ernährungszustandes in katabolen Phasen [38].

Bei Nahrungs- oder Nährstoffmangel mobilisiert der menschliche Organismus zur Glukosehomöostase intrazelluläres Protein und bildet daraus Glucose. Der intrazelluläre Proteinverlust führt zu einer Verkleinerung der ВCM. Gleichzeitig kommt es durch Abgabe des proteingebundenen intrazellulären Wassers zu einer Vergrößerung des Extrazellulärraumes. In unserer Messung wurde bei 69,56\% der Frauen und bei 75\% der Männer ein erhöhter ECW/ BCM-Index gemessen. Der Mittelwert des ECM/BCM-Index bei der COPD-Population beträgt 1,03 L/Kg bei Männern und 1,09 L/Kg bei Frauen. In den Messungen der Referenzpopulationen zeigten sich niedrigere Mittelwerte: 0,63 L/ $\mathrm{m}^{2}$ bei Männern und $0,78 \mathrm{~L} / \mathrm{m}^{2}$ bei Frauen.

Die Beobachtung, dass bei COPD-Patienten ein Verlust an Muskelmasse, ein erhöhter ECM/BCMIndex sowie eine Vergrößerung des Extrazellulärraumes durch die Zunahme des extrazellulären Wassers vorliegen, erklärt auch die bekannte Klinik der Patienten, die unter verminderter Belastbarkeit und peripherer Muskelschwäche leiden [6].

\subsection{Ist das Untergewicht bei COPD alleine von Bedeutung?}

Bereits seit vielen Jahren ist in mehreren Studien gezeigt worden, dass das Gewicht eine Beziehung zu Morbidität und Mortalität hat. [66]. Das Untergewicht stellt einen unabhängigen, negativen Effekt für die Sauerstoffsättigung im Muskel dar. Daher wirken sich sowohl Gewichtsverlust als auch ein Verlust an Muskelmasse ungünstig auf die Mortalität und Morbidität von COPD-Patienten aus [6].

Augenmerk sollte aber nicht nur auf das Unter-, sondern auch auf das Übergewicht (BMI > 30) gelegt werden, denn Letzteres führt zu einer gesteigerten Atemarbeit und hat somit ebenfalls einen negativen Einfluss auf die Belastbarkeit der Patienten [99].

In unserer Untersuchung waren 33,33\% der COPD-Männer untergewichtig; 10 Patienten (41,60\%) hatten ein normales Gewicht und 6 Patienten (25\%) waren übergewichtig. In der Analyse der Frauen haben wir festgestellt dass das Untergewicht überwiegend ist - 13 Patientinen (56,52\%) waren 
untergegewichtig. Der Anteil der Frauen mit Übergewicht beträgt 17,39\% und 26,08\% der Frauen mit COPD hatten ein normales Gewicht.

Es entsteht die Hypothese dass dem Normal- oder Übergewicht dieser Patienten vor allem eine Zunahme des extrazellulären Wassers und somit eine Erhöhung vom ECM/ BCM - Index zugrunde liegen könnte. Diese Hypothese wird im nächsten Kapitel analysiert.

In einer Studie mit 154 COPD-Patienten von De Benedetto im Jahre 2000 wurde gezeigt, dass der Anteil von übergewichtigen COPD-Patienten in Italien sehr hoch ist - 31\% [26]. Ähnliche Ergebnisse gehen von unserer Arbeit hervor. In unserem Kolektiv wurde bei 25\% der Männer und bei 17,39\% der Frauen Übergewicht festgestellt.

Das Übergewicht ist aktuell ein weitaus häufigeres Problem als Untergewicht. Nach dem Gesundheitsbericht von 1998 haben nur etwa $2 \%$ der Bevölkerung einen BMI unter $20 \mathrm{~kg} / \mathrm{m}^{2}$, hingegen $20 \%$ einen BMI über $30 \mathrm{~kg} / \mathrm{m}^{2}$, also eine Adipositas.

Noch häufiger ist das Übergewicht (BMI über $25 \mathrm{~kg} / \mathrm{m}^{2}$ ). Jede zweite in Deutschland lebende Person fällt in diese Kategorie. Übergewicht und Adipositas haben erhebliche Auswirkungen auf die Atmung. Die Atemarbeit steigt, und ein verminderter Atemantrieb kann zur Hypoventilation führen. Die Lungenmechanik ist charakterisiert durch eine reduzierte Lungendehnbarkeit, die respiratorische Muskulatur ermüdet früher, ihre Kraft und Ausdauer ist reduziert. Zusätzlich beobachtet man eine verminderte Chemosensitivität gegenüber Sauerstoff und $\mathrm{CO}_{2}[99]$.

\subsection{Ist der Body mass index ein valider Parameter zur Erkennung der Mangelernährung bei COPD?}

Die Ursachen des Untergewichts sind bei der COPD wie oben dargestellt sehr komplex. Biochemische und morphologische Veränderungen in peripheren Muskeln wurden bei COPD-Patienten insbesondere durch Analysen von Muskelgewebe mehrfach bestätigt. So unterscheidet sich die Zusammensetzung der Muskelfasertypen zwischen Gesunden und COPD-Patienten. Bei COPDPatienten wurden geringere Typ-I- und höhere Typ-II-Myosin-heavy- chain-Isoformen im peripheren Muskel gefunden [83].

Der BMI unterscheidet nicht zwischen Fett- und Muskelmasse. Bei gleichem BMI haben Frauen und ältere Menschen einen höheren prozentualen Fettanteil als Männer bzw. junge Menschen. Die Beziehung zwischen BMI und Fettmasse ist in verschiedenen Populationen unterschiedlich (z. B. bei Kaukasiern und Asiaten besteht ein geringerer Anteil an Fettmasse im Vergleich mit den anderen Populationen).

In unserer Untersuchung wiesen $43,47 \%$ der Frauen einen verminderten BMI auf. 30,43\% der Patientinen hatten einen normalen BMI und 26,08\% einen erhöhten Wert. Von den Männern hatten 33,33 $\%$ einen erniedrigten BMI, 37,5\% normale und 29,16\% erhöhte BMI-Werte.

Der Mittelwert des BMI's bei der COPD-Population beträgt $25,54 \mathrm{Kg} / \mathrm{m}^{2}$ bei Männern und 23,79 $\mathrm{Kg} / \mathrm{m}^{2}$ bei Frauen. In den Messungen der Referenzpopulationen zeigten sich keine relevanten Unterschiede der Mittelwerte: $25,22 \mathrm{Kg} / \mathrm{m}^{2}$ bei Männern und $24,92 \mathrm{Kg} / \mathrm{m}^{2}$ bei Frauen. 


\begin{tabular}{|c|c|}
\hline$M_{\text {Ref }}-$ Männer & $M_{\text {COPD }}$ - Männer \\
\hline $\mathbf{2 5 , 2 2}$ & $\mathbf{2 5 , 5 4}$ \\
\hline$M_{\text {Ref }}-$ Frauen & MW $_{\text {COPD }}$ - Frauen \\
\hline 24,92 & 23,79 \\
\hline
\end{tabular}

Tab. 15.1. BMI $\left(\mathrm{kg} / \mathrm{m}^{2}\right)$ der Referenzpopulation versus COPD-Population

Wie im Kap. 4.2 beschrieben, geht aus unserer Messung hervor, dass 78,26\% der Frauen und 75\% der Männer eine reduzierte Körperzellmasse (dargestellt durch BCM) aufweisen. Es lässt sich somit feststellen, dass ein großer Teil der COPD-Patienten mit einer reduzierten BCM einen normalen oder erhöhten BMI aufweisen. Eine reduziete Körperzellmasse ist also bei normgewichtigen und bei übergewichtigen COPD-Patienten häufig anzutreffen.

Weiterhin haben wir den Anteil des extrazellulären Wassers (ECW) am Ganzkörperwasser (TBW) untersucht. Sowohl bei Frauen als auch bei Männer bestätigen die Ergebnisse unsere Hypothese, dass die Zunahme des extrazellulären Wassers dem normalen Gewicht und dem normalen BMI zugrunde liegen könnte. Durch die Abnahme von Muskelmasse - BCM entsteht ein intrazellulärer Proteinverlust; der kolloidosmotische Druck sinkt und es kommt durch Abgabe des intrazellulären Wassers zu einer Vergrößerung des Extrazellulärraumes und somit des extrazellulären Wassers (ECW), wie in den nächsten Grafiken dargestellt wird. So konnten wir bei $69,56 \%$ der Frauen und 66,66\% der Männer eine Zunahme des extrazellulären Wassers nachweisen.

ECW \% TBW bei Frauen mit COPD im Vergleich zur Referenzpopulation

- COPD, ----10\% Quantile, ---- 90 \% Quantile

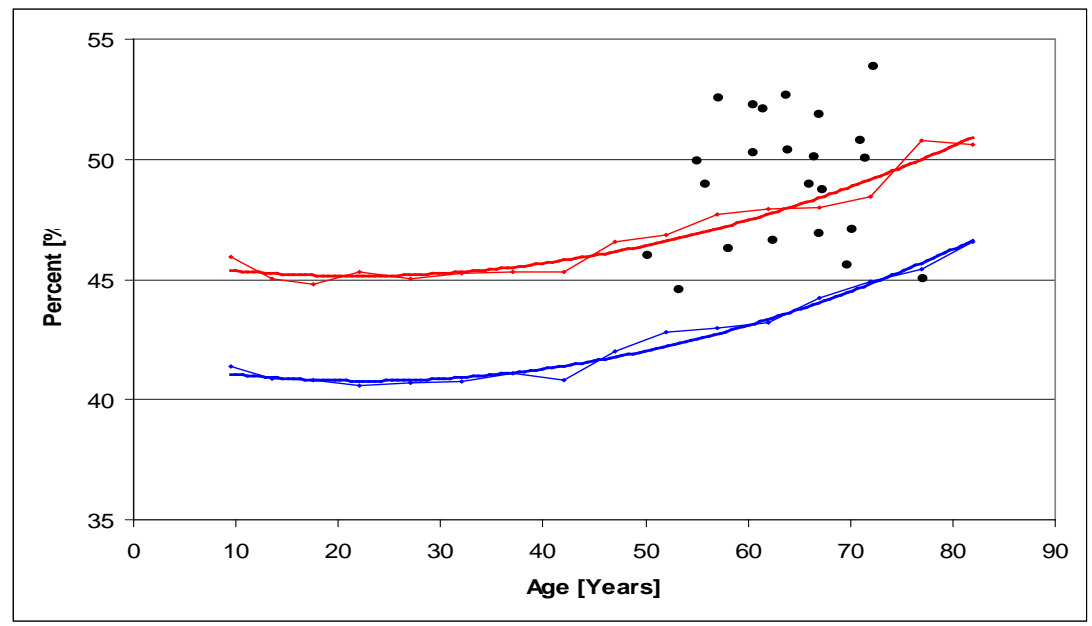




\section{ECW \% TBW bei Männern mit COPD im Vergleich zur Referenzpopulation}

- COPD, ----10\% Quantile, ---- $90 \%$ Quantile

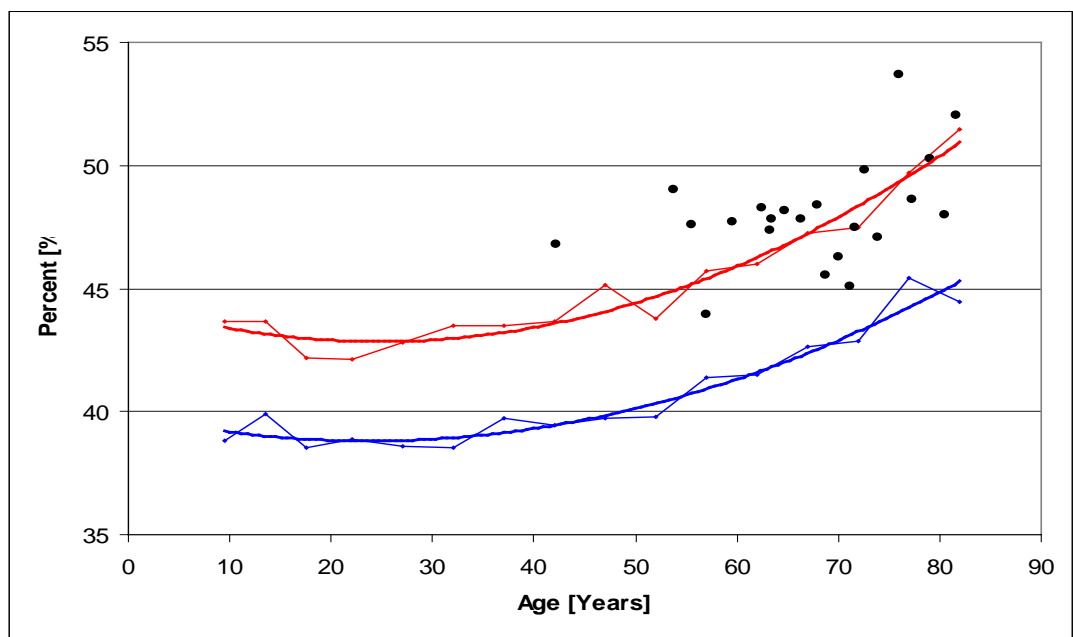

Die Erfassung von TBW und ICW können eine frühzeitige Diagnostik klinisch-relevanter Störungen des Ernährungszustandes der Flüssigkeitshomöostase und des Stoffwechsels ermöglichen.

Zusammenfassend lässt sich sagen, dass die Validität vom BMI bei COPD-Patienten in Frage gestellt werden soll und dass der BMI als Einzelparameter eine Mangelernährung nur unzureichend darstellt, denn es werden dabei die dynamischen Komponenten (Gewichtsabnahme, Nahrungszufuhr, Stress) nicht berücksichtigt.

\subsection{Die Muskelmasse hat auf die Ventilation einen großen Einfluss}

Eines der Hauptsymptome von COPD-Patienten ist die fortschreitende Reduktion der körperlichen Belastbarkeit. Diese zeigt eine klare Korrelation mit dem Schwund der Muskelmasse, die insbesondere an der Oberschenkelmuskulatur (M. quadriceps) untersucht wurde [6]. Entsprechend ist die Ermüdbarkeit bei COPD-Patienten deutlich höher als bei Gesunden.

Muskelverlust und Kachexie werden bei vielen chronischen Erkrankungen beobachtet (z.B. schwere Herzinsuffizienz, AIDS, chronische Niereninsuffizienz, Karzinome). Bei den meisten dieser Erkrankungen konnten, ebenso wie bei der COPD, klare Korrelationen zur Prognose festgestellt werden. Die Tatsache, dass Kachexie ein gemeinsames Phänomen der Endstrecke mehrerer chronischer Erkrankungen ist, legt einen gemeinsamen ursächlichen Mechanismus nahe. So konnte gezeigt werden, dass anabole Hormone (z.B. „insulin-like growth factor"[IGF] und Testosteron) bei diesen Patienten erniedrigt sind, während proinflammatorische Substanzen (z.B. TNF- $\alpha$, Interleukin-[ IL-]1, IL-6, IL-8, Interferon-[ IFN-]Y) erhöht sind. [83].

Die Atemmuskulatur ist wie die übrige Skelettmuskulatur den katabolen Veränderungen bei Mangelernährung und Kachexie in Form von reduzierter Proteinsynthese und erhöhtem Eiweißabbau 
unterworfen. Biochemische und morphologische Veränderungen im Zwerchfell von COPD-Patienten wurden in einer Studie von Ottenheijm et al. gezeigt. Es kommt zu einer Verminderung der antioxidativen Kapazität, zu Veränderungen in der Zusammensetzung der Muskelfaseranteile und zur Abnahme des Myosins in den Muskelfasern des Zwerchfells [110].

Der Verlust von Muskelmasse könnte einen direkten Einfluss auf die Ventilation und die Atemmuskulatur haben. Es scheint sogar so zu sein, dass der Verlust an Muskelmasse insgesamt die Atemmuskulatur prozentual mehr betrifft als die übrige Muskulatur [3].

Außerdem führt eine Mangel- und Unterernährung zu strukturellen Veränderungen der Lunge und Atemwege sowie zu einer Verminderung der pulmonalen Abwehrmechanismen. In Tiermodellen wurde hierfür eine Abnahme der Makrophagen-Aktivität verantwortlich gemacht [86]. Es konnte gezeigt werden, dass Mangelernährung die antibakterielle Abwehr der Lunge vermindert. Parallel dazu kommt es zu einer Veränderung des Arachidonsäuremetabolismus in Alveolarmakrophagen mit verminderter Produktion von Leukotrien $B_{4}$ und erhöhter Freisetzung von Thromboxan $B_{2}$ und Prostaglandin $E_{2}$ [94]. So existiert ein oft zu wenig beachteter Circulus vitiosus: eine chronische Lungenerkrankung wie COPD führt häufig zu Malnutrition, in deren Verlauf es zu Unter- und Mangelernährung mit einer Progression der chronischen Lungenerkrankung kommt.

Um den Einfluss von der Muskelmasse auf die Ventilation zu prüfen, haben wir die Frauen mit COPD in Abhängigkeit vom BCM-Index in zwei Gruppen eingeteilt. In der ersten Gruppe wurden die Patientinen mit einem BCM-Index kleiner als $4,62 \mathrm{~kg} / \mathrm{m}^{2}$ (Mittelwert - BCM-Index bei Frauen mit COPD) eingeschlossen und in der zweiten Gruppe wurden die Frauen mit einem BCM-Index grösser als 4,62 $\mathrm{kg} / \mathrm{m}^{2}$ eingeschlossen.

Der Mittelwert von FEV1 bei den COPD-Frauen lag in unserer Studie bei $530 \mathrm{ml}$.

Bei $75 \%$ von den Patientinen der ersten Gruppe, mit einem BCM -Index $<4,62 \mathrm{~kg} / \mathrm{m}^{2}$, wurden FEV1 Werte unter dem Mittelwert vom $530 \mathrm{ml}$ gemessen. Nur eine kleine Zahl der Patientinen (25\%) dieser Gruppe wies FEV1-Werte von über $530 \mathrm{ml}$ auf.

In der zweiten Gruppe, bei den COPD-Frauen mit BCM-Index Werten grösser als der Mittelwert von 4,62 kg/m², kamen wir zu folgenden Ergebnissen: die FEV1-Werte waren deutlich besser, 81\% dieser Frauen wiesen FEV1-Werte von über $530 \mathrm{ml}$ auf.

Es besteht somit ein Zusammenhang zwischen Muskelmasse, dargestellt durch BCM-I, und FEV1.

Die Ergebnisse bei Männern waren ähnlich. In der Gruppe mit einer reduzieren Muskelmasse (BCM Index kleiner als $7,03 \mathrm{~kg} / \mathrm{m}^{2}$ ) wurden bei $86 \%$ Patienten reduzierte FEV1-Werte gemessen (FEV1 unter dem Mittelwert von $880 \mathrm{ml}$ ).

Die andere Gruppe mit mehr Muskelmasse (BCM-Index größer als 7,03 kg/m ${ }^{2}$ ) hat lungenfunktionell deutlich besser abgeschnitten: $80 \%$ der Patienten hatten FEV1-Werte über 880ml.

In der Literatur wird auch eine Korrelation mit der Verminderung der Diffusionskapazität beschrieben[59]. 
Dass eine Verbesserung des Ernährungszustandes bei untergewichtigen COPD-Patienten zu einer Kräftigung der Atemmuskulatur und besseren Funktionsparametern führen kann, ist in einigen Studien belegt [34].

Im Anbetracht der Gesamtsituation lässt sich sagen, dass die FEV1-Werte bei den COPD Patienten mit mehr Muskelmasse, deutlich besser sind.

Durch Messung der Bioimpedanz haben wir gezeigt, dass bei den Patienten mit COPD ein großer Verlust von metabolisierendem und kontraktilem Gewebe vorliegt. Die Membranintegrität und der metabolische Zustand der Muskelzellen ist pathologisch verändert und der Hydratationsgrad der Körperzellmasse ist reduziert. Somit sollte die Validität der alleinigen Messung vom BMI bei COPDPatienten in Frage gestellt werden.

Die BIA ist eine einfache, nicht-invasive und preisgünstige Methode zur Messung der Körperzusammensetzung, die zur Früherkennung der Mangelernährung bei COPD-Patienten angewendet werden kann. In einer retrospektiven Auswertung der Mangelernährung bei COPD-Patienten fand Watson, dass die moderate Einnahme von Obst und Gemüse, insbesondere Äpfel, einen signifikant protektiven Effekt hat und das Risiko für die Verschlechterung der COPD bei Rauchern verringert. Eine der wenigen Studien, die den alten Spruch „An apple a day keeps the doctor away” wissenschaftlich zu belegen versuchte [109]. 


\section{Literaturverzeichnis}

1. Allaire J, Maltais F, LeBlac P, et al. (2002) Lipofuscin accumulation in the vastus lateralis in patients with chronic pulmonary disease. Muscle Nerve 25: 383-389

2. Anto, J. M., P. Vermeire, et al. (2001) Epidemiology of chronic obstructive pulmonary disease. Eur Respir J 17(5): 982-994

3. Arora NS, Rochester DF (1982) Effect of body weight and muscularity on human diaphragm muscle mass, thickness, and area. J Appl Physiol 52 (1): 64-70

4. Aris RM, Neuringer IP, Weiner MA, et al. (1996) Severe osteoporosis before and after lung transplantation. Chest 109:1176-83

5. Auwerx J, Staels B. (1998) Leptin. Lancet 351: 737-742

6. Baarends EM, Schols AM, Mostert R, et al. (1997) Peak exercise response in relation to tissue depletion in patients with chronic obstructive pulmonary disease. Eur Respir J 10: 2807-2813

7. Bals R (2004) Hiemstra $P$ Innate immunity in the lung: how epithelial cells fight against respiratory pathogens. Eur Respir J 23: 327-333

8. Barnes PJ (2000) Medical progress: chronic obstructive pulmonary disease. N Engl J Med 343: 269-280

9. Barnes PJ, Stockley RA. (2005) COPD: current therapeutic interventions and future approaches. Eur Respir J 25: 1084-1106

10. Beeh.J, Beier. (2006) Wirksamkeit von Tiotropiumbromid bei verschiedenen Schweregraden der chronisch-obstruktiven Lungenerkrankung, Pneumologie 60: 341-346

11. Bernard, S., F. Whittom, et al. (1999) Aerobic and strength training in patients with chronic obstructive pulmonary disease. Am J Respir Crit Care Med 3: 896-901

12. Braun SR, Keim NL, Dixon RM, et al. (1984) The prevalence and determinants of nutritional changes in chronic obstructive pulmonary disease. Chest 86:558-63

13. Boyd G, Mirice AH, Pounsford JG. et al. (1997) An evaluation of salmeterol in the treatment of chronic obstructive pulmonary disease. Eur Respir J 10: 815-821

14. Budweiser S, Heinemann F, Fischer W, et al. (2005) Long-term reduction of hyperinflation in stable COPD by non-invasive nocturnal home ventilation. Respir Med 99: 976-978

15. Buist A. S. et al. (2007) International variation in the prevalence of COPD (The BOLD Study): a population-based prevalence study. Lancet $370,741-750$

16. Burrows, B., R. J. Knudson, et al. (1977). Quantitative relationships between cigarette smoking and ventilatory function. Am Rev Respir Dis 115 (2): 195-205

17. Cai B, Zhu Y, My Y, et al. (2003) Effect of supplementing a high-fat, low-carbohydrat enteral formula in COPD patients. Nutrition 19: 229-232

18. Casanova C, Celli BR, Tost L, et al. (2000) Long-term controlled trial of nocturnal nasal positive pressure ventilation in patients with severe. COPD. Chest 118:1582-90 
19. Celli, B. R. and W. MacNee (2005) Standards for the diagnosis and treatment of patients with COPD: a summary of the ATS/ERS position paper. Eur Respir J 23 (6): 932-946

20. Chen, Y. (1999) Genetics and pulmonary medicine.10: Genetic epidemiology of pulmonary function. Thorax 54 (9): 818-824

21. Chung KF (2001) Cytokines in chronic obstructive pulmonary disease. Eur Respir J Suppl 34:50

22. Cooper JD, Patterson GA, Sundaresan RS. et al. (1996) J Results of 150 consecutive bilateral lung volume reduction procedures in patients with severe emphysema. J Thorac Cardiovasc Surg 1996;1; 123: 119-133

23. Creutzberg EC, Wouters E, Mostert R, et al. (2003) Efficacy of nutritional supplementation therapy in depleted patients with chronic obstructive pulmonary disease. Nutrition 19:120-7

24. Criée CP (2003). Neue Erkenntnisse in Diagnostik und Therapie - COPD -Management und COPD - Leitlinien. Notfall Medizin, 10

25. Dayal, H. H., S. Khuder, et al. (1994). Passive smoking in obstructive respiratory disease in an industrialized urban population. Environ Res 65 (2): 161-71

26. De Benedetto F, Del Ponte A, Marinari S, et al. (2000) In COPD patients, body weight excess can mask lean tissue depletion: a simple method of estimation. Monaldi Arch Chest Dis 55:273-278

27. De Marco, R., S. Accordini, et al. (2004) An international survey of chronic obstructive pulmonary disease in young adults according to GOLD stages. Thorax 59 (2): 120-5

28. Demedts IK, Demoor T, Bracke KR et al. (2006) Role of apoptosis in the pathogenesis of COPD and pulmonary emphysema. Respir Res 7: 53

29. Demedts M, Behr J, Buhl R. et al. (2005) High-dose acetylcysteine in idiopathic pulmonary fibrosis. N Engl J Med 353: 2229-2242

30. Devaraj S, Chan E, Jialal I. (2006) Direct demonstration of an antiinflammatory effect of simvastatin in subjects with the metabolic syndrome. J Clin Endocrinol Metab 91: 4489-4496

31. Di Francia M, Barbier D, Mege JL, et al. (2005) Tumor necrosis factor-alpha levels and weight loss in chronic obstructive pulmonary disease. Am J Respir Crit Care Med 150:1453-1455

32. Di Stefano A, Capelli A, Lusuardi M et al. (1998) Severity of airflow limitation is associated with severity of airway inflammation in smokers. Am J Respir Crit Care Med 158: 1277-1285

33. Donahoe M, Rogers RM, Wilson DO. et al. (1989) Oxygen consumption of the respiratory muscles in normal and in malnourished patients with chronic obstructive pulmonary disease. Am Rev Respir Dis 140 (2): 385-391

34. Efthimiou J, Fleming J, Gomes C. et al. (1988) The effect of supplementary oral nutrition in poorly nourished patients with chronic obstructive pulmonary disease. Am Rev Respir Dis 137 (5): 10751082

35. Engelen MP, Wouters EF, Deutz NE, et al. (2001) Effects of exercise on amino acid metabolism in patients with chronic obstructive pulmonary disease. Am J Respir Crit Care Med 163:859-864

36. Fehrenbach $H$, Kasper $M$, Tschernig $T$ et al. (1999) Keratinocyte growth factor-induced hyperplasia of rat alveolar type II cells in vivo is resolved by differentiation into type I cells and by apoptosis. Eur Respir J 14: 534-544 
37. Ferguson GT, Enright PL, Buist AS. et al. (2000) Office spirometry for lung health assessment in adults: A consensus statement from the National Lung Health Education Program. Ferguson Chest 117: 1146-1161

38. Fischer H, Lembcke B (1991) Die Anwendung der bioelektrischen Impedanzanalyse zur Beurteilung der Körperzusammensetzung und des Ernährungszustandes. Inn Med 18:13- 17

39. Gillissen A, Barczok M, Buhl R. et al. (2000) Inhalierbare Kortikosteroide in der Langzeittherapie der COPD. Pneumologie 54: 306-308

40. Gosker HR, Lencer NH, Franssen FM, et al. (2003) Striking similarities in systemic factors contributing to decreased exercise capacity in patients with severe chronic heart failure or COPD. Chest 123: 1416-1424

41. Gosker HR, van Memaren H, van Dijk PJ, et al. (2002) Skeletal muscle fibre-type shifting and metabolic profile in patients with chronic obstructive pulmonary disease. Eur Respir 19:617-625

42. Gross P, Pfitzer E, Tolker E et al. (1965) Experimental emphysema: its production with papain in normal and silicotic rats. Arch Environ Health 11: 50-58

43. Guyatt, G. H., L. B. Berman, et al. (1987) A measure of quality of life for clinical trials in chronic lung disease Thorax 42: 773-778

44. Hargreave FE, Leigh R. (1999) Induced sputum, eosinophilic bronchitis, and chronic obstructive pulmonary disease. Am J Respir Crit Care Med 160: S53-S57

45. Hogg J, Coxon HO, Pare PD. (2004) The nature of small-airway obstruction in chronic obstructive pulmonary disease. N Engl J Med 26: 2645-2653

46. Hosenpud JD, Bennett LE, Keck BM. et al. (1998) Effects of diagnosis on survival benefit of lung transplantation for end-stage lung disease. Lancet 3: 24-27

47. Hughes JA, Hutchison DM, MacArthur DCS. et al. (1986) Long-term changes in lung function after surgical treatment of bullos emphysema in smokers and exsmokers. Thorax 39: 140

48. Incalzi RA, Caradonna P, Ranieri P, et al. (2000) Correlates of osteoporosis in chronic obstructive pulmonary disease. Respir Med 94:1079-84

49. Kasahara Y, Tuder RM, Cool CD et al. (2001) Endothelial cell death and decreased expression of vascular endothelial growth factor and vascular endothelial growth factor receptor 2 in emphysema. Am J Respir Crit Care Med 163: 737-744

50. Kessler R, Faller M, Fourgaut G. et al. (1999) Predictive factors of hospitalization for acute exacerbation in a series of 64 patients with chronic obstructive pulmonary disease. Am J Respir Crit Care Med 159: 158-164

51. Khan, H., K. A. Salman, et al. (2002) Alpha-1 antitrypsin deficiency in emphysema. J Assoc Physicians India 50: 579-82

52. Kharitonov SA, Robbins RA, Yates D. et al. (1995) Acute and chronic effects of cigarette smoking on exhaled nitric oxide. Kharitonov Am J Respir Crit Care Med 152: 609-612

53. Kroidl, R. F., Nowak, D., Seysen, U. (2000) Bewertung und Begutachtung in der Pneumologie. Empfehlunge der Deutschen Gesellschaft für Pneumologie ind der Deutschen Atemwegsliga. Stuttgart-New York, Georg Thieme Verlag 2000: 98-101 
54. Knowles JB, Fairbarn MS, Wiggs BJ. et al. (1988) Dietary supplementation and respiratory muscle performance in patients with COPD. Chest 93: 977-983

55. Kushner RF, Schoeller DA. (1996) Estimation of total body water by bioelectrical impedance analysis. Am J Clin Nutr 44:417-24

56. Lacasse Y, Brosseau L, Milne S, Martin S, Wong E, Guyatt GH, et al. (2002). Pulmonary rehabilitation for chronic obstructive pulmonary disease. Cochrane Database Syst Rev;3: CD003793.

57. Langley SJ. et al. (2005). Effect of oral doxycycline on MMP-TIMP levels in induced sputum in subjects with COPD. A pilot study. ATS Poster (F18) San Diego

58. Leuenberger, P., H. P. Anderhub, et al. (2007) Management 1997 of chronic obstructive pulmonary disease. Working Group of the Swiss Society of Pneumology. Schweiz Med Wochenschr 127 (18): 766-82

59. Lopez AD, Murray CC. The global burden of disease, 1990 - 2002. Nat Med 4: 1241-1243

60. Lundback, B., A. Lindberg, et al. (2003) Not 15 but 50\% of smokers develop COPD?--Report from the Obstructive Lung Disease in Northern Sweden Studies. Respir Med 97 (2): 115-22

61. MacNee W, Rahman I. (2001) Is oxidative stress central to the pathogenesis of chronic obstructive pulmonary disease. Trends Mol Med 7: 55-62

62. MacNee W (2005) Pathogenesis of chronic obstructive pulmonary disease. Proc Am Thorac Soc 2: $258-266$

63. Marcu C, Gröschel A, Sybrecht GW (2008) Veränderungen der Körperzusammensetzung von kritisch kranken Patienten. Deutsche Interdisziplinäre Vereinigung für Intensiv- und Notfallmedizin - DIVI FPV04/18

64. Meecham Jones DJ, Paul EA, Jones PW. et al. (1995) Nasal pressure support ventilation plus oxygen compared with oxygen therapy alone in hypercapnic COPD. Am J Resp Crit Care Med 152: $538-544$

65. Moore FD, Olesen KH, McMurrey JD, Parker HU, Ball MR, Boyden CM (1993) The body cell mass and its supporting environment. Body composition in health and disease. WB Saunders Company Philadelphia, London 145-151

66. Müller MJ, Westenhöfer J, Bosy-Westphal A, et al. (2002) Ernährungsmedizinische Untersuchungen: 42-58

67. Murray, C. J. L., Lopez, A.D (1996) The global burden of disease: a compendium of incidence, pravalence and mortality estimates for over 200 conditions. Cambridge, Harvard University Press 338-341

68. Nannini L, Lasserson T, Poole P. (2003). Combined corticosteroid and longacting beta-agonist in one inhaler for chronic obstructive pulmonary disease. Cochrane Database Syst Rev 4: 3794

69. National Institutes of Health Technology Assessment Conference Statement (1996) Bioelectrical impedance analysis in body composition measurement. Am J Clin Nutr 64 (suppl):524S-532S

70. National Emphysema Treatment Trial Research Group (2001) Patients at high risk of death after lung-volume-reduction surgery. N Engl J Med 345: 1075-1083 
71. Nisar M, Earis JE, Pearson MG. et al. (1992) Acute bronchodilator trials in chronic obstructive pulmonary disease. Am Rev Respir Dis 146: 555-559

72. Noord JAvan, Aumann JL, Janssens E. et al. (2006) Effects of tiotropium with and without formoterol on airflow obstruction and resting hyperinflation in patients with COPD. Chest 129: $509-517$

73. Noguera A, Batle S, Miralles C, et al. (2001) Enhanced neutrophil response in chronic obstructive pulmonary disease. Thorax 56: 432-437

74. Pauwels RA, Buist AS, Calverley PM. et al. (2005) Global strategy for the diagnosis, management, and prevention of chronic obstructive pulmonary disease. NHLBI/WHO Global Initiative for Chronic Obstructive Lung Disease (GOLD) Workshop summary. Am J Respir Crit Care Med 163: 1256-1276

75. Puhan M, Scharplatz M, Troosters T, Steurer J. (2005). Respiratory rehabilitation after acute exacerbation of COPD reduces risk for readmission and mortality - a systematic review. Respir Res 6: 54

76. Rabinovich RA, Ardite E, Troosters T, et al. (2001) Reduced muscle redox capacity after endurance training in patients with chronic obstructive pulmonary disease. Am J Respir Crit Care Med 164:1114-1118

77. Rahman I. (2004) Reproducibility of oxidative stress biomarkers in breath condensate: are they reliable. Eur Respir J 23: 183-184.

78. Ram FS, Wellington S, Rowe $\mathrm{BH}$, et al. (2005) Non-invasive positive pressure ventilation for treatment of respiratory failure due to severe acute exacerbations of asthma. Cochrane Database Syst Rev: 4360

79. Rainer Kaelin, Werner Karrer (2006) Die Rehabilitation von COPD-Patienten: wirksame Massnahmen gegen die Hoffnungslosigkeit,. Schweiz Med Forum 6:1103-1107

80. Rennard, S., M. Decramer, et al. (2002) Impact of COPD in North America and Europe in 2000: subjects' perspective of Confronting COPD International Survey. Eur Respir J 20(4): 799-805

81. Report of the Medical Research Council Working Party (1981) Long-term domiciliary oxygen in chronic cor pulmonale complicating chronic bronchitis and emphysema. Lancet 1981-1: 681-685

82. Rychlik, R., T. Pfeil, et al. (2001) Socioeconomic relevance of acute exacerbations of chronic bronchitis in Germany. A prospective cost of illness study. Dtsch Med Wochenschr 126: 353-359

83. Satta A, Migliori GB, Spanevello A, et al. (1997) Fibre types in skeletal muscles of chronic obstructive pulmonary disease patients related to respiratory function and exercise tolerance. Eur Respir J 10:2853-2860

84. Sahebjami H, Doers JT, Render ML, et al. (1993) Anthropometric and pulmonary function test profiles of outpatients with stable chronic obstructive pulmonary disease. Am J Med 94:469-74

85. Schaberg T (2001) Pneumokokkenschutzimpfung. Pneumologie 55: 543-545

86. Shennib H, Chiu RC, Mulder DS. et al. (1984) Depression and delayed recovery of alveolar macrophage function during starvation and refeeding. Surg Gynecol Obstet 158: 535-540

87. Schols AW. (2002) COPD, when and how to feed. RINPE 20:113-23 
88. Schols AW, Soeters PJ, Dingemans AM (1993) Prevalence and characteristics of nutritional depletion in patients with stable COPD eligible for pulmonary rehabilitation. Am Rev Respir Dis 147: $1151-1156$

89. Schols AM, Dalsky G, Warner S, et al. (1997) Body composition and health-related quality of life in patients with obstructive airways disease. Eur Respir J 10:1576-80

90. Schultz S, Lang et al. (2007) Pneumologische Rehabilitation ist en vogue!, Pneumologie; 61: 148

91. Schara J (1990) Was bedeutet Lebensqualität bei Krebs. Die Lebensqualität des chronisch Krebskranken. Stuttgart: Thieme 1990 1-14

92. Sciurba FC (1997) Early and long-term functional outcomes following lung volume reduction surgery. Clin Chest Med 18: 259-276

93. Sin DD, Tu JV (2001) Inhaled corticosteroids and the risk of mortality and readmission in elderly patients with chronic obstructive pulmonary disease. Am J Respir Crit Care Med 164: 580-584

94. Skerrett SJ, Henderson WR, Martin TR (1990) Alveolar macrophage function in rats with severe protein calorie malnutrition. Arachidonic acid metabolism, cytokine release, and antimicrobial activity. J Immunol 144 (3): 1052-1061

95. Statistics, N. C. o. H. (1995) Current estimates from the National Health Interview Survey, United States, 1995. Washington DC, Department of Health and Human Services, Public Health Service, Vital and Health Statistics: Publication No. 96

96. Stavem K, Sandvik L, Erikssen J. Can (2006) Global Initiative for Chronic Obstructive Lung Disease Stage 0 provide prognostic information on long-term mortality in men? Chest 130: 318325

97. Steiner MC, Barton RL, Singh SJ, et al. (2003) Nutritional enhancement of exercise performance in chronic obstructive pulmonary disease: a randomised controlled trial. Thorax 58:745-51

98. Suzuki T, Yanai M, Yamaya M. et al. (2001). Erythromycin and common cold in COPD. Chest 120: $730-733$

99. Sybrecht G. W. (2003) COPD, die Systemerkrankung: Ernährung: zu wenig beachtet und noch ungelöst, Pneumologie 57: 681-689

100. Takabatake N, Nakamura H, Abe S, et al. (1999) Circulating leptin in patients with chronic obstructive pulmonary disease. Am J Respir Crit Care Med 159:1215-1219

101. Tang NL, Chung MI, Elia M, et al. (2002) Total daily energy expenditure in wasted chronic obstructive pulmonary disease patients. Eur J Clin Nutr 56:282-7

102. Taschkin DP (2003). The role of patient-centered outcomes in the course of chronic obstructive pulmonary disease: how long-term studies contribute to our understanding. Am J Med 119: 63-72

103. Taube C, Holz O, Mücke M. et al. (2001) Airway Response to Inhaled Hypertonic Saline in Patients with Moderate to Severe Chronic Obstructive Pulmonary Disease. Am J Respir Crit Care Med 164: 1810-1815

104. Toma TP, Hopkinson NS, Hillier J. et al. (2003) Bronchoscopic volume reduction with valve implants in patients with severe emphysema. Lancet 361: 931-933

105. The TORCH study group (2004) The TORCH survival study protocol. Eur Respir J ; 24: 206-210 
106. Vermeeren MA, Wouters EF, Nelissen LH, et al. (2001) Acute effects of different nutritional supplements on symptoms and functional capacity in patients with chronic obstructive pulmonary disease. Am J Clin Nutr 73:295-301

107. Venuta F, Yim APC, Wan IYP et al. (2006) Bronchoscopic Lung Volume Reduction for EndStage Emphysema: Report on the First 98 Patients. Chest 129: 518-526

108. Walter R, Ruiz Jean-Charles, Mourot Jacques et al. (1998) Evaluation of Dual-Energy X-Ray Absorptiometry for Body-Composition Assessment in Rats. The Journal of Nutrition Vol. 128: $1550-1554$

109. Watson L., Margetts BM. et al. (2001) Do dietary factors protect against chronic pulmonary disease; a control study. Am J Respir Crit Med. 163: A40

110. Weber B, Ottenheijm et al. (2008) Respiratory Research 9: 1465-9921

111. Weiner $P$, Azgad $Y$, Weiner $M$ (1993) The effect of corticosteroid on inspiratory muscle performance in humans. Chest 104: 1788-1791

112. Wirth R., Miklins P. (2002), Zeitschrift für Gerontologie und Geriatrie. 38, Numer 5: 315

113. Wilkens H, Grgic A, Heinrich M, Gröschel A, Sybrecht GW (2007) Niedrig-Dosis MehrzeilenComputertomographie zur Verlaufskontrolle nach Platzierung von Exhale Stents bei Patienten mit schwerem Lungenemphysem. Pneumologie 61: 43-49 


\section{Publikationen}

Marcu C, Gröschel A, Sybrecht GW (2008) Missing value of BMI and pathological body composition of COPD-patients. European Respiratory Society's congress FP 14/9

Marcu C, Gröschel A, Sybrecht GW (2008) Der Verlust an Musskelmasse von kritisch kranken Patienten. Deutsche Interdisziplinäre Vereinigung für Intensiv- und Notfallmedizin - DIVI FV04/18

Marcu C, Gröschel A, Becker J, Sybrecht GW (2007) Veränderungen der Körperzusammensetzung von COPD-Patienten. SPIG Saarländisch-Pfälzische Internistengesellschaft, FP 11

\section{Geplante Publikationen}

Marcu C, Gröschel A, Sybrecht GW (2009) The judgement of the pathological nutritional state and training of COPD-patients - European Respiratory Journal

Marcu C, Wilkens H, Sybrecht GW (2009) Community pulmonary rehabilitation after hospitalisation in patients with severe chronic pulmonary hypertension. 


\section{Danksagung}

Meiner Frau Christina möchte ich dafür danken, dass sie meinem Leben Sinn gibt. Sie bildet meinen sicheren Hintergrund aus liebevollem Verständnis und Geduld, ohne den eine klinische und wissenschaftliche Tätigkeit nicht möglich wäre.

Mein besonderer Dank gilt Herrn Professor Dr. Gerhard W. Sybrecht, Direktor der Klinik für Innere Medizin V-Pneumologie, der meinen Enthusiasmus gefördert und wissenschaftliche Absichten unterstützt hat. Mehr noch, Er hat mir auch in schwierigen Phasen sein Vertrauen geschenkt und mit seiner Dynamik und positiven Grundeinstellung immer wieder für wichtigen Schwung gesorgt hat.

Frau OÄ PD Dr. Heinrike Wilkens möchte ich für die persönliche Betreuung meiner Dissertation , für die wissenschaftlich stimulierende Atmosphäre und den lehrreichen Gedankenaustausch danken.

Last, but not least, möchte ich meinen Eltern Maria und Constantin Marcu danken, die - seit ich denken kann - zu mir gehalten haben, in selbstloser Art an meiner Entwicklung interessiert sind und mir jede erdenkliche Unterstützung gewährt haben und auch weiter gewähren. 


\section{Lebenslauf}

Geboren am 26. Oktober 1977 in Kronstadt, Rumänien wuchs ich als Sohn des Ehepaares Constantin und Maria Marcu neben meiner Schwester in der Gemeinde Trotzburg, Landkreis Kronstadt im Siebenbürgen - Transsylvanien. Nach der Grundschule in Kronstadt besuchte ich das Gymnasium für Informatik im Kronstadt und absolvierte 1996 dort das Abitur.

Im September 1996 wurde ich zum Medizinstudium an der Universität - Transsylvania in Kronstadt zugelassen, wo ich im Mai 2002 die ärztliche Prüfung ablegte und die Aprobation als Arzt bekamm.

Am 14. Oktober 2001 heiratete ich Christina Demetrescu.

Im Oktober 2003 begann ich nach einem Quereinstieg das 5. Semester am Universitätsklinikum des Saarlandes. Nach meinem Praktischen Jahr und nach Bestehen des dritten Abschnittes der ärztlichen Prüfung am 26.10.2005 trat ich eine Woche später, am 03.11.2005, die Anstellung als Assistenzarzt der Medizinischen Klinik V - Pneumologie unter Herrn Professor Dr. Gerhard W. Sybrecht an. Unter seiner exzellenter Leitung arbeite und forsche ich bis heute. 